\title{
Intraday Water Quality Patterns in East Fork Poplar Creek with an Emphasis on Mercury and Monomethylmercury
}

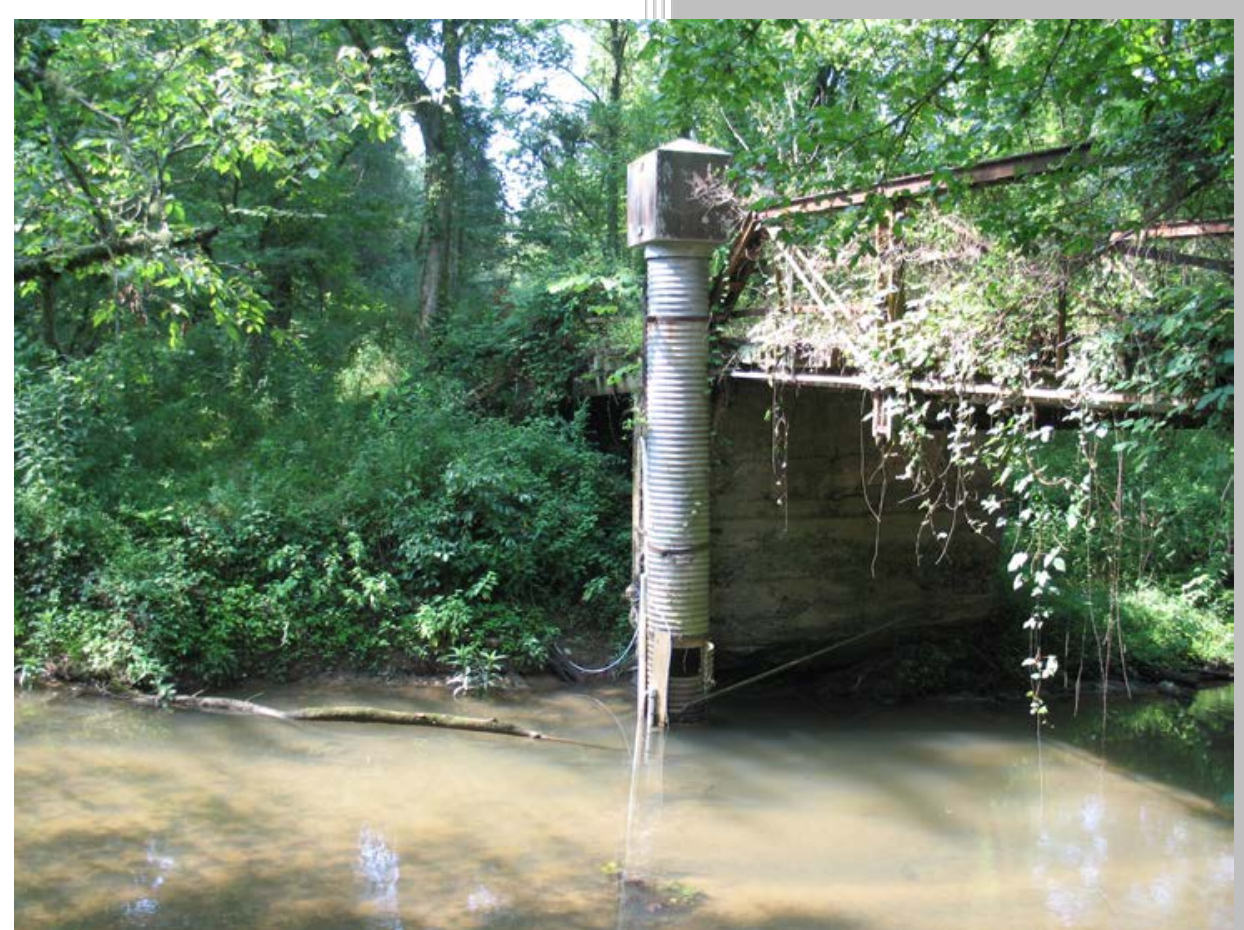

Approved for public release. Distribution is unlimited.
Scott C. Brooks Kenneth A. Lowe Tonia L. Mehlhorn Todd A. Olsen Xiangping Yin Allison M. Fortner Mark J. Peterson

May 2018 


\section{DOCUMENT AVAILABILITY}

Reports produced after January 1, 1996, are generally available free via US Department of Energy (DOE) SciTech Connect.

Website http://www.osti.gov/scitech/

Reports produced before January 1, 1996, may be purchased by members of the public from the following source:

National Technical Information Service

5285 Port Royal Road

Springfield, VA 22161

Telephone 703-605-6000 (1-800-553-6847)

TDD 703-487-4639

Fax 703-605-6900

E-mail info@ntis.gov

Website http://www.ntis.gov/help/ordermethods.aspx

Reports are available to DOE employees, DOE contractors, Energy Technology Data Exchange representatives, and International Nuclear Information System representatives from the following source:

Office of Scientific and Technical Information

PO Box 62

Oak Ridge, TN 37831

Telephone 865-576-8401

Fax 865-576-5728

E-mail reports@osti.gov

Website http://www.osti.gov/contact.html

This report was prepared as an account of work sponsored by an agency of the United States Government. Neither the United States Government nor any agency thereof, nor any of their employees, makes any warranty, express or implied, or assumes any legal liability or responsibility for the accuracy, completeness, or usefulness of any information, apparatus, product, or process disclosed, or represents that its use would not infringe privately owned rights. Reference herein to any specific commercial product, process, or service by trade name, trademark, manufacturer, or otherwise, does not necessarily constitute or imply its endorsement, recommendation, or favoring by the United States Government or any agency thereof. The views and opinions of authors expressed herein do not necessarily state or reflect those of the United States Government or any agency thereof. 
Environmental Sciences Division

\title{
INTRADAY WATER QUALITY PATTERNS IN EAST FORK POPLAR CREEK WITH AN EMPHASIS ON MERCURY AND MONOMETHYLMERCURY
}

Scott C. Brooks, ORNL Kenneth A. Lowe, ORNL Tonia L. Mehlhorn, ORNL Todd A. Olsen, ORNL Xiangping Yin, ORNL Allison M. Fortner, ORNL Mark J. Peterson, ORNL

Date Published: May 2018

Prepared for

Janice Hensley, UCOR/RSI

Oak Ridge, TN 37831

\author{
Prepared by \\ OAK RIDGE NATIONAL LABORATORY \\ Oak Ridge, TN 37831-6283 \\ managed by \\ UT-BATTELLE, LLC \\ for the \\ US DEPARTMENT OF ENERGY \\ under contract DE-AC05-00OR22725
}





\section{CONTENTS}

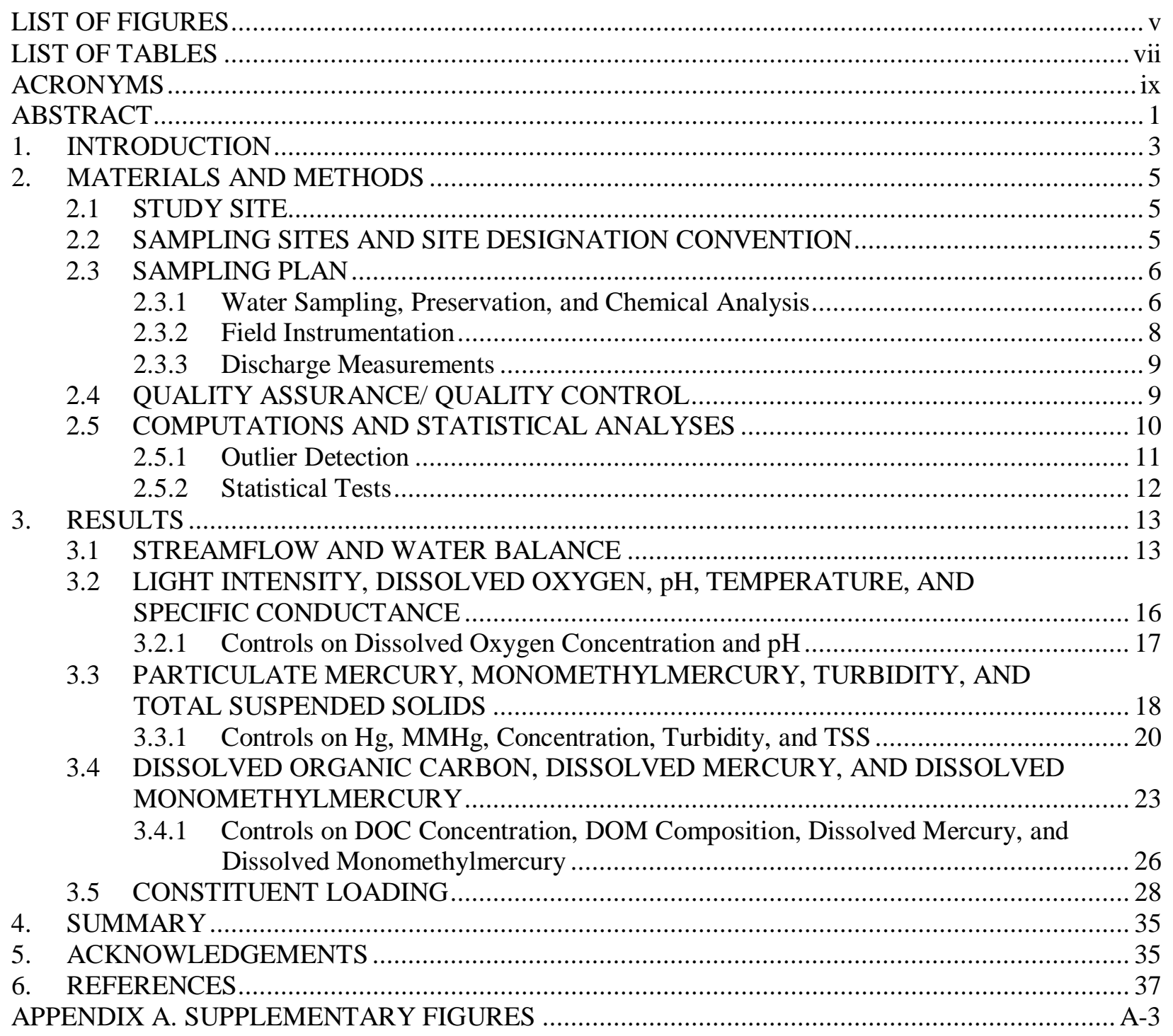





\section{LIST OF FIGURES}

Fig. 1. Map of East Fork Poplar Creek, sampling sites for this study, and a few additional relevant features....................................................................................................... 7

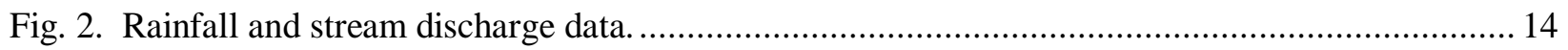

Fig. 3. Light intensity at each sampling location and Tower K. .................................................... 16

Fig. 4. Dissolved oxygen (A) and $\mathrm{pH}(\mathrm{B})$ at each station over the sampling period. ............................ 18

Fig. 5. Particulate Hg (A) and MMHg (B) over the sampling period.................................................. 19

Fig. 6. Turbidity (A) at EFK 16.2 and EFK 5.4 and total suspended solids at all three sites (B)

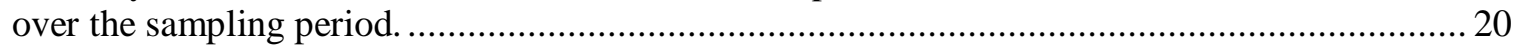

Fig. 7. (A) $\mathrm{Hg}_{\mathrm{P}}$ and (B) $\mathrm{MMHg}_{\mathrm{P}}$ versus TSS at each sampling site. .............................................. 21

Fig. 8. Hg:TSS ratio (A) and MMHg:TSS ratio (B) over the sampling period..................................... 22

Fig. 9. Dissolved organic carbon (A) and $\mathrm{SUVA}_{254}$ (B) at each site over the sampling period............... 23

Fig. 10. Dissolved (A) Hg and (B) MMHg concentration at each site. .............................................. 24

Fig. 11. Dissolved (A) Hg and (B) MMHg to DOC ratio at each site............................................. 25

Fig. 12. Total, dissolved, and particulate Hg load at each station over the 30-hour sampling

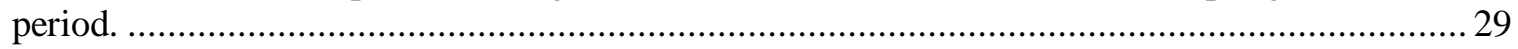

Fig. 13. $\log _{10}$ of the apparent Hg partitioning coefficient $\left(\mathrm{K}_{\mathrm{SW}}\right)$ at each sampling station.................... 29

Fig. 14. Total, dissolved, and particulate MMHg load at each station over the 30-hour sampling

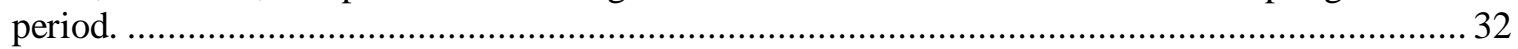

Fig. 15. $\log _{10}$ of the apparent MMHg partitioning coefficient $\left(\mathrm{K}_{\mathrm{sw}}\right)$ at each sampling station. ............... 33

Fig. 16. Percent difference in $\mathrm{Hg}$ (A, B, C) and MMHg (D, E, F) loading for instantaneous

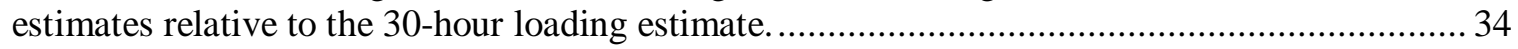





\section{LIST OF TABLES}

Table 1. Sample site coordinates ${ }^{\mathrm{a}}$.......

Table 2. Mean and standard deviation (sd) of relative percent difference (RPD) for field

duplicates, excluding values that were below detection..

Table 3. Spearman rank correlation coefficients $(\rho)$ and p-values for $\mathrm{Hg}_{\mathrm{P}}$ and $\mathrm{MMHg}_{\mathrm{P}}$ with TSS at each sampling station.... 19

Table 4. Constituent loadings at each sampling location, the Mill Branch tributary, and the Oak Ridge Wastewater Treatment Facility (ORWTF). 



\section{ACRONYMS}

$\begin{array}{ll}\text { CVAFS } & \text { cold vapor atomic fluorescence spectroscopy } \\ \text { DOC } & \text { dissolved organic carbon } \\ \text { DOM } & \text { dissolved organic matter } \\ \text { EFK } & \text { East Fork } \\ \text { EFPC } & \text { East Fork Poplar Creek } \\ \text { EPA } & \text { Environmental Protection Agency } \\ \text { Hg } & \text { mercury } \\ \text { Hg } & \text { dissolved mercury } \\ \text { Hg }_{P} & \text { particulate mercury } \\ \text { Hg } & \text { total mercury } \\ \text { Hg } & \text { solid concentration of mercury on suspended solids } \\ \text { HRD } & \text { Historical Release Deposit } \\ \text { IC } & \text { ion chromatography } \\ \text { ICP-MS } & \text { inductively coupled plasma-mass spectrometry } \\ \text { KSW } & \text { solid-water partitioning coefficient } \\ \text { LDPE } & \text { low density polyethylene } \\ \text { LEFPC } & \text { lower East Fork Poplar Creek } \\ \text { MAD } & \text { median absolute deviation } \\ \text { MMHg } & \text { monomethylmercury } \\ \text { MMHg } & \text { dissolved monomethylmercury } \\ \text { MMHg } & \text { particulate monomethylmercury } \\ \text { MMHg } & \text { total monomethylmercury } \\ \text { MMHg } & \text { solid concentration of monomethylmercury on suspended solids } \\ \text { NOM } & \text { natural organic matter } \\ \text { ORWTF } & \text { Oak Ridge Wastewater Treatment Facility } \\ \text { PES } & \text { polyethersulfone } \\ \text { PETG } & \text { polyethylene terephthalate glycol-modified } \\ \text { POC } & \text { particulate organic carbon } \\ \text { POR } & \text { period of record } \\ \text { RPD } & \text { relative percent difference } \\ \text { SFA } & \text { Scientific Focus Area } \\ \text { SRP } & \text { soluble reactive phosphorous } \\ \text { SUVA } & \text { specific UV absorbance at 254 nanometers } \\ \text { TSS } & \text { total suspended solids } \\ \text { UEFPC } & \text { upper East Fork Poplar Creek } \\ \text { USGS } & \text { United States Geological Survey } \\ \text { Y-12 NSC } & \text { Y-12 National Security Center } \\ & \end{array}$





\begin{abstract}
We conducted a diel sampling campaign at three locations along the mercury (Hg)-contaminated East Fork Poplar Creek (EFPC) in Oak Ridge, Tennessee to (i) quantify diel patterns of particulate and dissolved $\mathrm{Hg}$ and monomethylmercury (MMHg) (Hg, $\mathrm{Hg}_{\mathrm{P}}, \mathrm{MMHg}_{\mathrm{D}}$, and MMHg , respectively) and associated water quality parameters along a longitudinal gradient of EFPC during the summer season, (ii) determine if diel patterns in $\mathrm{Hg}$ and/or MMHg are related to the daily photocycle or any other short term cycle, such as wastewater treatment plant discharge, (iii) determine if diel variability in turbidity and dissolved organic matter (DOM) composition correspond to particulate $\mathrm{Hg}_{\mathrm{P}}$ or $\mathrm{MMHg}_{\mathrm{P}}$ and dissolved organic carbon (DOC) or dissolved $\mathrm{Hg}_{\mathrm{D}}$ or $\mathrm{MMHg}_{\mathrm{D}}$. Samples were collected every two hours for a 30hour period. The farthest upstream site was located at the boundary of Y-12 and the City of Oak Ridge (EFK 23.4) while two additional sites were located 7.2 kilometers (Wiltshire Drive, EFK 16.2) and 18 kilometers (Horizon Center, EFK 5.4) downstream of EFK 23.4.
\end{abstract}

$\mathrm{Hg}_{\mathrm{P}}$ and MMHg concentrations increased overnight at EFK 16.2 and EFK 5.4 coincident with increases in turbidity and total suspended solids (TSS). These overnight increases were likely due to diel changes in the activity of macrobiota (re)suspending contaminated sediments in the creek. Both $\mathrm{Hg}_{\mathrm{D}}$ and $\mathrm{MMHg}_{\mathrm{D}}$ were higher during the day at EFK 23.4 and EFK 5.4. The underlying causes for the patterns in $\mathrm{Hg}_{\mathrm{D}}$ and $\mathrm{MMHg}_{\mathrm{D}}$ are less clear but correspond with similar patterns in DOC concentration and DOM composition. Photochemical reactions may also play a role in these $\mathrm{Hg}_{\mathrm{D}}$, MMHg, DOC, and DOM patterns.

Biologically mediated processes, such as microbial MMHg production in actively photosynthesizing periphyton biofilms, likely influence diel MMHg patterns too. Total loads of both $\mathrm{Hg}$ and $\mathrm{MMHg}$ increased with downstream distance. The greatest increase in total, dissolved, and particulate Hg loading occurred in the reach from EFK 23.4 to EFK 16.2 which encompasses areas where the Historic Release Deposits (HRD) have been identified. These results demonstrate that diffuse legacy sources of $\mathrm{Hg}$, outside of Y-12, contribute Hg load to EFPC.

Both total and dissolved MMHg loads increased approximately linearly with downstream distance. Particluate MMHg loading increased in the upper reach but did not change over the lower reach. The HRD may contribute to $\mathrm{MMHg}_{\mathrm{P}}$ load in the upper reach but most of the total, dissolved, and particulate MMHg appears to originate from in-stream production. Due to intraday patterns in concentration and flow rate, loading estimates are best derived from diel sampling campaigns.

Intraday patterns in $\mathrm{Hg}$ and MMHg concentration and speciation have implications with respect to biotic exposure. Greater biotic activity and feeding during times of higher concentration would correspond to greater exposure than estimated from daily or longer-term averages. Both Hg and MMHg responded rapidly to processes governing their concentration. This latter point is encouraging from the perspective of site remediation as it suggests that MMHg concentrations and flux in EFPC would respond rapidly to appropriate remedial actions. 



\section{INTRODUCTION}

Diel biogeochemical patterns in aquatic ecosystems linked to the behavior of dominant and trace anions and contaminants have been reported in the literature for some time (Fuller and Davis 1989, Volkmar et al. 2011, Nagorski et al. 2003). Many of these reports have focused on lentic ecosystems with fewer studies conducted in lotic ecosystems. The physical setting and characteristics of streams and rivers (e.g., unidirectional turbulent flow, varying degrees of canopy cover from 0 to $100 \%$, longitudinal variation in width to depth ratio) differ significantly from ponds and lakes making it unclear which lessons from lentic ecosystems will apply to lotic ecosystems particularly with respect to monomethylmercury (MMHg) concentration dynamics. Several water quality parameters (dissolved oxygen, $\mathrm{pH}, \mathrm{CO}_{2}$ ) are linked to the daily photocycle and its influence on the opposing processes of photosynthesis and respiration. To the extent these processes are coupled to other biogeochemical processes, the daily photocycle may also be correlated to additional water quality parameters.

Mercury (Hg) is a pollutant of global, regional, and local concern. In aquatic ecosystems $\mathrm{Hg}$ can be methylated by microorganisms creating $\mathrm{MMHg}$ which is much more toxic and bioaccumulative than inorganic Hg. East Fork Poplar Creek (EFPC) is contaminated with Hg from an industrial source at its headwaters (Brooks and Southworth 2011, Loar, Stewart, and Smith 2011). Much has been learned about Hg in the EFPC system over the past few decades, but key questions remain regarding patterns and controls on Hg movement and transformation. Mercury has a complex cycle in aquatic environments where it is subject to a suite of abiotic (e.g., sorption-desorption, complexation, precipitation-dissolution), photochemical (photo-reduction and -oxidation), and microbially mediated reactions (methylationdemethylation, reduction and oxidation). To the extent that these reaction paths and their extent are sensitive to and respond rapidly to other diel cycles, parts of the Hg cycle may also exhibit diel patterns. In particular, monomethylmercury (MMHg) may be sensitive to the diel cycle. MMHg concentrations reflect the balance of the opposing processes of methylation and demethylation. MMHg can be demethylated by both biotic and abiotic (e.g., photodemethylation) (Qian et al. 2014) processes. Photodemethylation only occurs during the day whereas biotic demethylation can occur during the day and at night. Because some of the processes controlling MMHg concentration follow a diel pattern (photosynthesizing biofilms, photodemethylation) MMHg concentration may also have a diel pattern.

A few studies have specifically addressed daily patterns in $\mathrm{Hg}$ and $\mathrm{MMHg}$ concentrations in aquatic ecosystems and the variability in reported results reflects the variability of the ecosystems studied (lakes versus streams versus wetlands; freshwater versus estuarine; northern versus subtropical latitudes) and their characteristics (e.g., unidirectional turbulent flow in small streams versus relatively quiescent flow in large lakes; DOM structure and concentration). In a border wetland to the Great Salt Lake, dissolved MMHg (MMHg $)$ concentration declined during the day and increased at night (Naftz et al. 2011). The authors attributed the decline in MMHg during the day to photo-demethylation while the increase at night was believed to be due to turnover of thermally stratified water that was below the zone of photodemethylation. Similarly, MMHg concentrations doubled at night relative to daytime in an agricultural wetland planted with wild rice but did not change over a daily cycle in an adjacent plot planted with white rice suggesting other differences in ambient aquatic biogeochemical properties (e.g., DOM structure, microbial community differences between crops) can moderate the influence of photodegradation on the net MMHg budget (Fleck et al. 2009). Krabbenhoft et al. (Krabbenhoft et al. 1998), working in the Florida Everglades, reported reproducible diel cycles in dissolved gaseous mercury and reactive ( $\mathrm{SnCl}_{2}$ reducible) mercury concentration linked to the daily photocycle but diel trends in MMHg were not correlated to the photocycle. In addition to these field sampling studies, in situ bottle incubation studies have also highlighted the importance of MMHg photodegradation and its link to light intensity (e.g., (Sellers et al. 1996)). 
In contrast to these MMHg photodegradation studies, Siciliano et al. (Siciliano et al. 2005) noted MMHg concentration increased during the day in two lakes and was correlated with solar radiation. These observations and the results of in situ bottle incubations led the authors to conclude that photoproduction of MMHg was occurring and was dependent on the structure and concentration of DOM in the lakes. Nimick et al. (Nimick et al. 2007), working in two streams, also reported increasing $\mathrm{MMHg}_{\mathrm{D}}$ concentration during the day, peaking in early afternoon with overnight concentration minima. These authors suggested that these patterns may have been caused by sunlight and temperature dependent methylation pathways.

Monomethylmercury is not a direct contaminant to EFPC. Rather, it is formed in the creek from inorganic $\mathrm{Hg}$ in a microbially mediated process called $\mathrm{Hg}$ methylation. Previous research indicates that key controls on net methylation occur within the stream or on the stream bed (e.g., (Riscassi, Miller, and Brooks 2016)) as opposed to out of the stream. Mercury methylation requires anaerobic conditions and the presence of active methylating microorganisms. In EFPC anaerobic conditions exist within the creek sediments and in periphyton biofilms covering submerged surfaces in the creek. Active methylating microorganisms have been found in EFPC sediments and periphyton biofilms (Christensen et al. 2018, Porat et al. 2010, Mosher et al. 2012, Vishnivetskaya et al. 2011, Olsen, Brandt, and Brooks 2016). Olsen (2016) reported that actively photosynthesizing periphyton biofilms in EFPC may be important sources of MMHg. However, when incubated in the dark the rate of MMHg production from these biofilms decreased significantly, and in some cases the biofilms were net demethylating.

Our objectives for this study conducted in a Hg-impacted stream were to (i) quantify diel patterns of particulate and dissolved $\mathrm{Hg}$ and $\mathrm{MMHg}$ and associated water quality parameters along a longitudinal gradient of East Fork Poplar Creek (EFPC) during the summer season, (ii) determine if diel patterns in Hg and/or MMHg are related to the daily photocycle or any other short term cycle, such as wastewater treatment plant discharge, (iii) determine if diel variability in turbidity and DOM composition correspond to particulate $\mathrm{Hg}$ or $\mathrm{MMHg}$ ( $\mathrm{Hg}_{\mathrm{P}}$ and $\mathrm{MMHg}_{\mathrm{P}}$, respectively) and DOC or dissolved $\mathrm{Hg}$ or $\mathrm{MMHg}\left(\mathrm{Hg}_{\mathrm{D}}\right.$ and $\mathrm{MMHg}_{\mathrm{D}}$, respectively). 


\section{MATERIALS AND METHODS}

\subsection{STUDY SITE}

The detailed history and characterization of EFPC have been previously published (Brooks and Southworth 2011, Loar, Stewart, and Smith 2011, Stewart, Smith, and Loar 2011, Riscassi, Miller, and Brooks 2016). Briefly, the Y-12 National Security Complex (Y-12 NSC) is located at the headwaters of EFPC. Flow in the upper reaches originates from springs, groundwater, storm water runoff, and process and cooling water from Y-12 operations. The upper three kilometers of the creek lie within Y-12 and the channel consists of unlined, armored and channelized sections lined with concrete. From the Y-12 boundary the creek flows another 23 kilometers through commercial, residential, open-land, and forested areas until its confluence with Poplar Creek. The three-kilometer reach within Y-12 is administratively referred to as upper East Fork Poplar Creek (UEFPC) and the lower 23-kilometer reach is referred to as lower East Fork Poplar Creek (LEFPC). Mercury concentrations in water are highest near Y-12 NSC and decrease downstream. Conversely, MMHg concentrations in water are lowest near Y-12 and increase downstream.

Midway along the length of the creek the City of Oak Ridge Wastewater Treatment Facility (ORWTF) discharges treated water into EFPC which constitutes $~ 15 \%$ of the flow at EFK 5.4 (Fig. 1). During the period from 2011 through 2016 this effluent had mean ( \pm standard deviation) total and dissolved $\mathrm{Hg}$ concentrations of $5.5 \pm 11 \mathrm{ng} / \mathrm{L}(\mathrm{n}=41 ; 3.2 \pm 2$ after removing 3 potential outliers) $\mathrm{ng} / \mathrm{L}$ and $2.4 \pm 2.8$ $\mathrm{ng} / \mathrm{L}(\mathrm{n}=38 ; 1.6 \pm 0.6$ after removing 4 potential outliers) respectively, and total and dissolved MMHg concentrations of $0.12 \pm 0.07(n=38)$ and $0.07 \pm 0.04(n=41) n g / L$, respectively. At the reported discharge volumes (see section 3.1), on average ORWTF effluent constituted less than $1 \%$ of the total $\mathrm{Hg}$ flux and less than $6 \%$ of the MMHg flux measured at baseflow at our downstream monitoring station (EFK 5.4).

The daily schedule of operations at the ORWTF and the constituents in its effluent influence the stream. These are discussed in more detail in the Results (section 3). Briefly, discharge from the ORWTF contributes significant loads of dissolved organic carbon ( 48 kg/d), nitrate ( 407 kg/d), total phosphate $(\sim 60 \mathrm{~kg} / \mathrm{d})$, and soluble reactive phosphorous $(\sim 10 \mathrm{~kg} P / \mathrm{d})$. Intraday variations in discharge from the ORWTF are evident at EFK 5.4 in terms of both water flow and water composition.

\subsection{SAMPLING SITES AND SITE DESIGNATION CONVENTION}

Sites along EFPC are designated using an alphanumeric identifier: EFK\#\#. EFK stands for East Fork and the number indicates the creek kilometer, measured upstream from the mouth of the creek which has the designation EFK 0.

The diel sampling cycle was conducted under baseflow conditions (six days after the most recent significant rainfall) at three locations along EFPC: EFK 5.4, EFK 16.2 and EFK 23.4 (Fig. 1; Table 1). EFK 5.4 is located at the site of a former USGS gaging station (\#03538250) which was discontinued in 1988 and re-established by ORNL staff in 2012 under the BER-funded Scientific Focus Area (SFA) project. EFK 16.2 is located at the Wiltshire Drive

Table 1. Sample site coordinates ${ }^{\mathrm{a}}$

\begin{tabular}{ccc}
\hline Site & Latitude & Longitude \\
\hline EFK 5.4 & 35.962933 & -84.359167 \\
EFK 16.2 & 35.998857 & -84.300050 \\
EFK 23.4 & 35.994369 & -84.238538 \\
Tower K & 35.933336 & -84.386511 \\
\hline
\end{tabular}

${ }^{a}$ decimal degrees

overpass of lower EFPC. During this study, samples were collected $\sim 10 \mathrm{~m}$ upstream of the overpass at EFK 16.2. EFK 23.4 is located near the boundary of Y-12 and the City of Oak Ridge and is near Station 17. Watson et al. (Watson et al. 2016) divided the creek into five reaches for a modeling study. These 
creek reach designations have been used to bin sampling locations in a previous creek sediment study (Brooks et al. 2017). EFK 5.4 is in reach 1, EFK 16.2 is in reach 3, and EFK 23.4 is in reach 5.

The Mill Branch tributary makes its confluence with EFPC about $600 \mathrm{~m}$ downstream of the EFK 16.2 sampling site. Mill Branch is not contaminated with $\mathrm{Hg}$ and was not actively sampled during this study. Over the period December 2011 through October 2016, average baseflow total and dissolved $\mathrm{Hg}$ concentrations were $2.23 \pm 1.4 \mathrm{ng} / \mathrm{L}(\mathrm{n}=28)$ and $0.65 \pm 0.3 \mathrm{ng} / \mathrm{L}(\mathrm{n}=28)$, respectively. Average baseflow total and dissolved MMHg concentrations were $0.075 \pm 0.043 \mathrm{ng} / \mathrm{L}(\mathrm{n}=28)$ and $0.054 \pm 0.030$ $\mathrm{ng} / \mathrm{L}(\mathrm{n}=28)$, respectively. Methods used to estimate Mill Branch discharge and Hg and MMHg loading to EFPC are detailed in following sections.

\subsection{SAMPLING PLAN}

The field work described in this report occurred on 17-18 September 2015. All times given are Eastern Standard Time (EST = UTC - 5:00) and use a 24-hour clock. Sunset occurred on 17 September at $1843 \mathrm{~h}$ and sunrise on 18 September occurred at $0621 \mathrm{~h}$. Samples were collected every 2 hours for 30 hours beginning at $0900 \mathrm{~h}$ on the first day and continuing through $1500 \mathrm{~h}$ on the following day.

\subsubsection{Water Sampling, Preservation, and Chemical Analysis}

Samples were collected using a combination of manual sampling into a new $250 \mathrm{~mL}$ glycol-modified polyethylene terephthalate (PETG) bottle, or with a Teledyne ISCO ${ }^{\circledR}$ automated sampler retrofitted with a strainer and sample tubing made from Teflon ${ }^{\circledR}$ tubing and collected into ISCO ProPak ${ }^{\mathrm{TM}}$ disposable sample bags made of low-density polyethylene (LDPE). We previously demonstrated that this autosampling method does not compromise sample integrity for EFPC water when samples are retrieved from the autosampler, processed, and preserved within 24 hours of sample collection (Riscassi, Miller, and Brooks 2014b). Concurrent grab and automated samples collected throughout the study confirmed our previous findings. The relative percent difference (Eqn. (1) for total and dissolved Hg between grab and automated samples was $10.2 \pm 12.1 \%(\mathrm{n}=9)$ and $6.55 \pm 4.48 \%$, respectively (mean $\pm \mathrm{sd})$. The relative percent difference for total and dissolved MMHg between grab and automated samples was 7.66 $\pm 6.84 \%(\mathrm{n}=9)$ and $6.13 \pm 3.41 \%$, respectively. Autosampler failures resulted in the loss of one sample at EFK 16.2 and the loss of two samples at EFK 23.4.

Grab samples were collected by wading into the middle of the stream, facing upstream, and rinsing the PETG bottle three times with creek water. The bottle was then filled, sealed, and transported to the lab for immediate processing. The intake tubing for the autosamplers was placed in the middle of the stream suspended at approximately mid-water-column depth. The autosamplers were programmed to rinse sample tubing three times before filling two one-liter LDPE sample bags. One of the bags was used for chemical analyses and the other bag was used for total suspended solids (TSS) determination.

Immediately after collection in the field (either grab samples or samples retrieved from the autosamplers) samples were placed on ice in the dark and transported from the field to the Environmental Sciences Division, Oak Ridge National Laboratory ( 15-minute drive). An aliquot of the sample was retained for analysis of unfiltered (total) $\mathrm{Hg}$ and $\mathrm{MMHg}\left(\mathrm{Hg}_{\mathrm{T}}\right.$ and $\mathrm{MMHg}_{\mathrm{T}}$, respectively) and the remaining sample was filtered through either a $0.2 \mu \mathrm{m}$ analytical filter unit (Nalgene, polyethersulfone (PES)) for Hg and MMHg analysis or a $0.2 \mu \mathrm{m}$ PES syringe filter for dissolved organic carbon (DOC), UV-Vis, anion, and metals analysis. Previous work has shown that in EFPC, MMHg passing a $0.2 \mu \mathrm{m}$ filter also passes a 3 kiloDalton ultrafilter (nominal pore size $\sim 0.4 \mathrm{~nm}$; (Kocman et al. 2013). Samples collected for TSS were filtered through a tared and pre-ashed GF/F grade glass microfiber filter with a $0.7 \mu \mathrm{m}$ particle size 
retention at $98 \%$ efficiency in liquid. Filters were dried in an oven at $100^{\circ} \mathrm{C}$ to a constant weight, and TSS (mg/L) was calculated as the difference in filter weight divided by the volume of sample filtered.

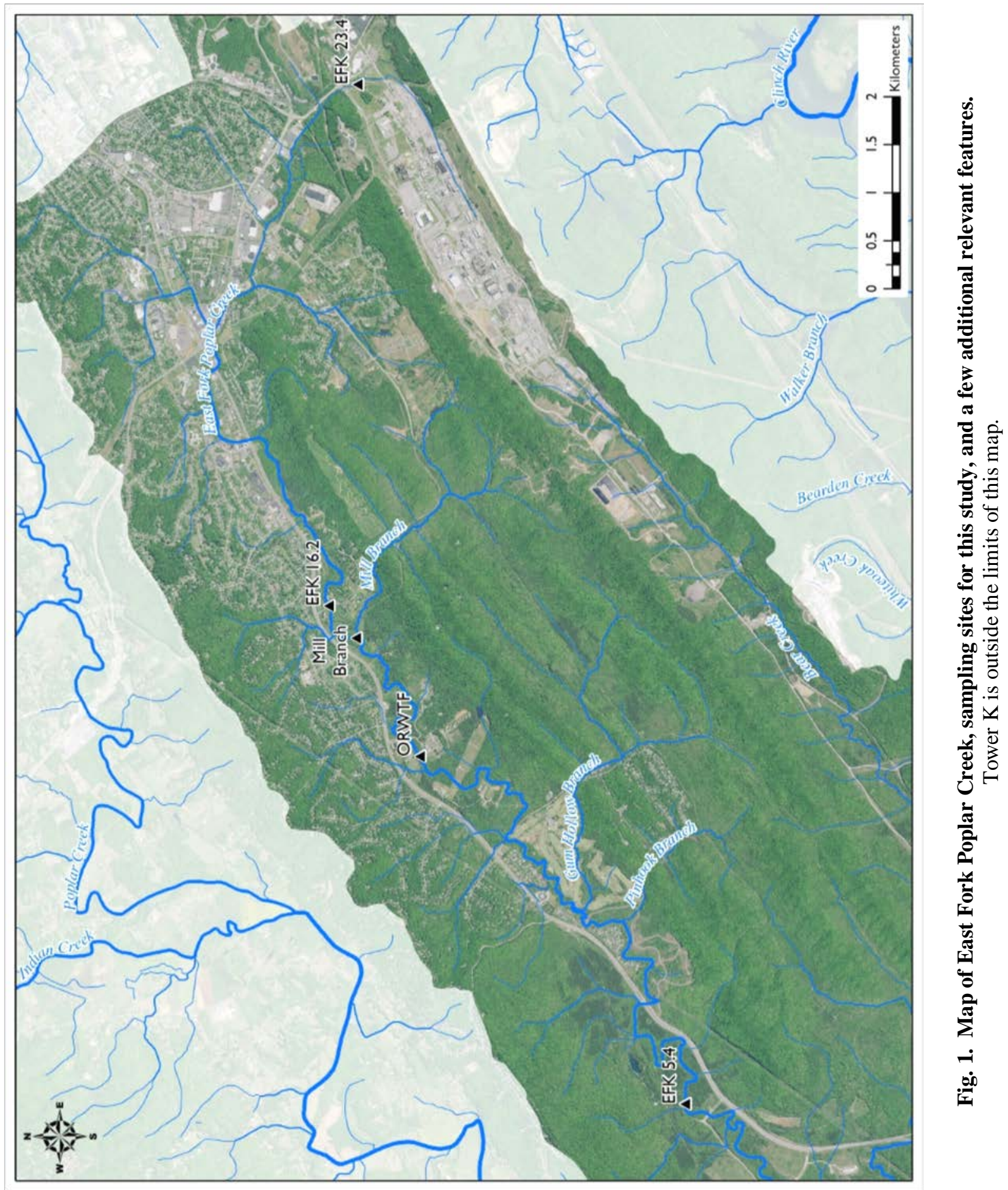


Unfiltered and filtered $\mathrm{Hg}$ and MMHg samples were preserved to $0.5 \%$ (v/v) $\mathrm{HCl}$ and DOC samples were preserved to $0.1 \%(\mathrm{v} / \mathrm{v}) \mathrm{HCl}$. Trace metal grade $\mathrm{HCl}$ was used for sample preservation. Unacidified subsamples for anion and UV-Vis analysis were held in amber glass vials. Samples for metals analysis were preserved to $0.5 \%(\mathrm{v} / \mathrm{v}) \mathrm{HNO}_{3}$ (trace metal grade). All samples were refrigerated at $4{ }^{\circ} \mathrm{C}$ in the dark until subsequent analysis. Filtered $\mathrm{Hg}$ and $\mathrm{MMHg}$ samples are herein referred to as dissolved $\mathrm{Hg}\left(\mathrm{Hg}_{\mathrm{D}}\right)$ and $\mathrm{MMHg}\left(\mathrm{MMHg}_{\mathrm{D}}\right)$, respectively. Particulate $\mathrm{Hg}$ and $\mathrm{MMHg}$ (Hg $\mathrm{H}_{\mathrm{P}}$ and $\mathrm{MMHg}_{\mathrm{P}}$, respectively) were calculated as the difference between total and dissolved. The fraction of $\mathrm{Hg}$ in dissolved or particulate form was calculated as $\mathrm{Hg}_{\mathrm{D}}$ or $\mathrm{Hg}_{\mathrm{P}}$ divided by $\mathrm{Hg}_{\mathrm{T}}$, respectively.

Analysis of Hg samples was conducted using a Hg purge and trap system (Brooks Rand MERX). Bromine monochloride was added to all $\mathrm{Hg}$ samples a minimum of $24 \mathrm{~h}$ before analysis. Hydroxylamine and stannous chloride were added to the samples and the $\mathrm{Hg}^{0}$ produced was purged from solution and trapped onto gold-coated sand analytical traps (U. S. EPA 2002). The traps were subsequently heated to release the Hg which was detected by the Cold Vapor Atomic Fluorescence Spectrophotometer (CVAFS). Ambient MMHg was analyzed using modifications of EPA method 1630 (U. S. EPA 2001) which involves the distillation of the water sample followed by ethylation, purge and trap onto Tenax traps, gas chromatographic separation of the Hg species and detection by inductively coupled plasma-mass spectrometry (ICP-MS). This analysis was performed with a Brooks Rand MERX MMHg instrument coupled with a Perkin Elmer Elan-DRC ICP-MS. An internal standard ( $\left.\mathrm{MM}^{200} \mathrm{Hg}\right)$ was added to samples prior to distillation and this isotope was used to quantify MMHg concentrations (Hintelmann and Ogrinc 2003).

DOC concentrations were measured using high-temperature platinum-catalyzed combustion followed by infrared detection of $\mathrm{CO}_{2}$ (Shimadzu TOC-5000A or Shimadzu TOC-L). UV-visible spectra were collected at 1-nm interval and 0.5 second exposure time from 190-1100 nm wavelength with an HP 8453 spectrophotometer using a 1-cm path length quartz cuvette. Specific ultraviolet absorbance at $254 \mathrm{~nm}$ $\left(\mathrm{SUVA}_{254}\right.$ ), a dissolved organic matter (DOM) composition indicator, was also computed. SUVA 254 was calculated as the UV absorbance at $254 \mathrm{~nm}\left(\mathrm{~m}^{-1}\right)$ divided by the DOC concentration $(\mathrm{mg} / \mathrm{L})$ and reported in units of $\mathrm{L} / \mathrm{mg} \mathrm{C} / \mathrm{m}$.

Major dissolved anions $\left(\mathrm{Cl}^{-}, \mathrm{NO}_{3}{ }^{-}, \mathrm{SO}_{4}{ }^{2-}, \mathrm{PO}_{4}{ }^{3-}\right.$ ) and metals (Na, $\mathrm{Mg}, \mathrm{Ca}, \mathrm{K}, \mathrm{Al}, \mathrm{Fe}, \mathrm{Mn}, \mathrm{Sr}, \mathrm{Ba}, \mathrm{U}$ ) were analyzed by ion chromatography (IC) (Dionex DX-120, Sunnyville, CA, USA) and ICP-MS (PerkinElmer, Waltham, MA, USA), respectively. Ammonium $\left(\mathrm{NH}_{4}{ }^{+}\right.$as $\left.\mathrm{N}\right)$ and soluble reactive phosphorous (SRP as P) were measured by flow injection analysis (Seal Analytical Autoanalyzer 3 HR).

\subsubsection{Field Instrumentation}

Each station was instrumented with a multiparameter sonde (Yellow Springs International, YSI) to measure and record water temperature $\left({ }^{\circ} \mathrm{C}\right)$, specific conductance $(\mu \mathrm{S} / \mathrm{cm}), \mathrm{pH}(\mathrm{SU})$, dissolved oxygen (mg/L), and turbidity (NTU) at 15-minute intervals. Turbidity was not measured at EFK 23.4. Each station was also equipped with a HOBO Pendant ${ }^{\circledR}$ light meter which measured and recorded light intensity (lux) over the wavelength range $150-1200 \mathrm{~nm}$ at 5-minute intervals. These creek-side light intensity measurements were supplemented with 15-minute solar radiation measurements (Watts $/ \mathrm{m}^{2}$ ) obtained from a tower located $4.5 \mathrm{~km}$ to the southwest of EFK 5.4 (Tower K on the Oak Ridge Reservation, Table 1) which was free of canopy cover and served to help distinguish when regional cloud cover contributed to decreases in light intensity relative to localized transient shading due to canopy cover as the sun changed position in the sky. 


\subsubsection{Discharge Measurements}

Stream stage at EFK 5.4 and EFK 16.2 was measured and recorded at 15-minute intervals by a pressure transducer within a stilling well at each site. Stream stage (meters) was converted to discharge (cubic meters per second, $\mathrm{m}^{3} / \mathrm{s}$ ) using stage-discharge relationships developed for each site. The site at EFK 5.4 was a former United States Geological Survey (USGS, \#03538250) surface water monitoring site that had a period of record (POR) from 1960 through 1988. A stage-discharge relationship was established for the site from measurements made during the POR. Additional discharge measurements at low and moderate flows $(n=5)$ were collected in $2012-2013$ and confirmed the historical rating remained applicable to the site. The accuracy of the rating curve developed at EFK 5.4 was last judged by the USGS to be "good" meaning that " 95 percent of the daily discharges are within 10 percent of the true value" (Lowery et al. 1988); and e.g., https://pubs.usgs.gov/sir/2006/5036/section7.html, accessed 16 February 2018). This estimate of discharge uncertainty includes both qualitative and quantitative factors and therefore likely represents more than one standard deviation.

A new stage-discharge relationship was developed for EFK 16.2 using measurements made at low to high flows $(n=10)$ during $2014-2015$. The rating curve at EFK 16.2 is still under development and is not yet reliable at flows greater than $\sim 1.7 \mathrm{~m}^{3} / \mathrm{s}$. We continue to try and resolve the problems with the rating curve at higher flows. The Tennessee Valley Authority noted similar issues in the early 1980's and were unable to reconcile the problem (Tennessee Valley Authority 1985), pp. 32-33). We assumed the rating curve at EFK 16.2 for flows less than $1.7 \mathrm{~m}^{3} / \mathrm{s}$ was "fair", which in the USGS context means that 95 percent of the daily discharges are within 15 percent of the true value.

Discharge data at 6-minute intervals for EFK 23.4 were provided by Y-12 NSC Environmental Compliance courtesy of Kimberly Hanzelka. Flow at EFK 23.4 is calculated from a rating curve that was also used by the USGS (\#03538235; K. Hanzelka, pers. comm.). The USGS last judged the accuracy of that rating curve to be "good" (Flohr et al. 2002). Daily mean discharge data for the ORWTF (located at EFK 13.5) was provided by the City of Oak Ridge courtesy of Janice Sproles.

\subsection{QUALITY ASSURANCE/ QUALITY CONTROL}

Instrument performance for both Hg and MMHg samples was verified with standards throughout the analytical run, matrix spikes, and analytical duplicates (distillation duplicates for MMHg). For MMHg distillation blanks were also run to verify no contamination was introduced in that process. Field duplicates and field blanks were also collected. Detection limits were determined for each analytical run based on the methods outlined by Oppenheimer et al. (Oppenheimer et al. 1983). For Hg analysis, minimum detection ranged from 0.15 to $0.59 \mathrm{ng} / \mathrm{L}$ (mean $\pm \mathrm{sd}=0.37 \pm 0.14 \mathrm{ng} / \mathrm{L}, n=6$ ) based on the analysis of a $20 \mathrm{~mL}$ sample and for MMHg 0.011 to $0.025 \mathrm{ng} / \mathrm{L}$ (mean $0.015 \pm 0.005 \mathrm{ng} / \mathrm{L}, n=5$ ) based on the analysis of a $45 \mathrm{~mL}$ sample. All samples analyzed were above method detection limits.

The relative percent difference (RPD) between duplicate samples or replicate analyses was calculated as:

$$
R P D(\%)=100 \frac{\left|x_{1}-x_{2}\right|}{\frac{x_{1}+x_{2}}{2}}
$$

where $x_{1}$ and $x_{2}$ are values for sample 1 and 2, respectively. For Hg, mean recovery for matrix spikes was $101.2 \pm 3.4 \%(n=3)$ and the mean RPD between analytical duplicates was $2.7 \pm 1.5 \%(n=9)$. The mean RPD for field duplicates for $\mathrm{Hg}_{\mathrm{D}}$ was $6.55 \pm 4.48 \%(\mathrm{n}=9)$ and the mean RPD for unfiltered $\mathrm{Hg}$ was $10.2 \pm 12.1 \%(n=9)$. The larger variability in unfiltered $\mathrm{Hg}$ field duplicates, relative to filtered, is a result of variability in the amount of suspended sediment captured in the sample bottle and in the aliquots 
poured off those samples for subsequent analysis due to non-uniform mixing. All field blanks for $\mathrm{Hg}$ were below detection limits $(n=6)$. For MMHg, mean recovery for matrix spikes was $99.77 \pm 4.25 \%$ ( $n$ $=4)$. The mean RPD between MMHg distillation duplicates was $5.54 \pm 5.57 \%(n=8)$. The mean RPD between field duplicates of filtered MMHg was $6.30 \pm 4.05 \%(n=4)$ and for unfiltered MMHg $12.1 \pm$ $13.4 \%(n=2)$. Field blanks for MMHg averaged $0.025 \pm 0.017 \mathrm{ng} / \mathrm{L}(n=6)$ and all distillation blanks were below detection limits.

Field blanks for all remaining measured parameters were below detection limits. The mean RPD for field duplicates for remaining analyses are given in Table 2.

\subsection{COMPUTATIONS AND STATISTICAL ANALYSES}

Particulate $\mathrm{Hg}$ and $\mathrm{MMHg}\left(\mathrm{Hg}_{\mathrm{P}}\right.$ and $\mathrm{MMHg}_{\mathrm{P}}$, respectively) were calculated as the difference between total $\mathrm{Hg}_{\mathrm{T}}$ (or $\mathrm{MMHg}_{\mathrm{T}}$ ) and filter passing $\mathrm{Hg}_{\mathrm{D}}$ (or $\mathrm{MMHg}_{\mathrm{D}}$ ).

Suspended solids were further characterized by calculating their specific $\mathrm{Hg}$ (or MMHg) concentration as the ratio of $\mathrm{Hg}_{\mathrm{P}}$ (or $\mathrm{MMHg}_{\mathrm{P}}$ ) to TSS:

$$
H g_{T S S}=\frac{H g_{P}}{T S S}
$$

Where $H g_{T S S}=$ TSS specific concentration of Hg or MMHg $(\mathrm{ng} / \mathrm{mg}) ; H g_{P}\left(M M H g_{P}\right)=$ concentration of particulate Hg (MMHg)(ng/L); TSS = total suspended solids concentration (mg/L).

The mean water travel time between sampling stations was estimated by dividing the distance between stations by the mean stream velocity. Using the field measurements collected during rating curve development, the stream velocity was plotted versus stream discharge. An equation was fit to these data (Fig. A1), and mean velocity was calculated from the equation using the measured mean discharge over the course of sampling. At EFK 23.4, the mean discharge fell outside the range of data used to create the rating curve. The estimated travel time between stations is reported as the mean $\pm 1 / 2$ range of the travel time estimated for the upstream and downstream station. In other words, the reported travel time from EFK 23.4 to EFK 16.2, a distance of 7,200 m, is reported as the mean of the travel times estimated using the velocity at EFK 23.4 and that at EFK 16.2.

Table 2. Mean and standard deviation (sd) of relative percent difference (RPD) for field duplicates, excluding values that were below detection

\begin{tabular}{crrrrrrr}
\hline \multicolumn{3}{c}{ Anions, nutrients, DOC, and TSS } & \multicolumn{3}{c}{ Metals } \\
\hline Parameter & mean & sd & $n$ & Parameter & mean & sd & $n$ \\
\hline $\mathrm{Br}^{-}$ & 4.97 & 2.03 & 4 & $\mathrm{Ca}$ & 2.02 & 1.08 & 9 \\
$\mathrm{Cl}^{-}$ & 0.67 & 0.51 & 9 & $\mathrm{Mg}$ & 1.36 & 1.47 & 9 \\
$\mathrm{NO}_{3}{ }^{-}$ & 1.18 & 0.95 & 9 & $\mathrm{Na}$ & 2.98 & 1.61 & 9 \\
$\mathrm{PO}_{4}{ }^{3-}$ & 13.17 & 18.42 & 5 & $\mathrm{~K}$ & 2.69 & 2.16 & 9 \\
$\mathrm{SO}_{4}{ }^{2-}$ & 0.56 & 0.42 & 9 & $\mathrm{Li}$ & 7.75 & 6.56 & 9 \\
$\mathrm{NH}_{4}{ }^{+}-\mathrm{N}$ & 18.04 & 10.90 & 9 & $\mathrm{Fe}$ & 9.16 & 8.78 & 6 \\
$\mathrm{SRP}^{-}$ & 10.58 & 7.42 & 9 & $\mathrm{Mn}$ & 13.41 & 20.64 & 6 \\
$\mathrm{DOC}$ & 4.87 & 2.96 & 9 & $\mathrm{Sr}$ & 1.14 & 0.73 & 9 \\
$\mathrm{TSS}$ & 18.43 & 9.25 & 9 & $\mathrm{U}$ & 2.43 & 1.9 & 9 \\
\hline
\end{tabular}

\footnotetext{
${ }^{a}$ soluble reactive phosphorous as phosphorous
} 
Total flow $\left(\mathrm{m}^{3}\right)$ at each monitoring station over the 30-h sampling period was calculated by integrating the area under the discharge versus time curve using the trapezoidal rule. Uncertainty in total flow was calculated using standard rules for propagating uncorrelated uncertainty in calculations (Taylor 1997) and assuming 10\% uncertainty for discharge measurements at EFK 23.4 and EFK 5.4 and 15\% uncertainty for discharge measurements at EFK 16.2 (see section 2.3.3). Total flow from the ORWTF was calculated as the product of the mean daily flow for 17-18 September and the elapsed time of our monitoring period (30 hours) and assuming $10 \%$ uncertainty in the mean daily flow.

The flux of measured constituents at each monitoring station was calculated by integrating the area under the concentration versus water volume curve using the trapezoidal rule. For estimating flux uncertainty, uncertainties in water volume were estimated as described earlier (section 2.3.3). Uncertainty in concentration for each constituent at EFK 23.4, EFK 16.2, and EFK 5.4 was assigned as the mean RPD for that constituent based on field duplicates (Table 2). For the Mill Branch tributary and discharge from the ORWTF flux was estimated using the volume of water (section 3.1) and the mean ( \pm standard deviation) concentration measured for baseflow samples collected from December 2011 through October 2016. The magnitude of diel variations, expressed as a percentage, was calculated after removing potential outliers (section 2.5.1) by dividing the difference between the maximum and minimum value by the minimum value. The maximum and minimum values over the entire data record were used regardless of sample collection time.

Solid-water partitioning coefficients $\left(\mathrm{K}_{\mathrm{sw}}\right)$ were calculated for $\mathrm{Hg}$ and $\mathrm{MMHg}$ as (using $\mathrm{Hg}$ as an example):

$$
K_{S W}=\frac{\frac{H g_{T}-H g_{D}}{T S S}}{H g_{D}}
$$

Where $K_{S W}=$ solid-water partitioning coefficient (L/kg), $H g_{T}=$ total $\mathrm{Hg}(\mathrm{ng} / \mathrm{L}), H g_{D}=$ dissolved $\mathrm{Hg}$ (ng/L), and TSS = total suspended solids $(\mathrm{kg} / \mathrm{L})$. The $\mathrm{K}_{\text {sw }}$ calculation is identical to that for the equilibrium distribution coefficient $\left(\mathrm{K}_{\mathrm{d}}\right)$ used to describe linear equilibrium sorption isotherms. Here we adopt a more conservative interpretation and do not consider $K_{s w}$ equal to the $K_{d}$ because conditions did not conform to equilibrium sorption isotherm interpretation. Specifically, (i) the $\mathrm{pH}$ and temperature of the creek water varied over the course of the sampling period, (ii) the equilibrium condition is uncertain (i.e., cannot rule out kinetic effects), (iii) partitioning behavior may be under the control of processes other than reversible sorption (e.g., precipitation-dissolution reactions).

\subsubsection{Outlier Detection}

Because of the small number of samples at each site, potential outliers were determined by two methods. The first method involved calculating modified z-scores (NIST 2017) for each measured parameter at each site as:

$$
z_{i}=0.6745\left(\frac{x_{i}-\tilde{x}}{M A D}\right)
$$

Where $z_{i}=$ modified z-score for observation $i ; x_{i}=$ observation $i ; \tilde{x}=$ median for all observations; $M A D=$ median absolute deviation of observations $=$ median $\left(\left|x_{i}-\tilde{x}\right|\right)$. Observations with a z-score greater than 3.5 or less than -3.5 were flagged as possible outliers. Modified z-scores were used to identify possible outliers due to the recognized limitations of the standard z-score for small sample size (Shiffler 1988). 
Tukey's fences were used in the second method for outlier detection (Hoaglin 2003). An observation was considered an outlier if its value fell outside the range defined by:

$$
\left[Q_{1}-1.5\left(Q_{3}-Q_{1}\right), Q_{3}+1.5\left(Q_{3}-Q_{1}\right)\right]
$$

Where $Q_{1}=$ first quartile and $Q_{3}=$ third quartile of the set of observations. An observation identified as an outlier by one method only is referred to as an outlier whereas an observation identified as an outlier by both methods is referred to as a strong outlier.

\subsubsection{Statistical Tests}

Statistical analyses were conducted in $R$ (R Core Team 2016). For all statistical tests, results were considered significant by adopting an a priori Type I error rate of $5 \%$. Analysis of variance (ANOVA) tests for unequal sample sizes were conducted using sampling site and day versus night as factors. When significant effects of sampling site or day versus night were found, comparisons among groups were made using Tukey's Honestly Significant Differences (Tukey's HSD) test holding the family-wise confidence level at 95\%. For other paired comparisons, Welch's t-test was used. Welch's t-test is a variant of the Student's t-test and is more accurate when samples have unequal variance and sample size. Reported correlations are Spearman's Rank Correlation coefficient $(\rho)$, a nonparametric measure of monotonic correlation between two variables. 


\title{
3. RESULTS
}

Data from this study are available online doi: 10.12769/1434238. The complete data set consists of one data explanation file in portable document format (EFPC 2015_09_17-18 Data Explanation.pdf) plus 4 comma-separated (*.csv) files (EFPC_Discharge_2015_09_17-18.csv; EFPC_LightMeter_2015_09_1718.csv; EFPC_SondeData_2015_09_17-18.csv; EFPC_WaterChemistry_2015_09_17-18.csv).

Over the 30-hour sampling period the weather remained clear with no to light winds and no precipitation. Sampling was conducted in mid-September before leaf fall began so the canopy was fully developed. In considering results of sampling along the length of a stream, it is important to remember that observations at a given location bear the integrated results of multiple hydrobiogeochemical processes occurring over some distance upstream of the monitoring point. Discriminating between local in-stream effects versus broader watershed scale influences in such ecosystems is challenging and perhaps more so for EFPC which has steep gradients in land cover and land use from its headwaters to the mouth of the creek. EFK 23.4 is $2.6 \mathrm{~km}$ downstream of the primary point source of discharge from Y-12. The watershed at that point is more than $80 \%$ developed with a high degree of impervious surface cover (roads and roofs; Fig. A2). Concentrations and their changes at this location may be more prone to reflect plant operations and direct runoff from impervious surfaces than the two downstream sampling points. The watershed at EFK 16.2 remains highly developed but has much less impervious surface cover and more forest cover so the water quality at this point reflects the mixed land use/ land cover. The EFK 5.4 watershed is the least developed (45\%), most heavily forested (46\%), and has the lowest impervious surface area among the three sampling stations.

In the presentation of results and discussion that follows, the period from the beginning of sampling to sunset on 17 September 2015 is referred to as Day 1, the period from sunset to sunrise is referred to as Night, and the period from sunrise on 18 September 2015 to the end of sampling is referred to as Day 2.

\subsection{STREAMFLOW AND WATER BALANCE}

\begin{abstract}
Streamflow remained constant or followed expected patterns at EFK 23.4 and EFK 5.4. An unexpected and unexplained drop in flow occurred at EFK 16.2 midway through the first day. Discharge increased downstream with the greatest increase occurring over the upper reach (EFK 23.4 to EFK 16.2). Approximately $80 \%$ of the additional discharge in the upper reach came from ungauged sources (either tributaries or diffuse groundwater inputs). The water accounting over the lower reach (EFK 16.2 to EFK 5.4) nearly balanced with $6.4 \pm 2.8 \%$ of the flow coming from ungauged sources.
\end{abstract}

Streamflow reflected a combination of natural and anthropogenic influences. During the time samples were collected for this study, mean streamflow increased with downstream distance from 0.095 to 0.531 to $0.714 \mathrm{~m}^{3} / \mathrm{s}$ at EFK 23.4, EFK 16.2, and EFK 5.4, respectively. The mean daily discharge from the ORWTF for $17-18$ September was $0.106 \mathrm{~m}^{3} / \mathrm{s}$ (one-half range $=0.004 \mathrm{~m}^{3} / \mathrm{s}$ ), comparable to the discharge at EFK 23.4, and constituted $15 \%$ of the discharge at EFK 5.4.

Over the 30-h sampling period, discharge remained relatively constant at EFK $23.4\left(0.095 \pm 0.003 \mathrm{~m}^{3} / \mathrm{s}\right.$; mean \pm sd) with $13 \%$ variability and no discernible temporal pattern (Fig. 2). Consequently, there was no correspondence between discharge and the water quality parameters (Fig. A3, Fig. A4). Estimated mean water travel time from EFK 23.4 to EFK 16.2 was $38 \pm 14.5$ hours (mean $\pm 1 / 2$ range). Total discharge at EFK 23.4 over the 30-h sampling period was $10,216 \pm 42 \mathrm{~m}^{3}$. 
In contrast, discharge at EFK 16.2 ranged between 0.49 and $0.65 \mathrm{~m}^{3} / \mathrm{s}$ (35\% variability) and showed a distinct decrease at $1400 \mathrm{~h}$ on 17 September (Fig. 2). Flow decreased by $0.16 \mathrm{~m}^{3} / \mathrm{s}$ over the next three hours and remained relatively steady over the remainder of the sampling period. The longer discharge record suggests flows at $\sim 0.5 \mathrm{~m}^{3} / \mathrm{s}$ were the more normal baseflow condition (Fig. 2B) which points to a source downstream of Y-12 contributing additional flow from 13-17 September. The concentration of most of the major dissolved constituents in the water increased with the flow decrease (Fig. A5, Fig. A6) although there were important differences in how constituents responded. Sodium and chloride responded rapidly as flow decreased whereas concentration changes for $\mathrm{Ca}, \mathrm{Mg}$, and sulfate were somewhat delayed and nitrate increases occurred noticeably later. Other constituents did not show

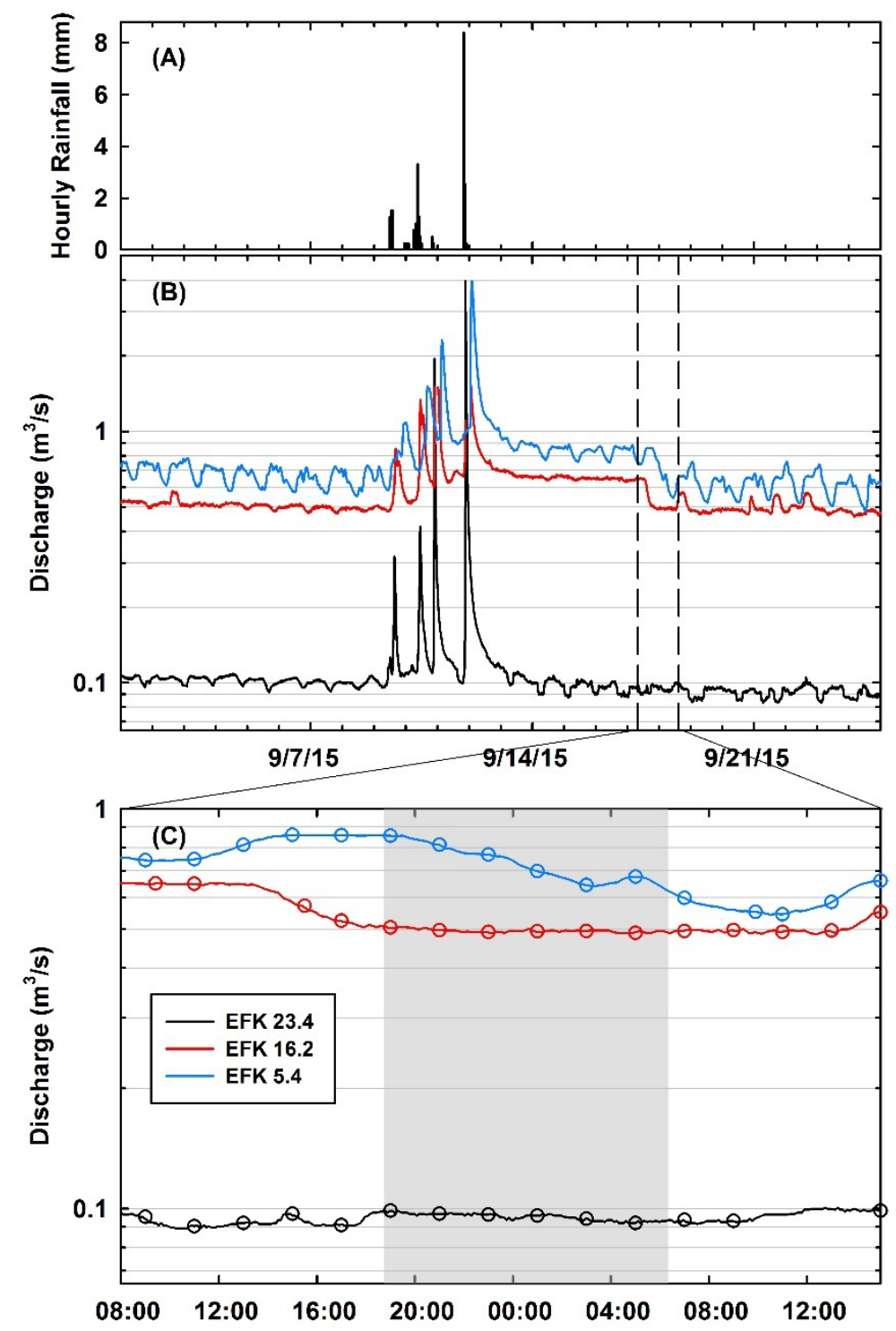

Fig. 2. Rainfall and stream discharge data. (A) Hourly rainfall data for the period 1-25 September 2015 (data from National Weather Service station KOQT in Oak Ridge); (B) stream discharge at the three sampling sites over the same period as (A). See section 2.3.1 for an explanation of the omitted data for EFK 16.2.; (C) detailed view of stream discharge during the 30 -h sampling campaign. Points indicate when samples were collected either manually or by autosampler. Autosampler failures resulted in the loss of on sample at EFK 16.2 on the first day and the loss of two samples at EFK 23.4 on the second day. Shaded portion indicates the period from sunset to sunrise. 
correspondence to flow changes (Hg, $\mathrm{Hg}_{\mathrm{P}}, \mathrm{MMHg}_{\mathrm{D}}, \mathrm{MMHg}_{\mathrm{P}}$, TSS, DOC, Turbidity). This suggests that the flow decrease was due to lower inputs of a more dilute water source originating outside of Y-12. Total discharge at EFK 16.2 over the 30 -h sampling period was 57,258 $\pm 558 \mathrm{~m}^{3}$. Ungauged water sources, including tributaries, diffuse groundwater sources, and anthropogenic discharges, between EFK 23.4 and EFK 16.2 contributed an additional 47,042 $\pm 559 \mathrm{~m}^{3}$ of water or $82 \pm 1 \%$ of the flow as measured at EFK 16.2. The higher flow during the early hours of the study accounted for $3,258 \mathrm{~m}^{3}$ of flow above the more normal baseflow of $0.5 \mathrm{~m}^{3} / \mathrm{s}$. Several unnamed and ungauged tributaries enter EFPC between EFK 23.4 and EFK 16.2 but we did not have data to estimate what those contributions were versus those from other sources (e.g., diffuse groundwater inputs). Nevertheless, given that the tributaries in this reach are all rather small it suggests that groundwater inputs contributed an important fraction of the additional flow.

At EFK 5.4, creek flow increased initially from 0.74 to $0.86 \mathrm{~m}^{3} / \mathrm{s}$ then began to decrease at $1915 \mathrm{~h}$, reaching a minimum of $0.54 \mathrm{~m}^{3} / \mathrm{s}$ at $1030 \mathrm{~h}$ the following day. A diel pattern in discharge at EFK 5.4 has been evident throughout our period of record (e.g., Fig. 2B) and is due to decreased discharge from the ORWTF as daily use decreases overnight and daily maintenance is performed during these off-peak hours. However, the length of the decline in flow and the range of discharge $\left(0.54\right.$ to $0.86 \mathrm{~m}^{3} / \mathrm{s} ; 58 \%$ variability) over this 30 -h period were both substantially greater than is normally observed. The typical diel variability at EFK 5.4 is on the order of $10 \%$ and occurs over a period of $\sim 7$ hours in contrast to the 13-hour period observed in this study. Additionally, the typical daily decrease in flow occurs after midnight rather than $1900 \mathrm{~h}$. These differences in diel flow pattern at EFK 5.4 are likely related to the flow decrease noted at EFK 16.2. The longer discharge record suggests baseflow was elevated from 1317 September and returned to a more normal baseflow of $\sim 0.6-0.7 \mathrm{~m}^{3} / \mathrm{s}$ after this flow decrease (Fig. $2 \mathrm{~B}$ ). The estimated mean travel time from EFK 16.2 to EFK 5.4 was $27.5 \pm 7.9$ hours based on the method described in section 2.5. Using the time difference to the onset of the flow decrease between EFK 16.2 and EFK 5.4 the mean travel time was 7.5 hours which equates to a stream discharge of $3.5 \mathrm{~m} / \mathrm{s}$, roughly $5 \times$ higher than observed. Total discharge at EFK 5.4 over the 30 -h sampling period was 77,174 $\pm 504 \mathrm{~m}^{3}$.

Constituents in the water that are characteristic of the ORWTF discharge decreased with decreased flow (e.g., $\mathrm{Na}, \mathrm{K}, \mathrm{Cl}^{-}, \mathrm{NO}_{3}{ }^{-}$, DOC; Fig. A7, Fig. A8) while other constituents more associated with watershed water sources showed no correspondence with flow changes (e.g., $\mathrm{Ca}, \mathrm{Mg}, \mathrm{SO}_{4}{ }^{2-}, \mathrm{Hg}_{\mathrm{D}}, \mathrm{Hg}_{\mathrm{P}}, \mathrm{MMHg}_{\mathrm{D}}$, MMHg, TSS, Turbidity).

Mill Branch, one of the larger natural tributaries to EFPC in the study reach, makes its confluence with the creek about $600 \mathrm{~m}$ downstream of EFK 16.2. Mill Branch is not contaminated with Hg. Average total and dissolved $\mathrm{Hg}$ concentrations are $2.23 \pm 1.4 \mathrm{ng} / \mathrm{L}(\mathrm{n}=28)$ and $0.65 \pm 0.3 \mathrm{ng} / \mathrm{L}(\mathrm{n}=28)$, respectively. Average total and dissolved MMHg concentrations are $0.075 \pm 0.043 \mathrm{ng} / \mathrm{L}(\mathrm{n}=28)$ and $0.054 \pm 0.030 \mathrm{ng} / \mathrm{L}(\mathrm{n}=28)$, respectively. These Hg and MMHg concentrations are lower than measured in the ORWTF effluent (see section 2.1). The tributary and upstream and downstream sections near the confluence are ungauged, but the relative contribution of Mill Branch to flow locally was estimated by dilution gauging using measured chloride concentrations. From these measurements, we estimate Mill Branch contributes $6.1 \pm 2.9 \%$ ( $\mathrm{n}=9$ over a 13-month period) of flow immediately downstream of its confluence with EFPC. Assuming minimal change in flow in the 600 meters from EFK 16.2 to the confluence with Mill Branch, this equates to approximately 3,493 $\pm 1661 \mathrm{~m}^{3}$ over the 30-hour period or about $4.5 \%$ of the discharge as measured at EFK 5.4, a minor contribution.

After accounting for discharges from the ORWTF $\left(11,448 \pm 1,145 \mathrm{~m}^{3}\right)$ and Mill Branch net contributions from ungauged sources between EFK 16.2 and EFK 5.4 were estimated to be 4,975 $\pm 2,153 \mathrm{~m}^{3}$ or $6.4 \pm$ $2.8 \%$ of the flow along this reach. There are two other ungauged tributaries in the reach between EFK 16.2 and EFK 5.4 (Gum Hollow Branch, EFK 9.7, and Pinhook Branch, EFK 9.0) that are of similar size to Mill Branch. We do not have similar data to that for Mill Branch with which to estimate their 
discharge, but it is likely that their contributions make up the difference in flow within measurement precision. This is not to say that there were no diffuse groundwater inputs, but it suggests that groundwater inputs were balanced by losses from surface water to groundwater or due to evapotranspiration. The smaller groundwater inputs in the lower reach relative to the upper reach corresponds with the higher percent forest cover in the lower reach (Fig. A2) and accompanying higher evapotranspiration rate that would decrease diffuse groundwater inputs.

\subsection{LIGHT INTENSITY, DISSOLVED OXYGEN, pH, TEMPERATURE, AND SPECIFIC CONDUCTANCE}

\section{Light intensity measurements reflected the low cloud cover as well as differences in canopy cover at each location. Dissolved oxygen and pH measurements showed diel variations correlated to the daily photocycle and driven by the opposing processes of photosynthesis and respiration.}

Solar radiation recorded at Tower K meteorological station indicates the mostly clear and sunny conditions during our sampling (Fig. 3). Light intensities recorded creek side reflected differences in natural and anthropogenic shading at each location. The sampling site at EFK 23.4 has little natural vegetative cover and channel shading during the day comes from topographic features (steep high creek banks, shadows cast by nearby ridges) or man-made structures. This is reflected in the generally higher light intensities recorded at EFK 23.4. The lower EFPC watershed becomes increasingly forested downstream (31\% at EFK 16.2, 48\% at EFK 5.4; Fig. A2) with corresponding increases in canopy cover and channel shading (Fig. 3). Light intensity at EFK 5.4 was a small fraction of that measured at either of the two other upstream locations. During a kayak-based whole-creek survey conducted in 2013 under full canopy conditions (Peterson et al. 2014) light intensity at the creek surface was measured. This light intensity data was used to estimate the percentage canopy cover over the lower EFPC channel. For the reach from EFK 23.4 to EFK 16.2 canopy cover was estimated to be 73\% and from EFK 16.2 to EFK 5.4 we estimated canopy cover to be $83 \%$.

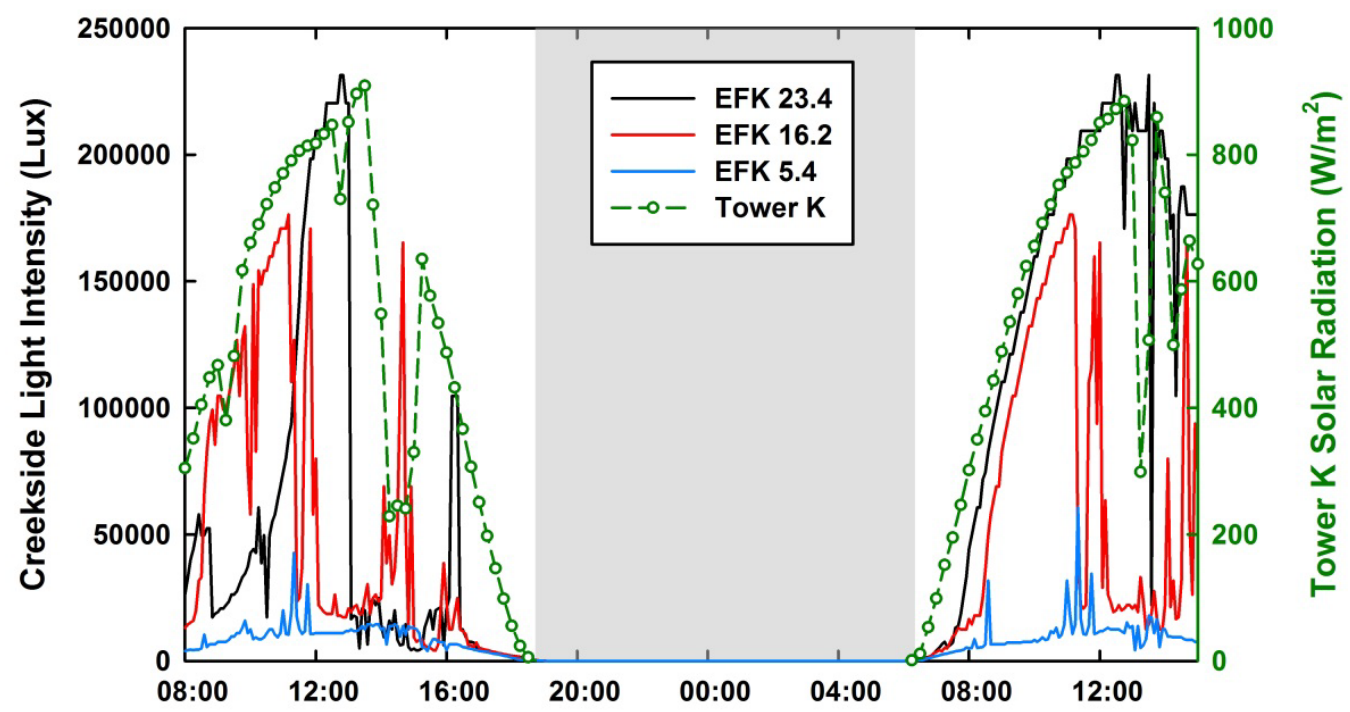

Fig. 3. Light intensity at each sampling location and Tower K. Shaded portion indicates the period from sunset to sunrise.

At each location, DO concentration exhibited a diel pattern correlated with the daily photocycle in which concentration increased during the morning reaching mid-day maxima then declined in the afternoon with 
overnight minima (Fig. 4). The range of DO values was greatest at EFK 23.4 (38\% variability) and smaller at EFK 16.2 and EFK 5.4 (17\% and 18\% variability, respectively).

The $\mathrm{pH}$ at each location followed a pattern similar to DO. Values increased in the morning to midday maxima with afternoon decreases and overnight minima (Fig. 4). The largest range of $\mathrm{pH}$ was measured at EFK 23.4 (11\% variability) followed by EFK 5.4 and EFK 16.2 (4.3\% and 1.6\% variability, respectively). Water temperature showed diel patterns similar to DO and $\mathrm{pH}$ (Fig. A9). The specific conductance of the water at EFK 23.4 also showed a similar diel pattern to the other parameters at that station. In contrast, the specific conductance at EFK 5.4 was relatively constant during daylight with a small overnight decrease. The specific conductance at EFK 16.2 was not correlated with the photocycle (Fig. A9) and was likely driven by the major ion concentration increases that occurred as flow decreased.

\subsubsection{Controls on Dissolved Oxygen Concentration and pH}

At each location, diel patterns in $\mathrm{DO}$ and $\mathrm{pH}$ were consistent with photosynthesis occurring in the creek. The range or variability in these parameters was inversely correlated with the amount of creek canopy cover. Additionally, $\mathrm{pH}$ and $\mathrm{DO}$ were strongly correlated at each site in accordance with the canonical relationship between photosynthesis, respiration, $\mathrm{O}_{2}$ and $\mathrm{CO}_{2}$ production and consumption driving $\mathrm{pH}$ changes:

\section{Photosynthesis}

$$
n \mathrm{CO}_{2}+n \mathrm{H}_{2} \mathrm{O} \stackrel{\text { light }}{\longrightarrow}\left(\mathrm{CH}_{2} \mathrm{O}\right)_{n}+n \mathrm{O}_{2}
$$

Respiration

$$
\left(\mathrm{CH}_{2} \mathrm{O}\right)_{n}+n \mathrm{O}_{2} \rightarrow n \mathrm{CO}_{2}+n \mathrm{H}_{2} \mathrm{O}+\text { Energy }
$$

The opposing processes of photosynthesis and respiration remove $\mathrm{CO}_{2}$ from and add $\mathrm{CO}_{2}$ to the water, respectively. $\mathrm{CO}_{2}$ consumption during photosynthesis causes the $\mathrm{pH}$ to increase while $\mathrm{CO}_{2}$ production during respiration causes the $\mathrm{pH}$ to decrease. Respiration occurs in the light and the dark whereas photosynthesis only occurs in the light. Increasing $\mathrm{pH}$ during daylight indicates the rate of $\mathrm{CO}_{2}$ removal from photosynthesis exceeded the combined rates of $\mathrm{CO}_{2}$ production from respiration and the rate of $\mathrm{CO}_{2}$ diffusion from the air into the water. During nighttime photosynthesis-driven $\mathrm{CO}_{2}$ removal ceases while $\mathrm{CO}_{2}$ production from respiration and resupply from the atmosphere continues leading to decreasing $\mathrm{pH}$.

Photosynthesis produces $\mathrm{O}_{2}$ during daylight and does not occur in the dark. This is the cause for increasing DO during the day, peaking during periods with the highest light intensity, and overnight minima. The greater range in DO and pH at EFK 23.4 versus those at EFK 16.2 and EFK 5.4 is due to the greater light intensity and consequent greater photosynthetic activity at the upstream station. 


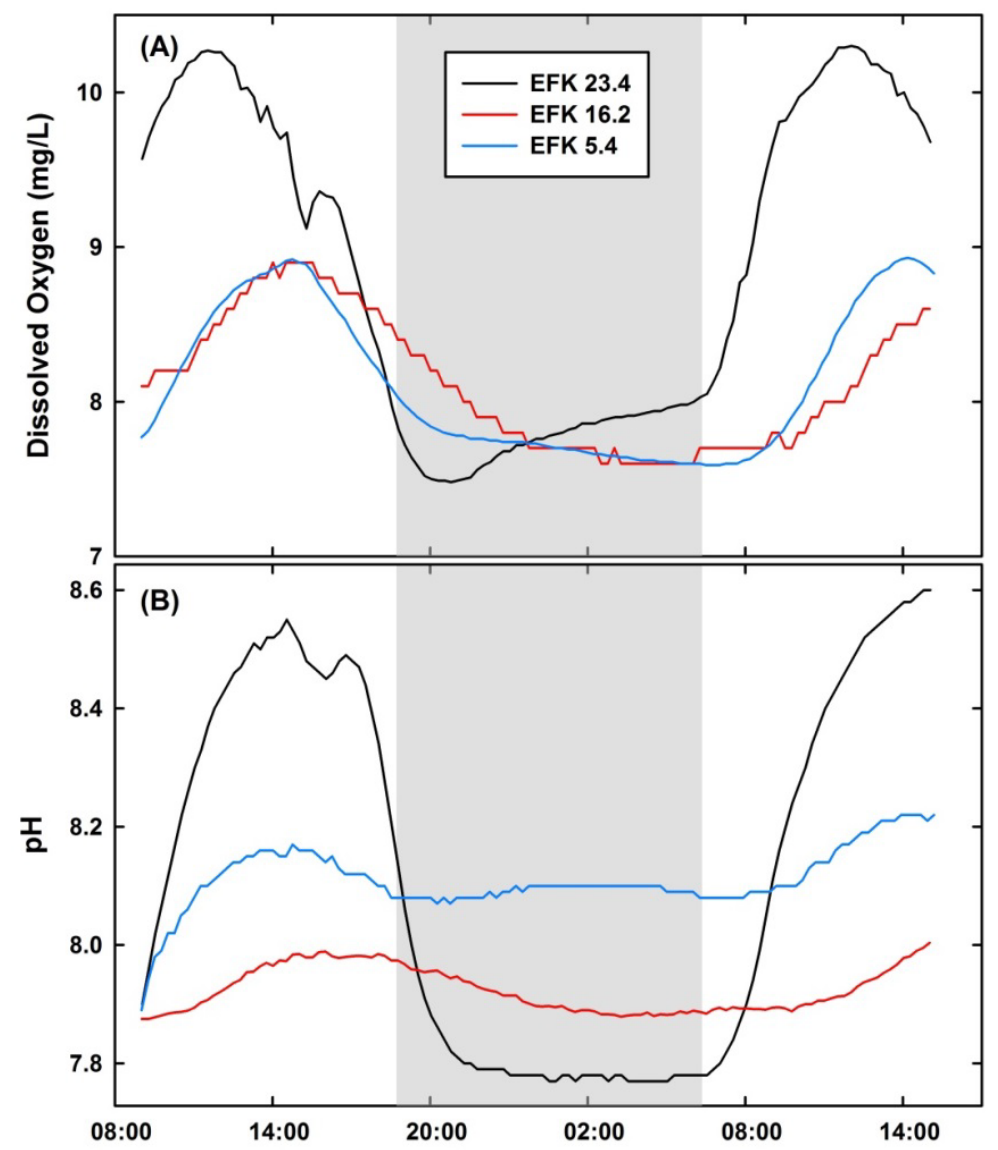

Fig. 4. Dissolved oxygen (A) and pH (B) at each station over the sampling period. Shaded portion indicates the period from sunset to sunrise.

\subsection{PARTICULATE MERCURY, MONOMETHYLMERCURY, TURBIDITY, AND TOTAL SUSPENDED SOLIDS}
Particulate $\mathrm{Hg}$ and particulate $\mathrm{MMHg}\left(\mathrm{Hg}_{P}\right.$ and $\mathrm{MMHg}_{P}$, respectively) increased significantly overnight at EFK 16.2 and EFK 5.4. Increased $\mathrm{Hg}_{P}$ and $\mathrm{MMHg}_{P}$ corresponded to increased turbidity and TSS overnight. These overnight increases were likely driven by bioturbation and the (re)suspension of fine particulates from the stream bed. Hg concentration on suspended particles decreased downstream consistent with past assessments.

The concentration of particulate $\mathrm{Hg}$ (Hgp; expressed in units of nanograms per liter) increased significantly overnight relative to the daytime samples at both EFK 16.2 and EFK 5.4 (p = 0.0277 and 0.0121, respectively). At EFK 16.2 and EFK $5.4 \mathrm{Hg}_{\mathrm{P}}$ increased $217 \%$ and 93\%, respectively, relative to daytime minima (Fig. 5). Particulate MMHg (MMHg, ng/L) increased overnight at EFK 5.4 (p = 1.67e3) relative to both days and at EFK 16.2, after removal of the potential strong outlier (18 Sept 0500), MMHgp was higher at night relative to Day $1(\mathrm{p}=0.0214)$ but not Day $2(\mathrm{p}=0.496)$. At EFK 16.2 and EFK 5.4 MMHg increased 145\% (after removal of the potential outlier at on 18 Sept at $0500 \mathrm{~h}$ ) and $540 \%$, respectively. The higher overnight concentration of $\mathrm{Hg}_{\mathrm{P}}$ and $\mathrm{MMHg}_{\mathrm{P}}$ at the two downstream 


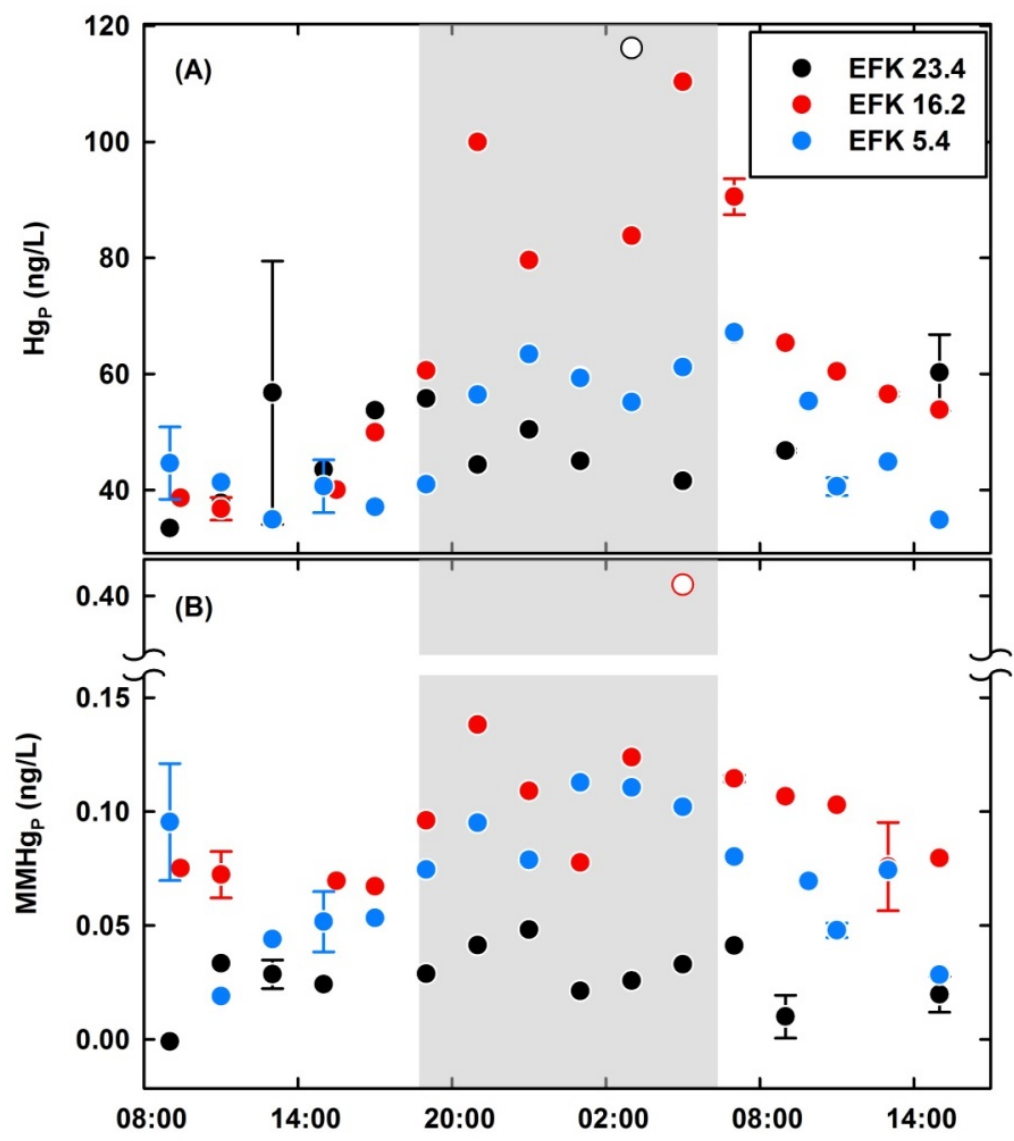

Fig. 5. Particulate Hg (A) and MMHg (B) over the sampling period. Error bars indicate the range of values for field duplicates. Strong potential outliers are indicated by the open symbols. Shaded portion indicates the period from sunset to sunrise.

locations were coincident with significant increases in turbidity and TSS (Fig. 6). Both $\mathrm{Hg}_{\mathrm{P}}$ and $\mathrm{MMHg}_{\mathrm{P}}$ were strongly to very strongly and significantly correlated with TSS at EFK 16.2 and EFK 5.4 (Table 3, Fig. 7). Diel variability in turbidity at EFK 16.2 and EFK 5.4 was $397 \%$ and $403 \%$, respectively, after removal of potential outliers. Variability in TSS was $77 \%, 194 \%$ and $100 \%$ at EFK 23.4, EFK 16.2, and EFK 5.4, respectively. In contrast, at EFK 23.4 there was no discernible diel pattern in $\mathrm{Hg}_{\mathrm{P}}$ (either with or without the potential strong outlier at 18 Sept $0300 \mathrm{~h}$ ), MMHg$_{\mathrm{P}}$, or TSS (turbidity was not measured at this location) although

Table 3. Spearman rank correlation coefficients $(\rho)$ and p-values for Hg and MMHgP with TSS at each sampling station

\begin{tabular}{ccc}
\hline Site & Hg $_{\mathbf{P}}(\mathbf{n g} / \mathbf{L})$ & MMHg $_{\mathbf{P}}(\mathbf{n g} / \mathbf{L})$ \\
\hline EFK 23.4 & $\rho=-0.261, \mathrm{p}=0.366$ & $\rho=0.1165, \mathrm{p}=0.692$ \\
& $\rho=-0.0769^{a}, \mathrm{p}=0.803^{a}$ & \\
EFK 16.2 & $\rho=0.636, \mathrm{p}=0.0109$ & $\rho=0.693, \mathrm{p}=4.19 \mathrm{e}-3$ \\
& & $\rho=0.653^{a}, \mathrm{p}=0.0114^{a}$ \\
EFK 5.4 & $\rho=0.806, \mathrm{p}=1.64 \mathrm{e}-4$ & $\rho=0.747, \mathrm{p}=8.82 \mathrm{e}-4$ \\
\hline
\end{tabular}

${ }^{a}$ Correlation statistics after removal of potential strong outliers in Hgp and MMHg. See Fig. 5.

the calculated diel variability for each was large $\left(\mathrm{Hg}_{\mathrm{P}}=100 \%\right.$ after removal of the strong potential outlier; $\mathrm{MMHg}_{\mathrm{P}}=174 \%$ after removal of negative or nondetect values; TSS $=77 \%$ ). 


\subsubsection{Controls on Hg, MMHg, Concentration, Turbidity, and TSS}

Overnight increases in turbidity, TSS, $\mathrm{Hg}_{\mathrm{P}}$, and MMHg likely were caused by bioturbation due to changes in the activity of macrobiota in the stream (Waters 1972, Wallace, Webster, and Cuffney 1982, Richardson et al. 2009, Loperfido et al. 2010). Fine particulate matter export in streams depends on the activity of macroinvertebrates (Wallace, Webster, and Cuffney 1982). Loperfido et al. (Loperfido et al. 2010) attributed nighttime increases in turbidity in an Iowa stream to nocturnal feeding behavior of fish. Richardson et al. (Richardson et al. 2009), studying a third-order stream in southeast Pennsylvania, reported diel patterns in suspended solids and particulate organic carbon (POC) due to bioturbation. On average over eleven months, nighttime suspended solids and POC increased by $80 \%$ and $43 \%$, respectively, over daytime minima. However, the diel variability was positively correlated with temperature and maximum variability was found in June where nighttime TSS and POC were $155 \%$ and $105 \%$ greater than daytime values, respectively. Similarly, in EFPC, the magnitude of the diel turbidity pattern decreased from summer through autumn into winter (Fig. A10) coincident with decreasing water temperature.

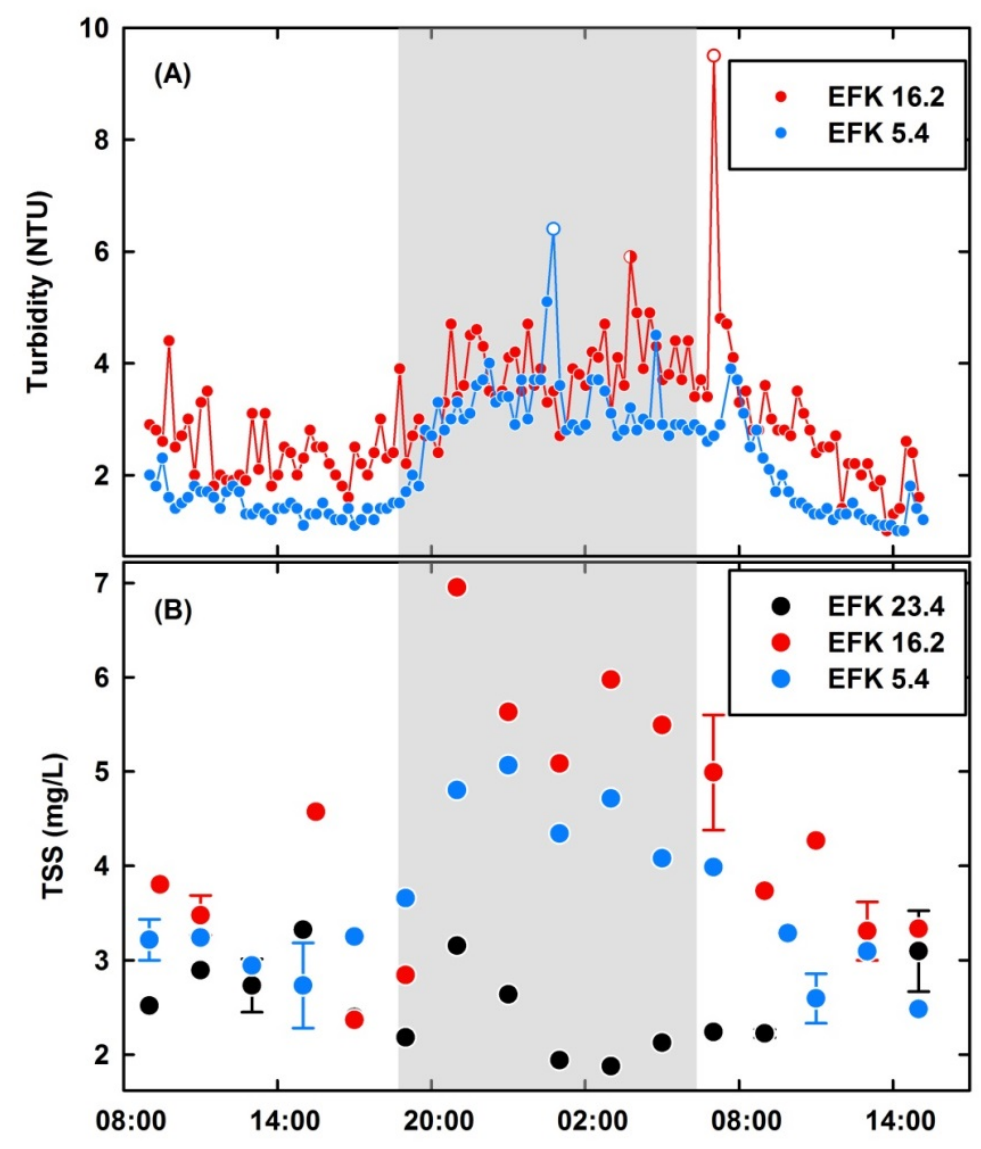

Fig. 6. Turbidity (A) at EFK 16.2 and EFK 5.4 and total suspended solids at all three sites (B) over the sampling period. Error bars indicate the range of values for field duplicates. Half-filled symbols indicate potential outliers; open symbols indicate strong potential outliers. Shaded portion indicates the period from sunset to sunrise. 
Other potential sources of diel variability in turbidity cannot account for the range or timing of our observations. The concordance between turbidity and TSS patterns for both EFK 16.2 and EFK 5.4 indicates that other diel patterns did not interfere with the turbidity instrument. For example, instrument manufacturers report a temperature dependence of up to $-0.6 \%$ turbidity per degree Celsius increase. For the observed temperature range at EFK $16.2\left(2.15^{\circ} \mathrm{C}\right)$ this accounts for $1.3 \%$ variability in instrument reading compared to the $494 \%$ observed (after removal of the potential outlier at 18 Sept 0700 h) and at EFK 5.4 (temperature range $2.47^{\circ} \mathrm{C}$ ) this accounts for $1.5 \%$ variability in instrument reading compared to the 500\% observed (after removal of the potential outlier at 18 Sept 0045 h). Additionally, the range of diel temperature variation in the creek is similar in each season but diel patterns in turbidity vary throughout the year with maximal diel variability in spring and summer (Fig. A10). If diel temperature variation was a significant factor in turbidity values, then a similar diel turbidity pattern should also be observed in autumn and winter.

Diel patterns in streamflow were not in phase with the turbidity and TSS patterns (Fig. A6, Fig. A8, Fig. A11, Fig. A12). The daily increase in flow at EFK 5.4 starting at $0900 \mathrm{~h}$ coincided with decreased turbidity and TSS whereas at nighttime increased turbidity and TSS starting at $1900 \mathrm{~h}$ coincided with decreased streamflow.

Finally, diel patterns in precipitation and dissolution reactions involving carbonate minerals in response to diel $\mathrm{pH}$ changes in this hard water creek seem unlikely to account for the turbidity patterns. The $\mathrm{pH}$ decreased overnight, favoring dissolution of carbonate minerals which would decrease turbidity and TSS, opposite of the observed increase.

The lack of a diel pattern in TSS, Hgp, and MMHgp at EFK 23.4 may be due to several factors. Approximately 25\% of the creek channel upstream of EFK 23.4 is concrete lined with little sediment to be resuspended by fish or benthic macroinvertebrates in addition to being poor habitat for the latter. The benthic macroinvertebrate community upstream of EFK 23.4 is lower density and less rich in pollution intolerant species than at other downstream locations (Peterson, Greeley Jr., et al. 2017). Finally, EFK 23.4 has the shortest upstream reach $(2.6 \mathrm{~km})$ of the three sites so integrates fewer cumulative upstream effects.

There were no significant differences in the TSS specific Hg or MMHg concentration (Hg TSS $_{\text {and }}$ $\mathrm{MMHg}_{\mathrm{TSS}}$ ) over the diel cycle at all three sites over the 30-h sampling period (Fig. 8) regardless of whether the apparent strong outliers indicated in Fig. 8 were included in the analysis. This suggests 
that higher TSS concentrations (and $\mathrm{Hg}_{\mathrm{P}}, \mathrm{MMHg}_{\mathrm{P}}$ ) at night were due to (re)suspension of the same source materials that contribute TSS load during the day and is not consistent with overnight input of TSS from new or different sources relative to daytime inputs.

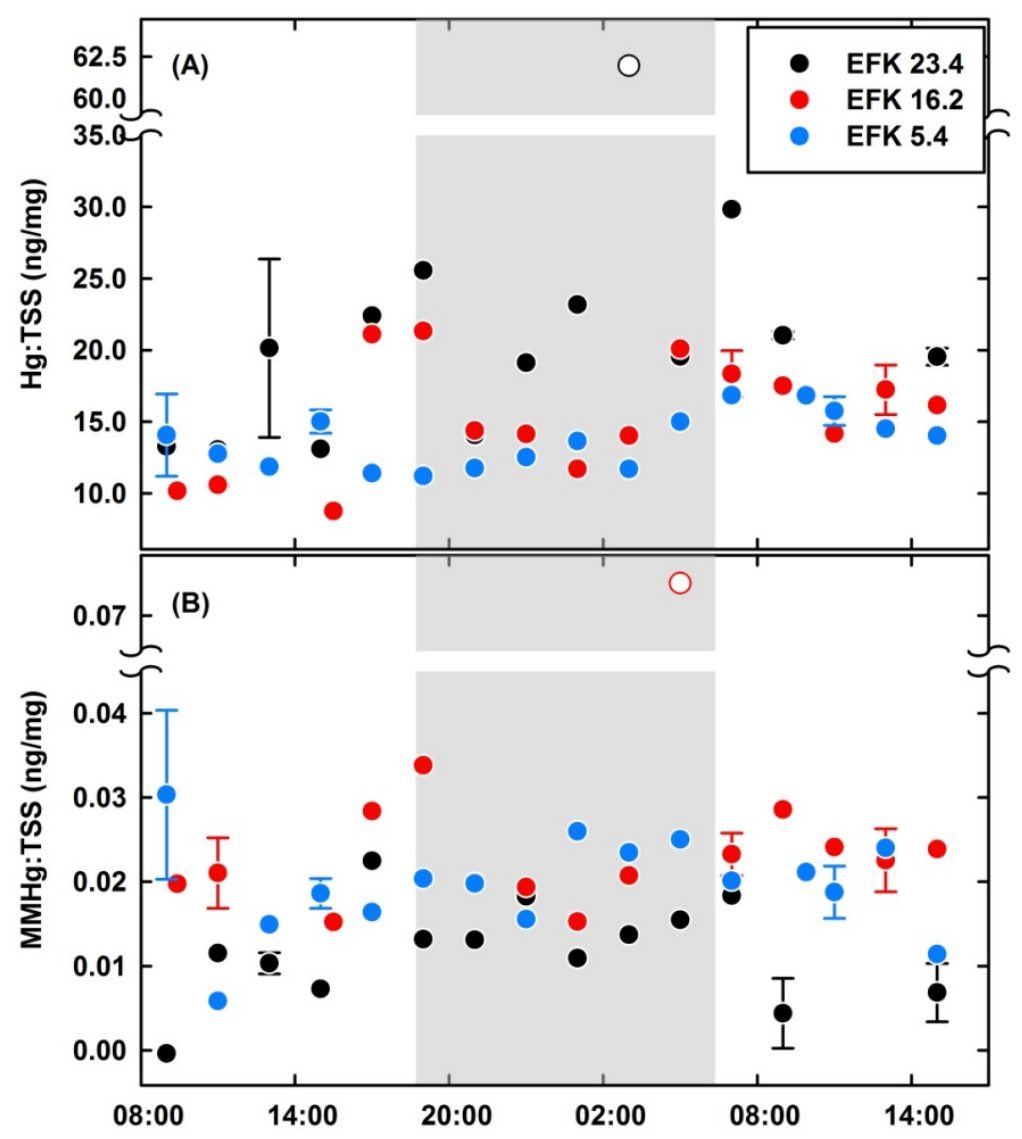

Fig. 8. Hg:TSS ratio (A) and MMHg:TSS ratio (B) over the sampling period. Error bars indicate the range of values for field duplicates. Strong potential outliers are indicated by the open symbols. Shaded portion indicates the period from sunset to sunrise.

Although there were no day-versus-night patterns in $\mathrm{Hg}_{\mathrm{TSS}}$ there were significant longitudinal differences along the length of EFPC. After removal of the strong potential outlier at EFK 23.4, $\mathrm{Hg}_{\text {TSS }}$ decreased from $19.7 \pm 5.2$ to $15.3 \pm 4.0$ to $13.9 \pm 2.1 \mathrm{ng} / \mathrm{mg}$ at EFK 23.4, EFK 16.2, and EFK 5.4, respectively. The $\mathrm{Hg}_{\mathrm{TSS}}$ value at EFK 23.4 was significantly greater than at either EFK 16.2 or EFK $5.4(\mathrm{p}=0.012$ and $\mathrm{p}=$ 7.38e-4, respectively). The HgTss between EFK 16.2 and EFK 5.4 was not significantly different ( $\mathrm{p}=$ 0.608). The downstream decrease in $\mathrm{Hg}_{\mathrm{TSS}}$ was attributed to greater increases in TSS relative to EFK 23.4 than it was due to decreased $\mathrm{Hg}_{\mathrm{P}}$ concentration. These results are consistent with samples collected between 1995 and 2000 that showed a similar pattern of decreasing $\mathrm{Hg}_{\text {TsS }}$ downstream (Fig. A13). However, in the older dataset decreasing $\mathrm{Hg}_{\mathrm{TSS}}$ downstream can be attributed to decreasing $\mathrm{Hg}_{\mathrm{P}}$ and increasing TSS concentrations downstream. 


\title{
3.4 DISSOLVED ORGANIC CARBON, DISSOLVED MERCURY, AND DISSOLVED MONOMETHYLMERCURY
}

\begin{abstract}
$\mathrm{Hg}_{D}$ and $\mathrm{MMHg}$ concentrations were higher during the day and decreased overnight at EFK 23.4 and EFK 5.4. These patterns corresponded to diel patterns in DOC concentration and DOM composition although the underlying mechanisms are not clear at this time. The patterns for $\mathrm{Hg}_{D}$, DOC concentration and DOM composition are subtle. Higher $\mathrm{MMHg}_{D}$ concentrations during the day are consistent with recent findings that actively photosynthesizing periphyton biofilms in EFPC may be important sources of MMHg.
\end{abstract}

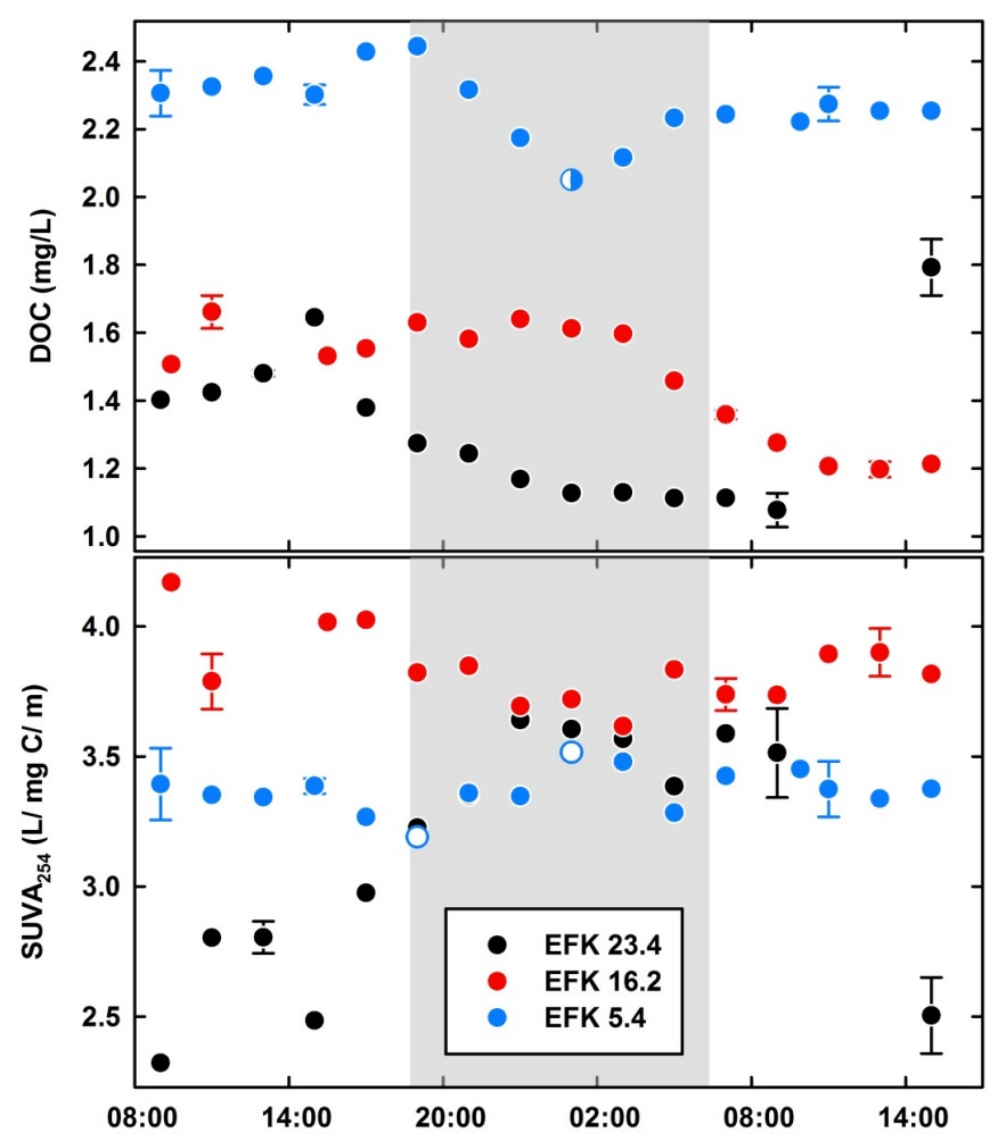

Fig. 9. Dissolved organic carbon (A) and SUVA254 (B) at each site over the sampling period. Error bars indicate the range of values for field duplicates. Half-filled symbols indicate potential outliers; open symbols indicate strong potential outliers. Shaded portion indicates the period from sunset to sunrise.

Dissolved organic carbon (DOC) concentration exhibited trends at each location over the 30-h sampling campaign (Fig. 9). At EFK 23.4 DOC decreased significantly ( $\mathrm{p}=0.0116)$ overnight from daytime high values and increased the following day (83\% variability). The nighttime concentration decrease was accompanied by increasing SUVA 254 (significantly higher at night, $\mathrm{p}=2.76 \mathrm{e}-3$ ). SUVA 254 is a proxy measure of dissolved organic matter (DOM) composition (Wei et al. 2008, Weishaar et al. 2003) with higher SUVA $_{254}$ values being associated with higher molecular weight DOM of terrestrial origin. 
At EFK 16.2 DOC concentration remained constant at $1.6 \mathrm{mg} / \mathrm{L}$ over the first 18 hours then declined over the next 10 hours to $1.2 \mathrm{mg} / \mathrm{L}$ (42\% variability). Overall, SUVA 254 values were higher at EFK 16.2 than at EFK 23.4 suggesting allochthonous input of terrestrial DOM along that reach. Additionally, DOM composition remained unchanged over the sampling period $\left(\mathrm{SUVA}_{254}=3.84 \pm 0.14 \mathrm{~L} / \mathrm{mg} \mathrm{C} / \mathrm{m}\right.$ ). The high percentage of canopy cover over the channel between these two sampling points (73\%) would minimize the potential for DOM photobleaching during the day.

At EFK 5.4 DOC concentration declined overnight (19\% variability) in close correspondence with streamflow variation caused by daily patterns in discharge from the ORWTF (Fig. A8). DOC concentration in ORWTF discharge is generally higher than in EFPC, between 2011-2016 average DOC concentration of the effluent was $5.2 \pm 1.8 \mathrm{mg} / \mathrm{L}(n=45)$. Decreased discharge from that facility overnight might reasonably be expected to lower DOC in the creek. Similar to EFK 16.2, DOM composition at EFK 5.4 showed no diel pattern $\left(\mathrm{SUVA}_{254}=3.34 \pm 0.09 \mathrm{~L} / \mathrm{mg} \mathrm{C} / \mathrm{m}\right)$ either with or without the two apparent strong outliers.

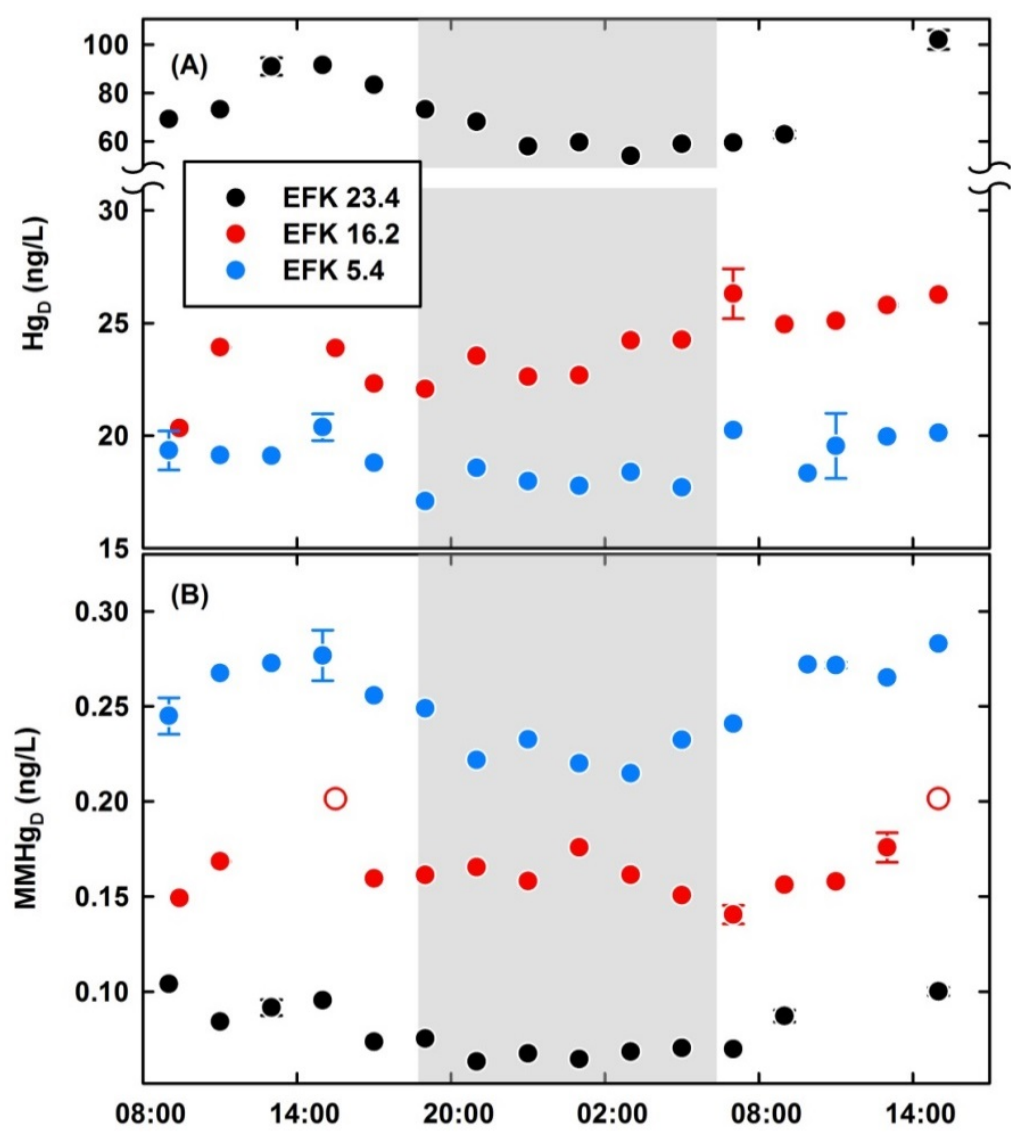

Fig. 10. Dissolved (A) Hg and (B) MMHg concentration at each site. Error bars indicate the range of values for field duplicates. Strong potential outliers are indicated by the open symbols. Shaded portion indicates the period from sunset to sunrise.

Over the 30-hour sampling period Hg $\mathrm{Hg}_{\mathrm{D}}$ at EFK 23.4, EFK 16.2, and EFK 5.4 averaged $58.9 \pm 9 \%, 29 \pm$ 7\%, and $29.5 \pm 5 \%$, respectively, of the total $\mathrm{Hg}$ concentration. Dissolved $\mathrm{Hg}\left(\mathrm{Hg}_{\mathrm{D}}, \mathrm{ng} / \mathrm{L}\right)$ concentrations were higher during the day at both EFK 23.4 and EFK 5.4. The effect was more pronounced at EFK 23.4 (96\% variability) than at EFK 5.4 (23\% variability). $\mathrm{Hg}_{\mathrm{D}}$ concentration changes at EFK 23.4 
corresponded with the daily photocycle gradually increasing to mid-afternoon maxima then slowly declining overnight (Fig. 10A). In contrast, at EFK 5.4 daytime $\mathrm{Hg}_{\mathrm{D}}$ concentration was relatively stable and significantly greater than the concentration overnight (day $19.56 \pm 0.97 \mathrm{ng} / \mathrm{L}, n=13$; night $17.92 \pm$ 0.53, $n=6 ; \mathrm{p}=2.01 \mathrm{e}-4)$. There was a steady, significant $(\mathrm{p}=3.32 \mathrm{e}-4)$ increase in Hg at EFK 16.2 over the 30 -h sampling period and no significant difference in day versus night $(\mathrm{p}=0.058)$.

Dissolved MMHg (MMHg ${ }_{\mathrm{D}}$ ) at EFK 23.4, EFK 16.2, and EFK 5.4 averaged $75 \pm 13 \%, 62 \pm 11 \%$, and 79 $\pm 8 \%$, respectively, of the total MMHg concentration. $\mathrm{MMHg}_{\mathrm{D}}$ concentration showed a diel pattern at EFK 23.4 and EFK 5.4 where daytime concentrations were greater than nighttime concentrations (EKF 23.4, $\mathrm{p}=3.55 \mathrm{e}-4$; EFK 5.4, p = 1.2e-4) (Fig. 10). The visual pattern of MMHg $\mathrm{D}_{\mathrm{D}}$ suggested a diel cycle for this parameter at EFK 16.2 also: MMHg$_{\mathrm{D}}$ concentration increased during both daylight periods but the overnight decreases were not great enough to demonstrate a significant effect with or without the two potential strong outliers.

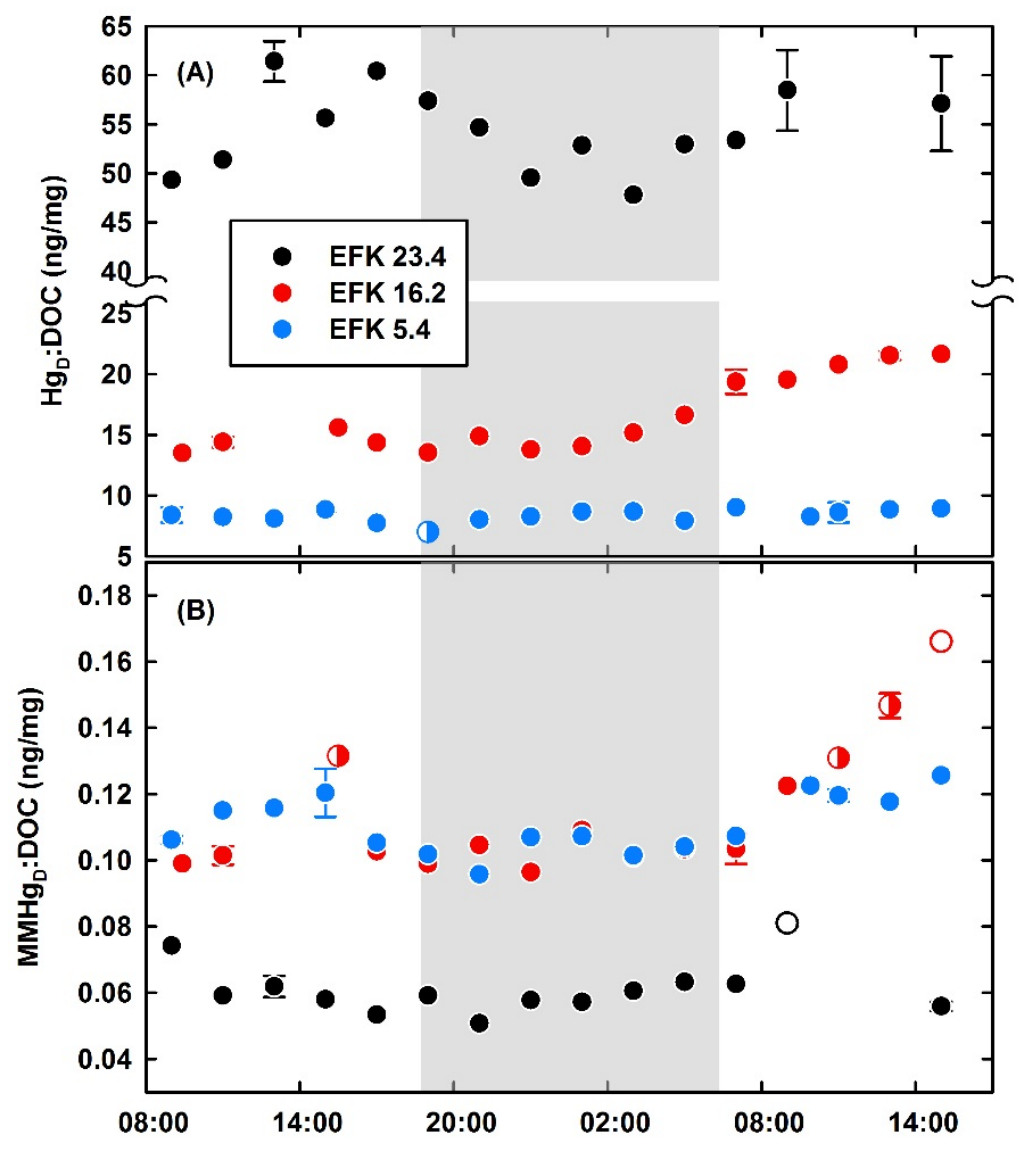

Fig. 11. Dissolved (A) Hg and (B) MMHg to DOC ratio at each site. Error bars indicate the range of values for field duplicates. Half-filled symbols indicate potential outliers; open symbols indicate strong potential outliers. Shaded portion indicates the period from sunset to sunrise.

There were no diel patterns in $\mathrm{Hg}_{\mathrm{D}}$ :DOC ratio over the sampling period (Fig. 11A). The pattern for this ratio at EFK 23.4 suggested a possible diel pattern but the day versus night difference was not significant. At EFK 16.2 the ratio was constant over Day 1 and night but the ratio on Day 2 was greater than both Day $1(p=4.87 e-6)$ and night $(p=2.43 e-6)$. The Hg:DOC ratios observed for the surface water were $\sim 100 \times$ 
smaller than observed for Hg and organic carbon associated with creek sediments and bank soils (Brooks et al. 2017).

For the MMHg:DOC ratio there were no diel patterns at either EFK 23.4 or EFK 16.2 (Fig. 11B). Like the $\mathrm{Hg}_{\mathrm{D}}$ :DOC ratio the $\mathrm{MeHg}_{\mathrm{D}}$ :DOC ratio at EFK 16.2 on Day 2 was greater than at night $(\mathrm{p}=0.0171)$. At EFK 5.4 there was a diel pattern in $\mathrm{MMHg}_{\mathrm{D}}$ :DOC ratio where the daytime average $(0.116 \pm 0.008)$ was significantly greater than the nighttime average $(0.103 \pm 0.004 ; \mathrm{p}=2.42 \mathrm{e}-4)$.

\subsubsection{Controls on DOC Concentration, DOM Composition, Dissolved Mercury, and Dissolved Monomethylmercury}

DOC Concentration and DOM Composition. Both natural and anthropogenic factors affected observed patterns in DOC concentration and DOM composition and $\mathrm{Hg}_{\mathrm{D}}$ and MMHg. The very strong and significant negative correlation $(\rho=-0.811, \mathrm{p}=4.32 \mathrm{e}-4)$ between DOC concentration and $\mathrm{SUVA}_{254}$ values at EFK 23.4 suggest several contributing mechanisms. First, higher daytime and lower nighttime DOC concentrations coupled with lower daytime and higher nighttime SUVA 254 values suggest these patterns are influenced by photobleaching during the day (Spencer et al. 2007). Other recorded parameters discussed previously (e.g., light intensity, water temperature, $\mathrm{pH}$, dissolved oxygen) demonstrate the channel upstream of EFK 23.4 is largely exposed to direct sunlight making photobleaching of DOM in this reach of the creek a possible contributor to diel SUVA 254 patterns. Correspondence between DOC concentration and DOM composition at EFK 23.4 also suggests in-stream photosynthetic activity may contribute to these patterns. Photosynthesis can generate relatively simple carbon compounds that would have low SUVA 254 values. Overnight cessation of photosynthesis would decrease the release of these simple organic compounds with corresponding decreased DOC and increased SUVA 254 (Spencer et al. 2007).

Finally, daily changes in Y-12 plant operations and consequent changes in the composition of plant discharges may also contribute to the observed patterns. Note, however, that these changes were not accompanied by noticeable changes in water flow (Fig. 2). The data collected here do not allow us to distinguish the relative contribution of the processes postulated.

Higher and less variable (15\% variability) SUVA $_{254}$ values at EFK 16.2 suggest that although DOC concentration was similar to EFK 23.4, DOM composition at the downstream site was different. The higher SUVA 254 values are consistent with inputs of higher molecular weight, higher aromatic content, terrestrial DOM along the $7.2 \mathrm{~km}$ reach between the sites. Additionally, the high percentage of canopy cover between EFK 23.4 and EFK 16.2 would minimize the potential for DOM photobleaching and yield less variable $\mathrm{SUVA}_{254}$ as observed. These observations would also be consistent with lower light intensity and smaller range of light intensity, DO, pH, and temperature patterns at EFK 16.2.

DOC concentration and DOM composition patterns at EFK 5.4 reflect contributions from the EFPC watershed and effluent from the ORWTF. On average, the DOC concentration at EFK 5.4 was 55 - 70\% greater than at the two upstream stations. DOC loading from Mill Branch plus the ORWTF discharge contributed an estimated $37 \pm 12 \%$ (34.2 $\pm 11.8 \%$ from ORWTF, $3.2 \pm 2.8 \%$ from Mill Branch) of the additional DOC at EFK 5.4 based on the mean daily flow for the sampling period and average DOC content of the effluent. The remaining DOC came from other sources within the watershed, both instream and out-of-stream. Between December 2011 and October 2016, average SUVA 254 values from the ORWTF were $2.38 \pm 0.8 \mathrm{~L} / \mathrm{mg} \mathrm{C} / \mathrm{m}(\mathrm{n}=35)$. If the average $\mathrm{SUVA}_{254}$ from EFK 16.2 is representative of non-ORWTF influenced EFPC water, and if SUVA 254 values mix conservatively, mixing calculations show a predicted SUVA 254 value at EFK $5.4=3.34 \pm 0.28 \mathrm{~L} / \mathrm{mg} \mathrm{C} / \mathrm{m}$ compared to the average observed value of $3.37 \pm 0.09 \mathrm{~L} / \mathrm{mg} \mathrm{C} / \mathrm{m}$. Thus, both natural and anthropogenic sources contribute to the $\mathrm{C}$ 
balance in EFPC. Similar to EFK 16.2, the high percentage of canopy cover in the lower sections of the creek would minimize DOM photobleaching resulting in relatively stable SUVA 254 .

Dissolved Inorganic Mercury. Day versus night differences in HgD were most apparent at EFK 23.4, subtler at EFK 5.4, and were not evident at EFK 16.2. Changes in $\mathrm{Hg}_{\mathrm{D}}$ could reflect additional inputs of $\mathrm{Hg}$ to the water column or changes to $\mathrm{Hg}$ sorption that govern the partitioning behavior of $\mathrm{Hg}$ between filter-passing and filter-retained phases. There were no similar changes in $\mathrm{Hg}_{\mathrm{P}}$ or TSS at EFK 23.4. We cannot rule out the possibility that the schedule of operations at Y-12 influenced the HgD pattern at EFK 23.4. If those operations influenced $\mathrm{Hg}_{\mathrm{D}}$, they did not have a discernible effect on most of the other physical (e.g., discharge) and chemical parameters measured making it difficult to assess possible connections. Of those parameters that did vary and that likely influence Hg sorption (e.g., $\mathrm{pH}$ ) they are closely tied to natural processes that have a diel cycle independent of Y-12 operations.

$\mathrm{pH}$ is considered a master variable governing sorption behavior. Under an assumption of equilibrium or pseudo-equilibrium, as a cation, $\mathrm{Hg}$ sorption is expected to increase with increasing $\mathrm{pH}$ resulting in lower Hg. $\mathrm{pH}$ values increased during the day when $\mathrm{Hg}_{\mathrm{D}}$ was highest at EFK 23.4 and EFK 5.4; the opposite of expected cation-like sorption behavior. Additionally, $\mathrm{Hg}$ cation sorption is relatively insensitive to $\mathrm{pH}$ over the range seen in our samples (7.8 - 8.6)(Dzombak and Morel 1990). On the other hand, virtually all of the dissolved Hg in EFPC is complexed with natural organic matter (NOM)(Dong et al. 2009, Miller et al. 2009) that likely results in a net negative charge on the Hg-NOM complex. In this case, Hg would exhibit anion-like sorption behavior in which $\mathrm{Hg}$ sorption would decrease with increasing $\mathrm{pH}$ and would result in higher Hg. This effect would be consistent with the timing and magnitude of $\mathrm{pH}$ changes at each location. Thus, it seems that diel $\mathrm{pH}$ change, driven by photosynthetic activity in the creek may be a small contributing factor in the $\mathrm{Hg}_{\mathrm{D}}$ concentration variations because the magnitude of the $\mathrm{pH}$-dependent sorption effect is probably small over the low range and values of $\mathrm{pH}$.

Temperature can also influence sorption through several mechanisms, but cation sorption is generally regarded as being an endothermic reaction (sorption increases with increasing temperature) whereas anion sorption is considered to an exothermic reaction (sorption decreases with increasing temperature). While the temperature range at EFK 23.4 was small in this context (Fig. A9), increasing temperatures during the day may have made small contributions to higher $\mathrm{Hg}_{\mathrm{D}}$ through decreased sorption of anionic Hg-DOM complexes.

In addition to $\mathrm{pH}$ controls on $\mathrm{Hg}_{\mathrm{D}}$ concentrations, there may have also been photochemical effects that contributed to higher daytime Hg. Light exposure at each site differed producing different diel patterns in DOM composition as evidenced by the SUVA 254 results. Similar effects on the NOM associated with sorbed Hg-NOM complexes may lead to release of $\mathrm{Hg}$ from particles to the dissolved phase. However, previous investigations using stable natural abundance $\mathrm{Hg}$ isotopes suggest that photoreduction of $\mathrm{Hg}^{\text {II }}$ to $\mathrm{Hg}^{0}$ is likely not an important factor overall (Demers et al. 2018).

Although there were diel patterns in $\mathrm{Hg}_{\mathrm{D}}$ concentration overall at the two downstream locations $\mathrm{Hg}_{\mathrm{D}}$ was remarkably stable given the range of total $\mathrm{Hg}\left(\mathrm{Hg}_{\mathrm{T}}\right)$ concentration. Similar results have been reported for EFPC over much larger $\mathrm{Hg}_{\mathrm{T}}$ ranges for studies that included flood events (Riscassi, Miller, and Brooks 2016, Southworth et al. 2013, Southworth et al. 2010) and speaks to the degree to which dissolved Hg is buffered by its affinity for particles.

Dissolved Monomethylmercury. In general, MMHg concentration followed the daily photocycle increasing during the day with mid-afternoon maxima followed by gradual decreases and overnight minima. These results stand in contrast to those of most other published studies in which daytime $\mathrm{MMHg}$ concentrations are lower than those at nighttime due to photodemethylation (Naftz et al. 2011, Sellers et al. 1996, Qian et al. 2014). The range of MMHg concentration was greatest at EFK 5.4 where light 
intensity, and potential photodemthylation, was lowest. Interestingly, at EFK 23.4 which had the highest light intensity and highest potential photodemethylation, daytime $\mathrm{MMHg}_{\mathrm{D}}$ concentration was greater than nighttime values suggesting that the rate of MMHg production exceeded the rate of $\mathrm{MMHg}$ demethylation.

Recent studies in EFPC have highlighted the role of photosynthetic biofilms as net sources of MMHg to the creek (Olsen, Brandt, and Brooks 2016, Olsen et al. 2018). Olsen et al. (2016) reported that actively photosynthesizing periphyton biofilms from EFPC were net producers of MMHg. When these biofilms were incubated in the dark, the rate of MMHg production decreased significantly and in some cases the biofilms destroyed more MMHg than they produced. To the extent these laboratory results apply back to the creek, this provides a mechanism consistent with the daily photocycle for a diel pattern in MMHg concentration as was observed.

\subsection{CONSTITUENT LOADING}

Hg loading increased downstream indicating that diffuse legacy sources of $\mathrm{Hg}$, outside of Y-12, contribute $\mathrm{Hg}$ to EFPC. The largest increase in total, dissolved, and particulate $\mathrm{Hg}$ loading occurred over the upper reach and likely can be attributed to the HRD layer. MMHg loading also increased downstream but most of that increase likely was due primarily to instream MMHg production rather than inputs from out of stream sources. Total and dissolved MMHg load increased over both the upper and lower reaches. Particulate MMHg increased over the upper reach but did not change or decreased slightly over the lower reach.

The presentation of results and the discussion thus far have focused on concentration changes over time at three locations along EFPC. We now turn to estimated constituent loads at each of our sampling locations to assess if and to what extent individual reaches may have acted as sources or sinks of materials to EFPC with a focus on Hg and MMHg.

Inorganic Mercury. The total Hg load increased downstream from $1.29 \pm 0.04 \mathrm{~g}$ to $5.0 \pm 0.2 \mathrm{~g}$ to $5.2 \pm$ $0.1 \mathrm{~g}$ at EFK 23.4, EFK 16.2, and EFK 5.4, respectively (Table 4; Fig. 12). The combined total Hg load from Mill Branch and the ORWTF was $0.045 \pm 0.024 \mathrm{~g}$ or $0.86 \pm 0.47 \%$ of the total load at EFK 5.4 and $23 \pm 28 \%$ of the increased $\mathrm{Hg}_{\mathrm{T}}$ load between EFK 16.2 and EFK 5.4.

At EFK 23.4, $57 \pm 3 \%$ of the total load was dissolved $\mathrm{Hg}(0.74 \pm 0.02 \mathrm{~g})$ whereas instream loads at all downstream locations were less than $30 \%$ dissolved $\mathrm{Hg}$. This change in Hg partitioning is reflected in the increasing $\mathrm{K}_{\mathrm{sw}}$ at the downstream sites (Fig. 13). Mercury loading from the ORWTF, considered an out of stream source, was $51 \pm 39 \%$ dissolved $\mathrm{Hg}$.

The reach between EFK 23.4 and EFK 16.2 contributed the greatest load of Hg (total, particulate, and dissolved) and over this reach there was a significant change in partitioning between dissolved and particulate phases. This reach of EFPC encompasses the areas where the Historical Release Deposit (HRD) has been documented (Peterson, Mayes, et al. 2016, Dickson et al. in prep). It seems likely that the additional $\mathrm{Hg}$ load along this reach can be attributed to the presence of those high $\mathrm{Hg}$ concentration deposits underlying portions of the floodplain and exposed along the creek banks.

The HRD may contribute $\mathrm{Hg}_{\mathrm{P}}$ loads to the creek through several potential mechanisms. One of these mechanisms is direct erosion of the HRD bank soils into EFPC and subsequent (re)suspension of the finer particulates into the water column. This could account for both increased load and the increased proportion of that load associated with the particulate phases. Note that over this same reach TSS load increased from $26 \pm 1 \mathrm{~kg}$ to $250 \pm 12 \mathrm{~kg}$. The baseflow conditions preceding and during the sampling 
campaign would not contribute to active erosion of the HRD, all of which is well above the baseflow waterline. However, previous study of the creek sediment indicates that there are locations within this reach where sediment Hg concentrations are elevated suggestive of HRD erosion and temporary storage in the creek sediments (Southworth et al. 2013, Southworth et al. 2010, Brooks et al. 2017, Dickson et al. in prep).

Hg concentrations in the HRD span a broad range with a geometric mean of $430 \mathrm{mg} / \mathrm{kg}(133-1388$ $\mathrm{mg} / \mathrm{kg}, 1$ standard deviation range). Assuming the increased $\mathrm{Hg}_{\mathrm{P}}$ load at EFK 16.2 (3.07 g) is attributable solely to the entrainment of HRD particles into the water column and using the geometric mean value, this equates to $7.1 \mathrm{~kg}(2.2-$ $23 \mathrm{~kg}$ ) of suspended HRD solids or 3.2\% (1-10\%) of the additional TSS load over the same reach. This evaluation does not account for $\mathrm{Hg}$ loss from the solid phase when HRD materials enter the creek but demonstrates that entrainment of a small amount of HRD materials ( $3 \%$ of the additional TSS load) into the suspended load of EFPC can account for the additional $\mathrm{Hg}_{\mathrm{P}}$ load observed.

It follows that the remainder of the increased TSS load originates from non-HRD materials either in the creek bank or the stream bed. Particles from these other TSS source areas have much lower Hg concentration (Brooks et al. 2017, Dickson et al. in prep) and may be efficient accumulators of dissolved $\mathrm{Hg}$ which would contribute to the increasing $\mathrm{Hg} \mathrm{K}_{\mathrm{sw}}$ downstream. Recall that the $\mathrm{K}_{\text {sw }}$ is the ratio of $\mathrm{Hg}_{\mathrm{TSS}}$ to $\mathrm{Hg}_{\mathrm{D}}((3)$, and while $\mathrm{Hg}_{\text {TSS }}$ decreased downstream (30\% decrease from EFK 23.4 to EFK 5.4; Fig. 8) there was a greater relative decrease in $\mathrm{Hg}_{\mathrm{D}}$ (75\% decrease from EFK 23.4 to EFK 5.4; Fig. 10) driving the increased $\mathrm{K}_{\mathrm{sw}}$ downstream. The decreasing $\mathrm{Hg}_{\mathrm{D}}$ concentration cannot be attributed to dilution with increased flow downstream as the flux of $\mathrm{Hg}_{\mathrm{D}}$ increased.

Hg-contaminated particles from Y-12 deposited on the streambed and subsequently remobilized can also contribute to the increased $\mathrm{Hg}_{\mathrm{P}}$ load at EFK 16.2. As a coarse estimate of the TSS load from Y12 needed to account for the increased $\mathrm{Hg}_{\mathrm{P}}$ load at

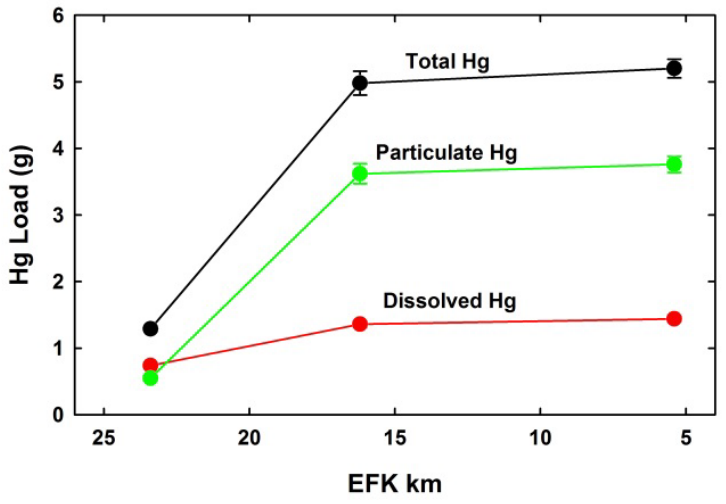

Fig. 12. Total, dissolved, and particulate Hg load at each station over the 30 -hour sampling period.

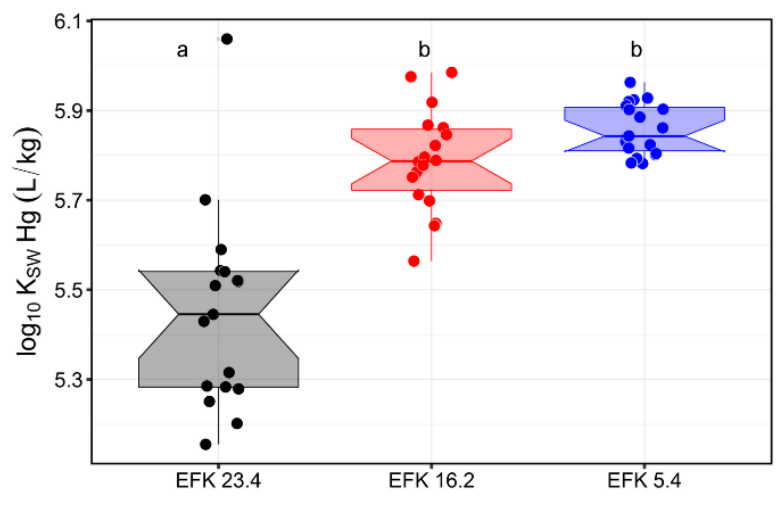

Fig. 13. $\log _{10}$ of the apparent $\mathrm{Hg}$ partitioning coefficient $\left(\mathrm{K}_{\mathrm{sw}}\right)$ at each sampling station.

Horizontal lines and notches represent the median and its approximate 95\% confidence interval. Box limits represent the $25^{\text {th }}$ and $75^{\text {th }}$ percentiles and the whiskers represent Tukey's fences (see section 2.5.1). The lower-case letters indicate significant differences among the sites. The groupings are unchanged when potential outliers are removed.

EFK 16.2 we assumed the average $\mathrm{Hg}_{\text {Tss }}$ value at EFK 23.4 to be representative of baseflow conditions (22.1 $\pm 11.4 \mathrm{ng} / \mathrm{mg}$ ). Under this assumption, $138 \pm 72 \mathrm{~kg}$ of TSS are needed to account for the increased $\mathrm{Hg}_{\mathrm{P}}$ load which is $86 \pm 73 \mathrm{~kg}$ less than the increased TSS load from EFK 23.4 to EFK 16.2. Streambed sediments upstream of EFK 16.2 have an average Hg concentration very similar to the TSS reported in this study (Brooks et al. 2017). Even if those coarser streambed sediments were suspended under baseflow conditions, their contribution would not change the results of these calculations substantially. 
Table 4. Constituent loadings at each sampling location, the Mill Branch tributary, and the Oak Ridge Wastewater Treatment Facility (ORWTF)

\begin{tabular}{|c|c|c|c|c|c|c|c|c|c|c|c|}
\hline \multirow[b]{2}{*}{ Constituent } & \multicolumn{11}{|c|}{ Mill } \\
\hline & units & EFK 23.4 & $\pm^{a}$ & EFK 16.2 & \pm & Branch & \pm & ORWTF & \pm & EFK 5.4 & \pm \\
\hline $\mathrm{Hg}_{\mathrm{T}}$ & g & 1.293 & 0.041 & 4.98 & 0.18 & 0.0078 & 0.0061 & 0.037 & 0.023 & 5.2 & 0.14 \\
\hline $\mathrm{Hg}_{\mathrm{D}}$ & g & 0.739 & 0.024 & 1.362 & 0.045 & 0.0023 & 0.0015 & 0.019 & 0.008 & 1.443 & 0.032 \\
\hline $\mathrm{Hg}_{\mathrm{P}}$ & g & 0.554 & 0.037 & 3.62 & 0.15 & 0.0055 & 0.0056 & 0.018 & 0.025 & 3.76 & 0.12 \\
\hline $\mathrm{MMHg}_{\mathrm{T}}$ & $\mathrm{mg}$ & 1.111 & 0.038 & 15.86 & 0.62 & 0.26 & 0.19 & 1.39 & 0.77 & 24.63 & 0.72 \\
\hline $\mathrm{MMHg}_{\mathrm{D}}$ & $\mathrm{mg}$ & 0.819 & 0.022 & 9.49 & 0.32 & 0.19 & 0.14 & 0.87 & 0.46 & 19.14 & 0.42 \\
\hline MMHg$_{P}$ & $\mathrm{mg}$ & 0.292 & 0.032 & 6.38 & 0.46 & 0.07 & 0.19 & 0.53 & 0.89 & 5.49 & 0.61 \\
\hline DOC & $\mathrm{kg}$ & 13.4 & 0.34 & 84.9 & 2.8 & 5.6 & 4.9 & 60 & 21 & 174.4 & 3.6 \\
\hline TSS & $\mathrm{kg}$ & 25.8 & 1.2 & 250 & 12 & 15 & 10 & 19 & 14 & 282 & 11 \\
\hline Chloride & $\mathrm{kg}$ & 248.7 & 5.5 & 896 & 27 & 10.5 & 6.4 & 472 & 130 & 1564 & 29 \\
\hline Nitrate & $\mathrm{kg}$ & 129.6 & 2.8 & 309 & 12 & 2.7 & 1.8 & 509 & 205 & 1846 & 35 \\
\hline Phosphate & $\mathrm{kg}$ & 4.33 & 0.17 & 18.84 & 0.82 & 0.56 & 0.53 & 75 & 78 & 257 & 8 \\
\hline Sulfate & $\mathrm{kg}$ & 367.4 & 8.1 & 1773 & 54 & 47 & 27 & 339 & 55 & 2043 & 38 \\
\hline $\mathrm{NH}_{4}-\mathrm{N}$ & $\mathrm{kg}$ & 0.456 & 0.021 & 1.333 & 0.066 & 0.041 & 0.024 & 0.27 & 0.26 & 1.685 & 0.065 \\
\hline SRP-P & $\mathrm{kg}$ & 0.8 & 0.037 & 2.32 & 0.12 & 0.036 & 0.023 & 12.5 & 9.4 & 58.5 & 2.3 \\
\hline Sodium & $\mathrm{kg}$ & 147.1 & 3.4 & 523 & 16 & $-{ }^{b}$ & -- & -- & -- & 1087 & 21 \\
\hline Magnesium & $\mathrm{kg}$ & 124.7 & 2.7 & 661 & 20 & -- & -- & -- & -- & 838 & 16 \\
\hline Calcium & $\mathrm{kg}$ & 504 & 11 & 2832 & 87 & -- & -- & -- & -- & 3638 & 69 \\
\hline Potassium & $\mathrm{kg}$ & 20.91 & 0.47 & 115 & 3.6 & -- & -- & -- & -- & 303.3 & 5.9 \\
\hline Lithium & $\mathrm{kg}$ & 0.854 & 0.028 & 0.568 & 0.020 & -- & -- & -- & -- & 0.677 & 0.016 \\
\hline Strontium & $\mathrm{kg}$ & 1.449 & 0.032 & 7.47 & 0.23 & -- & -- & -- & -- & 8.68 & 0.16 \\
\hline Uranium & $\mathrm{g}$ & 82.5 & 1.9 & 253.2 & 7.7 & -- & -- & -- & -- & 227.9 & 4.4 \\
\hline
\end{tabular}

${ }^{a}$ Estimated uncertainty which likely represents more than 1 standard deviation. See sections 2.3 .3 and 2.5

${ }^{b}$ No data available 
This suggests that the increased HgP and TSS loads between EFK 23.4 and EFK 16.2 must include materials that are not immediately sourced from Y-12.

The HRD can make additional contributions to the $\mathrm{Hg}_{\mathrm{D}}$ load via $\mathrm{Hg}$ leaching off solids that fall into the creek. The leaching could occur through any one of multiple mechanisms including desorption, dissolution of precipitated phases, and ligand enhanced desorption and dissolution with, e.g., DOM. The HRD may also contribute $\mathrm{Hg}_{\mathrm{D}}$ load to the creek via leaching of dissolved or colloidal phases as rainwater and soil water percolate vertically through HRD layers underlying the floodplain and eventually discharge into the creek. Similarly, rising floodwaters can inundate the HRD migrating laterally into the creek banks during high water and subsequently drain back into the creek as flood waters recede delivering dissolved and colloidal Hg phases to the creek.

The sum of the total Hg load at EFK 16.2, Mill Branch, and the ORWTF accounts for $96.6 \pm 4.3 \%$ of the $\mathrm{Hg}_{\mathrm{T}}$ load at EFK 5.4 suggesting that over this 30-hour sampling period any unaccounted-for $\mathrm{Hg}$ sources or sinks along the reach from EFK 16.2 to EFK 5.4 had minor effect on the net $\mathrm{Hg}_{\mathrm{T}}$ load. Nevertheless, a longer data record shows that along this reach significant additional Hg loading can occur although the source(s) of that load are not known (Peterson et al. 2015, Peterson, Brooks, et al. 2016, Peterson, Mayes, et al. 2017). The results for $\mathrm{Hg}_{\mathrm{D}}$ and $\mathrm{Hg}_{\mathrm{P}}$ loads are like those for $\mathrm{Hg}_{\mathrm{T}}$ : the three upstream sources account for $95.9 \pm 3.8 \%$ of the $\mathrm{Hg}_{\mathrm{D}}$ load and $96.9 \pm 5.1 \%$ of the $\mathrm{Hg}_{\mathrm{P}}$ load at EFK 5.4.

Past assessments of Hg sources and export for EFPC have concluded that inputs from Y-12 were the primary contributions sustaining baseflow Hg concentrations (Southworth et al. 2013, Southworth et al. 2010) and that bank erosion and particle resuspension were required to sustain Hg export rates (Southworth et al. 2013, Southworth et al. 2010, Watson et al. 2016). The present study adds further evidence in support of the idea that bank erosion, and specifically in areas where the HRD is present, are a major source of Hg loading to the creek. Hg sources outside of Y-12 accounted for $75 \pm 1 \%$ of the total $\mathrm{Hg}, 49 \pm 2 \%$ of the $\mathrm{Hg}_{\mathrm{D}}$, and $85 \pm 1 \%$ of the $\mathrm{Hg}_{\mathrm{P}}$ loads over this 30 -hour study.

This 30-hour study (Fig. 13) and the several-year record both show increasing $\mathrm{Hg}_{\mathrm{T}}, \mathrm{Hg}_{\mathrm{D}}$, and $\mathrm{Hg}_{\mathrm{P}}$ load with downstream distance under baseflow. Recently, Demers et al. (2018) collected baseflow samples along EFPC in October 2011, and April and August 2012. During each survey $\mathrm{Hg}_{\mathrm{T}}, \mathrm{Hg}_{\mathrm{D}}$, and $\mathrm{Hg}_{\mathrm{P}}$ load increased from EFK 23.4 to EFK 5.0. The increases, relative to EFK 23.4, ranged from $43 \%$ to $146 \%$ for $\mathrm{Hg}_{\mathrm{T}}, 11 \%$ to $62 \%$ for $\mathrm{Hg}_{\mathrm{D}}$, and 38 to 185\% for Hg. Riscassi et al. (Riscassi, Miller, and Brooks 2016) estimated that for water year 2013 the annual total $\mathrm{Hg}$ load at EFK 5.4 was $98.055 \mathrm{~kg}(1.003 \mathrm{~kg} \mathrm{Hg}$, $97.052 \mathrm{~kg} \mathrm{Hg}$ ) which was 4.6-19× greater than the estimated annual Hg flux at EFK 23.4 for the same period (URS | CH2M Oak Ridge LLC 2013, 2014).

Previous estimates of baseflow Hg loading along EFPC have shown variable trends with downstream distance. In June 1998, $\mathrm{Hg}_{\mathrm{T}}$ loading decreased from EFK 23.4 to EFK 13.8 by 13\% then increased 155\% over the next four kilometers and decreased again over the next 1.5 kilometers for a net increase in $\mathrm{Hg}$ loading of 20\% (Bechtel Jacobs Co. LLC 1998). Similar results were obtained in August 1998: $\mathrm{Hg}_{\mathrm{T}}$ loading decreased $30 \%$ from EFK 23.4 to EFK 13.8 then increased 20\% to EFK 6.3 for a net decrease in loading of 15\% over the reach from EFK 23.4 to EFK 6.3. The June and August 1998 samples were supplemented with bimonthly samples over the next twelve months and the aggregate data set showed a small (10\%) increase from EFK 23.4 to EFK 13.8 then a 61\% increase to EFK 6.3 for a $75 \%$ net increase in $\mathrm{Hg}_{\mathrm{T}}$ loading (Bechtel Jacobs Co. LLC 1999).

The results of that 1999 study are in sharp contrast to the present study in which the greatest increase in $\mathrm{Hg}_{\mathrm{T}}$ load occurred in the upper reach and a smaller increase occurred over the lower reach. Interestingly, in the 1998-1999 dataset the reach encompassing the HRD layers showed increased $\mathrm{Hg}_{\mathrm{T}}$ loading of $1.24 \pm$ $1.87 \mathrm{~g} \mathrm{Hg}$ per day suggesting no net change to $\mathrm{Hg}_{\mathrm{T}}$ load, again in contrast to the present results. The 
authors of the earlier study hypothesized that the more abundant deep slow-moving pools in the lower reach were depositional zones for stormflow mobilized particulates that were later resuspended under baseflow accounting for the increased flux in the lower reach of EFPC. The authors concluded there was no strong evidence for additional Hg loading downstream of Y-12. However, in their analysis they compared the average daily load at EFK 23.4, which included baseflow and stormflow load estimates, to the baseflow load at EFK 6.3. They may have reached a different conclusion had they included stormflow loads at their downstream monitoring point. Stormflow carries the overwhelming majority of the Hg load (e.g., (Riscassi, Miller, and Brooks 2016)).

Monomethylmercury. Total MMHg load increased from $1.11 \pm 0.04 \mathrm{mg}$ to $15.9 \pm 0.6 \mathrm{mg}$ to $24.6 \pm 0.7$ mg at EFK 23.4, EFK 16.2, and EFK 5.4, respectively (Table 4, Fig. 14). The combined total MMHg load from Mill Branch $(0.26 \pm 0.19 \mathrm{mg})$ and the ORWTF $(1.39 \pm 0.77 \mathrm{mg})$ accounted for $1.65 \pm 0.79 \mathrm{mg}$ or $6.7 \pm 3.2 \%$ of the total MMHg load at EFK 5.4. In contrast to the inorganic Hg, dissolved $\mathrm{MMHg}$ dominated the MMHg load at $74 \pm 3 \%, 60 \pm 3 \%$, and $78 \pm 3 \%$ at EFK 23.4, EFK 16.2, and EFK 5.4, respectively.

There were significant MMHg loads to the creek in each reach during the study consistent with previous longer term assessments (Fig. 14, Table 4)(Peterson et al. 2015, Peterson, Brooks, et al. 2016, Peterson, Mayes, et al. 2017). An accounting of MMHg is more difficult than for inorganic $\mathrm{Hg}$ because it does not behave conservatively, i.e., it is both created and destroyed by several mechanisms during transit down the creek and in storage, for example, in bed sediments. For the reach between EFK 23.4 and EFK 16.2 we applied a similar analysis of potential HRD contributions to the total MMHg loading as was done for $\mathrm{Hg}$ loading. The HRD has a geometric mean $\mathrm{MMHg}_{\mathrm{P}}$ concentration of

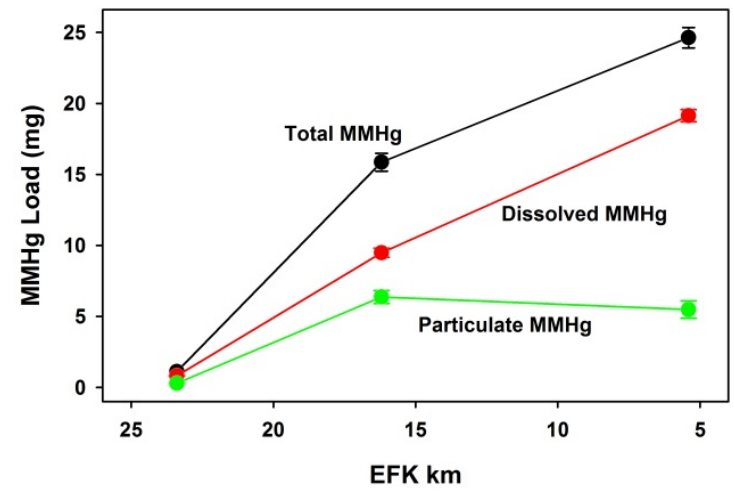

Fig. 14. Total, dissolved, and particulate MMHg load at each station over the 30 -hour sampling period. $18.6 \mu \mathrm{g} / \mathrm{kg}$ (9.1 - 38.1, 1 standard deviation range). To account for the increased MMHg load (6.08 mg), $327 \mathrm{~kg}(160-338 \mathrm{~kg})$ of HRD materials would have to be added to the suspended particle load. This value is greater than the increased TSS load over that reach (224 kg; Table 4) but does not account for MMHg loss from the solids due to leaching or demethylation. Additionally, the necessary HRD loading to TSS to account for the increased $\mathrm{MMHg}_{\mathrm{P}}$ load would overestimate inorganic Hg loading by nearly $50 \times$. On the other hand, the HRD loading needed to account for the additional $\mathrm{Hg}_{\mathrm{P}}$ load $(7.1 \mathrm{~kg}$, see previous section) underestimates $\mathrm{MMHg}_{\mathrm{P}}$ loading by nearly $50 \times$. Therefore, it seems likely that instream MMHg production (Hg methylation) accounts for a substantial portion of the increased total and particulate MMHg load between EFK 23.4 and EFK 16.2.

Over the lower reach from EFK 16.2 to EFK 5.4 both total and dissolved MMHg load increased whereas particulate MMHg load declined although the decrease is likely not significant $(0.88 \pm 0.76 \mathrm{mg})$. If erosion from creek banks and resuspension of MMHg-bearing particulates is a contributing factor to the $\mathrm{MMHg}_{\mathrm{P}}$ load in the upper reach, then the flat to declining profile in the lower reach is consistent with the fact that there are no known features like the HRD in the lower reach. Further, if the observed decline is real it also suggests that some MMHg rich particles settle out along that reach and/or there is a net loss of MMHg from suspended particles due to either desorption or demethylation. Nevertheless, the increase in total and dissolved MMHg loads over the lower reach points to ongoing in-stream MMHg production. 
The sum of total MMHg at EFK 16.2, Mill Branch, and the ORWTF accounts for $71.1 \pm 4.5 \%$ of the load at EFK 5.4 indicating that a net amount of $7.1 \pm 1.2 \mathrm{mg}$ MMHg originated from as yet unidentified sources. Those sources likely include in situ production in periphyton biofilms (Olsen, Brandt, and Brooks 2016, Olsen et al. 2018) and production in metabolically active storage zones in the hyporheic zone, as well as diffuse groundwater inputs.

Shallow groundwater close to the stream channel can have $\mathrm{MMHg}_{\mathrm{D}}$ concentration substantially greater than EFPC surface water (Watson et al. 2016, Peterson, Mayes, et al. 2016, Demers et al. 2018). Given that $\sim 80 \%$ of the flow in the upper reach came from ungauged sources including diffuse groundwater inputs (section 3.1) some of the additional MMHg loading in the upper reach may derive from this shallow groundwater. However, it is currently unknown if or to what extent that groundwater influences surface water chemistry under hydroclimatic conditions similar to those during this study. In the lower reach, ungauged sources were a minor contribution to the overall water balance and could all be attributed to surface water tributaries that have very low MMHg concentration. Therefore, over the lower study reach groundwater sources of dissolved $\mathrm{MMHg}$ loading would appear to be negligible.

The increased proportion of the MMHg load that was dissolved in the lower reach may be due in part to the DOC load from the ORWTF $(60 \pm 21$ $\mathrm{kg}$ DOC) which constituted $34 \pm 12 \%$ of the DOC load at EFK 5.4. Based on SUVA 254 values DOM from the ORWTF has a different composition from that in the creek (section 3.4.1 and Fig. 9B) that may decrease MMHg partitioning onto suspended particles. Note that the $\mathrm{MMHg} \mathrm{K}_{\mathrm{sw}}$ at EFK 5.4 was significantly lower than at EFK 16.2 ( $p=0.022$; Fig. 13). However, the same DOM had no apparent effect on $\mathrm{Hg}_{\mathrm{D}}$ or the $\mathrm{Hg} \mathrm{K}_{\mathrm{sw}}$.

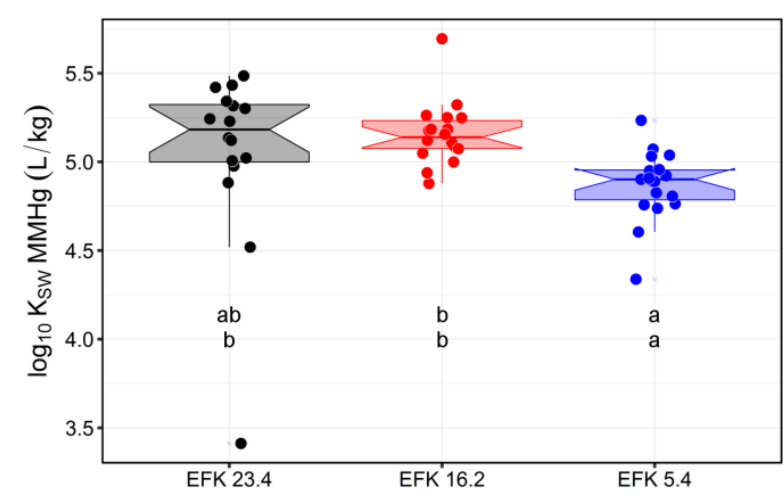

Fig. 15. $\log _{10}$ of the apparent MMHg partitioning coefficient $\left(\mathrm{K}_{\mathrm{sw}}\right)$ at each sampling station. Horizontal lines and notches represent the median and its approximate $95 \%$ confidence interval. Box limits represent the $25^{\text {th }}$ and $75^{\text {th }}$ percentiles and the whiskers represent Tukey's fences (see section 2.5.1). The lower-case letters indicate significant differences among the sites. The lower row of letters indicates significant differences when potential outliers are removed.

To illustrate the effect of diel patterns in concentration and flow rate on loading estimates, Hg and MMHg loads were estimated using an alternate approach. The maximum and minimum concentrations measured during daylight hours were multiplied by the flow rate corresponding to the time of sample collection and extrapolated over a 30-hour period. The range of results obtained by this method was compared relative to the 30-hour load estimate presented in Table 4. Here, we assume that most instantaneous load estimates are based on samples collected during the day.

For 4 of 18 comparisons, the two loading estimates agreed within $\pm 15 \%$ (MMHg $_{\mathrm{T}}$ EFK 23.4, $\mathrm{Hg}_{\mathrm{D}} \mathrm{EFK}$ 16.2, $\mathrm{MMHg}_{\mathrm{T}} \mathrm{EFK}$ 16.2, and $\mathrm{Hg}_{\mathrm{T}} \mathrm{EFK}$ 5.4). The remaining 14 estimates fell outside this range. Additionally, both instantaneous load estimates for $\mathrm{Hg}_{\mathrm{D}}$ at EFK 16.2 were biased high (although the bias was small) and both instantaneous load estimates for $\mathrm{MMHg}_{\mathrm{P}}$ at EFK 16.2 and for $\mathrm{MMHg}_{\mathrm{T}}$ at EFK 5.4 were biased low relative to the 30-hour load estimate. The lack of agreement for the two methods at EFK 16.2 and EFK 5.4 was due to diel variability in flow and concentration. The longer discharge record (Fig. 2) suggests flow the variability we experienced at EFK 16.2 was unusual but intraday concentration patterns are likely a consistent feature. At EFK 5.4 diel patterns in discharge are evident throughout our period of record (Fig. 2). Similarly, previous sampling campaigns are EFK 5.4 have documented diel 
concentration patterns for Hg and MMHg (Brooks, Riscassi, and Miller 2014, Riscassi, Miller, and Brooks 2014a). Flow remained steady at EFK 23.4 and lack of agreement for the two load estimation methods (5 of 6 comparisons) is attributable solely to daily concentration patterns. Instantaneous load estimates are equally likely to underestimate or overestimate loads depending on the time of day when samples are collected.
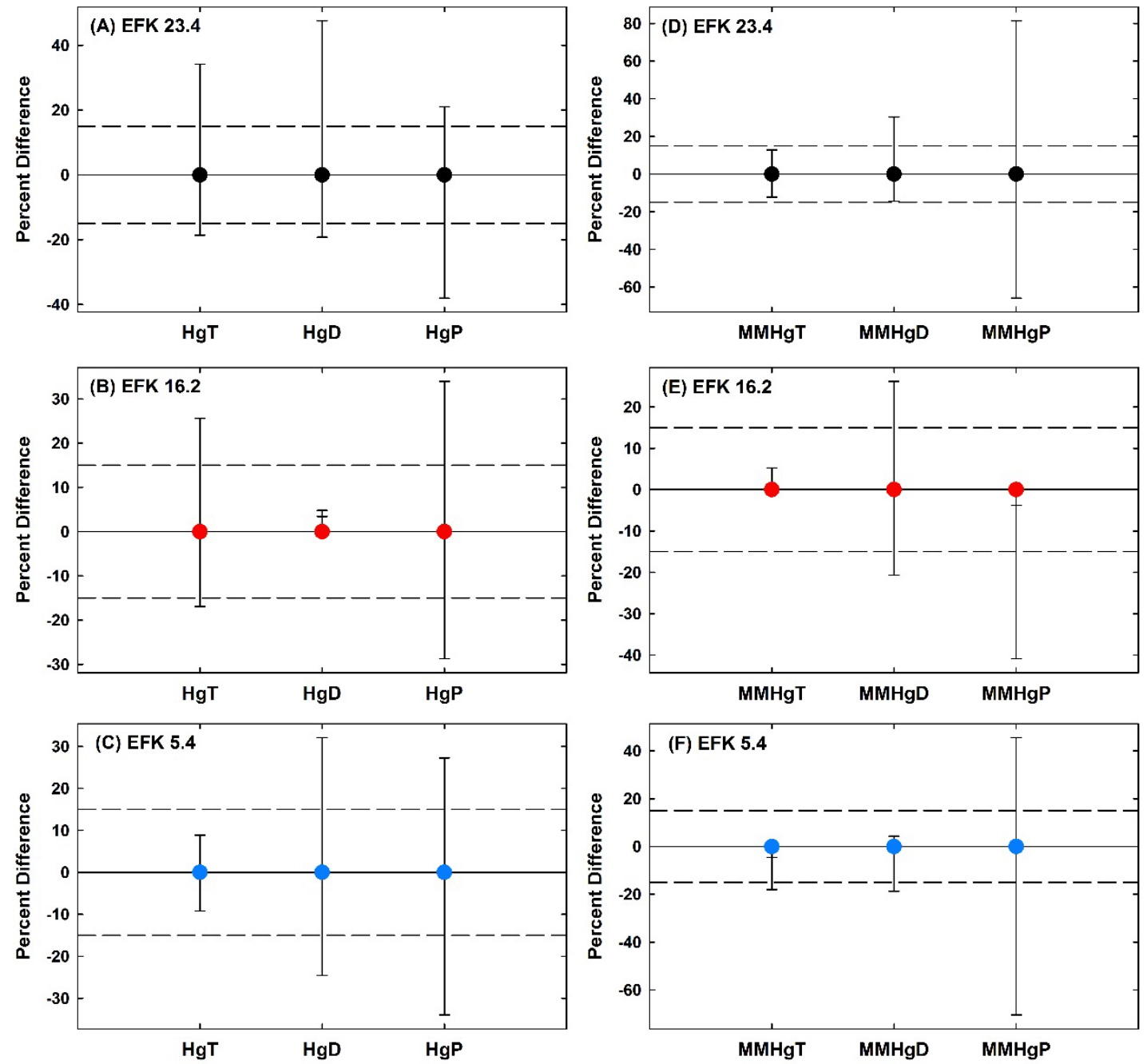

Fig. 16. Percent difference in $\mathrm{Hg}(\mathrm{A}, \mathrm{B}, \mathrm{C})$ and $\mathrm{MMHg}(\mathrm{D}, \mathrm{E}, \mathrm{F})$ loading for instantaneous estimates relative to the 30 -hour loading estimate. 


\section{SUMMARY}

Diel sampling at three locations along EFPC revealed complex patterns among water quality parameters that directly influenced $\mathrm{Hg}$ and MMHg concentrations and speciation in EFPC. $\mathrm{Hg}_{\mathrm{P}}$ and $\mathrm{MMHg}_{\mathrm{P}}$ concentrations increased overnight at EFK 16.2 and EFK 5.4 coincident with increases in turbidity and total suspended solids (TSS). These overnight increases were likely due to diel changes in the activity of macrobiota (re)suspending contaminated sediments in the creek. Both $\mathrm{Hg}_{\mathrm{D}}$ and $\mathrm{MMHg}_{\mathrm{D}}$ were higher during the day at EFK 23.4 and EFK 5.4. The underlying causes for the patterns in $\mathrm{Hg}_{\mathrm{D}}$ and $\mathrm{MMHg}_{\mathrm{D}}$ are less clear but correspond with similar patterns in DOC concentration and DOM composition. Photochemical reactions may also play a role in these $\mathrm{Hg}_{\mathrm{D}}, \mathrm{MMHg}_{\mathrm{D}}$, DOC, and DOM patterns. Biologically mediated processes, such as microbial MMHg production in actively photosynthesizing periphyton biofilms, likely influence diel MMHg patterns too. Total loads of both $\mathrm{Hg}$ and $\mathrm{MMHg}$ increased with downstream distance. The greatest increase in total, dissolved, and particulate Hg loading occurred in the reach from EFK 23.4 to EFK 16.2 which encompasses areas where the Historic Release Deposits (HRD) have been identified. These results demonstrate that diffuse legacy sources of Hg, outside of Y-12, contribute Hg load to EFPC.

Both total and dissolved MMHg loads increased approximately linearly with downstream distance. Particluate MMHg loading increased in the upper reach but did not change over the lower reach. The HRD may contribute to $\mathrm{MMHg}_{\mathrm{P}}$ load in the upper reach but most of the total, dissolved, and particulate MMHg appears to originate from in-stream production. Due to intraday patterns in concentration and flow rate, loading estimates are best derived from diel sampling campaigns.

Intraday patterns in $\mathrm{Hg}$ and $\mathrm{MMHg}$ concentration and speciation have implications with respect to biotic exposure. Greater biotic activity and feeding during times of higher concentration would correspond to greater exposure than estimated from daily or longer-term averages. Both Hg and MMHg responded rapidly to processes governing their concentration. This latter point is encouraging from the perspective of site remediation as it suggests that MMHg concentrations and flux in EFPC would respond rapidly to appropriate remedial actions.

\section{ACKNOWLEDGEMENTS}

This work was funded by the US Department of Energy's Oak Ridge Office of Environmental Management (ORO-EM) and URS | CH2M Oak Ridge LLC (UCOR) and is a product of ORNL's Mercury Remediation Technology Development Program. We thank Chris DeRolph (ORNL) for producing Fig. 1. We thank Ranjeet Devarakonda and Michael Crow (ORNL) for help in archiving the data. 



\section{REFERENCES}

Bechtel Jacobs Co. LLC. 1998. Mercury Abatement Report for the U. S. Department of Energy's Oak Ridge Y-12 Plant for Fiscal Year 1998, BJC/OR-183. Prepared by Environmental Sciences Division, Oak Ridge National Laboratory, Oak Ridge, TN.

Bechtel Jacobs Co. LLC. 1999. Mercury Abatement Report for the U. S. Department of Energy's Oak Ridge Y-12 Plant for Fiscal Year 1999, BJC/OR-422. Prepared by Environmental Sciences Division, Oak Ridge National Laboratory, Oak Ridge, TN.

Bechtel Jacobs Co. LLC. 2000. Mercury Abatement Report for the U. S. Department of Energy's Oak Ridge Y-12 Plant for Fiscal Year 2000, BJC/OR-782. Prepared by Environmental Sciences Division, Oak Ridge National Laboratory, Oak Ridge, TN.

Brooks, S. C., and G. R. Southworth. 2011. "History of mercury use and environmental contamination at the Oak Ridge Y-12 Plant.” Environ. Poll. 159 (1):219-228. doi: 10.1016/j.envpol.2010.09.009.

Brooks, Scott C., A. L. Riscassi, and Carrie L. Miller. 2014. Diel mercury-concentration variations in a mercury impacted stream. Paper read at Geological Society of America, 19-22 October 2014, at Vancouver, BC, Canada.

Brooks, Scott, Virginia Eller, Johnbull O. Dickson, Jennifer Earles, Kenneth Lowe, Tonia Mehlhorn, Todd A. Olsen, C. DeRolph, D. B. Watson, Debra Phillips, and Mark Peterson. 2017. Mercury Content of Sediments in East Fork Poplar Creek: Current Assessment and Past Trends. ORNL/TM-2016/578. Oak Ridge National Laboratory. doi: 10.2172/1338545. doi: $10.2172 / 1338545$.

Christensen, Geoff A., Anil C. Somenahally, James G. Moberly, Carrie M. Miller, Andrew J. King, Cynthia C. Gilmour, Steven D. Brown, Mircea Podar, Craig C. Brandt, Scott C. Brooks, Anthony V. Palumbo, Judy D. Wall, and Dwayne A. Elias. 2018. "Carbon Amendments Alter Microbial Community Structure and Net Mercury Methylation Potential in Sediments.” Applied and Environmental Microbiology 84 (3). doi: 10.1128/aem.01049-17.

Demers, Jason D., Joel D. Blum, Scott C. Brooks, PatrickM Donovan, Ami L. Riscassi, Carrie L. Miller, Wang Zheng, and Baohua Gu. 2018. "Hg isotopes reveal in-stream processing and legacy inputs in East Fork Poplar Creek, Oak Ridge, Tennessee, USA.” Environmental Science: Processes \& Impacts. doi: 10.1039/C7EM00538E.

Dickson, Johnbull O., Melanie A. Mayes, Scott C. Brooks, Tonia L. Mehlhorn, Kenneth A. Lowe, Jennifer K. Earles, Leroy Goñez-Rodriguez, Virginia Eller, and Mark J. Peterson. in prep. "Source relationships between streambank soils and streambed sediments in a mercurycontaminated stream."

Dong, W. M., L. Y. Liang, S. Brooks, G. Southworth, and B. H. Gu. 2009. "Roles of dissolved organic matter in the speciation of mercury and methylmercury in a contaminated ecosystem in Oak Ridge, Tennessee.” Environ. Chem. 7 (1):94-102.

Dzombak, David A., and Francois M. M. Morel. 1990. Surface Complexation Modeling: Hydrous Ferric Oxide. New York: John Wiley \& Sons.

Fleck, J. A., B. D. Downing, J. F. Saraceno, G. Gill, M. Stephenson, Charles N. Alpers, and B. A. Bergamaschi. 2009. Diurnal trends in methylmercury concentration and organic matter photoreactivity in agricultural wetlands of the Yolo Bypass, California. In Geological Society of America Annual Meeting, 18-21 October 2009. Portland, OR: GSA.

Flohr, D. F, J. W. Garrett, T. T. Hamilton, and T. D Phillips. 2002. Water Resources Data, Tennessee, Water Year 2002. Water-Data Report TN-02-1. Water-Data Report TN-02-1.

Fuller, C. C., and J. A. Davis. 1989. "Influence of coupling of sorption and photosynthetic processes on trace-element cycles in natural-waters.” Nature 340 (6228):52-54. doi: 10.1038/340052a0.

Hintelmann, H., and N. Ogrinc. 2003. "Determination of stable mercury isotopes by ICP/MS and their application in environmental studies.” In Biogeochemistry of Environmentally Important Trace Elements, edited by Y. Cai and O. C. Braids, 321-338. Washington: Amer Chemical Soc. 
Hoaglin, D. C. 2003. “John W. Tukey and data analysis.” Statistical Science 18 (3):311-318. doi: 10.1214/ss/1076102418.

Kocman, D., S. C. Brooks, C. L. Miller, and X. P. L. Yin. 2013. "Evaluation of centrifugal ultrafilters for size fractionation of total mercury and methylmercury in freshwaters." Environmental Chemistry 10 (4):323-332. doi: 10.1071/en12199.

Krabbenhoft, D. P., J. P. Hurley, M. L. Olson, and L. B. Cleckner. 1998. "Diel variability of mercury phase and species distributions in the Florida Everglades.” Biogeochemistry 40 (2-3):311-325. doi: 10.1023/a:1005938607225.

Loar, J. M., A. J. Stewart, and J. G. Smith. 2011. “Twenty-Five Years of Ecological Recovery of East Fork Poplar Creek: Review of Environmental Problems and Remedial Actions.” Environ. Management 47 (6):1010-1020. doi: 10.1007/s00267-011-9625-4.

Lockheed Martin Energy Systems Inc. 1995. Mercury Abatement Report for the U. S. Department of Energy's Oak Ridge Y-12 Plant for Fiscal Year 1995. Prepared by Environmental Sciences Division, Oak Ridge National Laboratory, Oak Ridge, TN, Y/ER-251.

Lockheed Martin Energy Systems Inc. 1996. Mercury Abatement Report on the U.S. Department of Energy's Oak Ridge Y-12 Plant for Fiscal Year 1996. Prepared by Environmental Sciences Division, Oak Ridge National Laboratory, Oak Ridge, TN, Y/ER-277, Oak Ridge, TN.

Lockheed Martin Energy Systems Inc. 1997. Mercury Abatement Report for the U. S. Department of Energy's Oak Ridge Y-12 Plant for Fiscal Year 1997. Prepared by Environmental Sciences Division, Oak Ridge National Laboratory, Oak Ridge, TN, Y/ER-297.

Loperfido, J. V., C. L. Just, A. N. Papanicolaou, and J. L. Schnoor. 2010. "In situ sensing to understand diel turbidity cycles, suspended solids, and nutrient transport in Clear Creek, Iowa.” Water Resour. Res. 46:W06525. doi: 10.1029/2009wr008293.

Lowery, J. F., R. H. Counts, F. D. Edwards, and J. W. Garrett. 1988. Water Resources Data, Tennessee, Water Year 1988. TN-88-1, $382 \mathrm{p}$.

Miller, Carrie L., G. R. Southworth, S. C. Brooks, Liyuan Liang, and B. Gu. 2009. "Kinetic controls on the complexation between mercury and dissolved organic matter in a contaminated environment." Environ. Sci. Technol. 43 (22):8548-8553.

Mosher, J. J., T. A. Vishnivetskaya, D. A. Elias, M. Podar, S. C. Brooks, S. D. Brown, C. C. Brandt, and A. V. Palumbo. 2012. "Characterization of the Deltaproteobacteria in contaminated and uncontaminated stream sediments and identification of potential mercury methylators.” Aquatic Microbial Ecology 66 (3):271-282. doi: 10.3354/ame01563.

Naftz, D. L., J. R. Cederberg, D. P. Krabbenhoft, K. R. Beisner, J. Whitehead, and J. Gardberg. 2011. "Diurnal trends in methylmercury concentration in a wetland adjacent to Great Salt Lake, Utah, USA.” Chem. Geol. 283 (1-2):78-86. doi: 10.1016/j.chemgeo.2011.02.005.

Nagorski, S. A., J. N. Moore, T. E. McKinnon, and D. B. Smith. 2003. "Geochemical response to variable streamflow conditions in contaminated and uncontaminated streams.” Water Resour. Res. 39 (2). doi: 10.1029/2001wr001247.

Nimick, D. A., B. R. McCleskey, C. H. Gammons, T. E. Cleasby, and S. R. Parker. 2007. "Diel mercuryconcentration variations in streams affected by mining and geothermal discharge." Sci. Tot. Environ. 373 (1):344-355. doi: 10.1016/j.scitotenv.2006.11.008.

NIST. http://www.itl.nist.gov/div898/handbook/eda/section3/eda35h.htm 2017 [cited 30 May 2017.

Olsen, Todd A., Craig C. Brandt, and Scott C. Brooks. 2016. "Periphyton Biofilms Influence Net Methylmercury Production in an Industrially Contaminated System.” Environ. Sci. Technol. 50 (20):10843-10850. doi: 10.1021/acs.est.6b01538.

Olsen, Todd A., Katherine A. Muller, Scott L. Painter, and Scott C. Brooks. 2018. "Kinetics of Methylmercury Production Revisited.” Environmental Science \& Technology 52 (4):2063-2070. doi: 10.1021/acs.est.7b05152.

Oppenheimer, Leonard, Thomas P. Capizzi, Roger M. Weppelman, and Hina Mehta. 1983. "Determination of the lowest limit of reliable assay measurement." Anal. Chem 55 (4):638-643. 
Peterson, M. J., S. C. Brooks, T. J. Mathews, M. A. Mayes, Alexander Johs, D. B. Watson, Monica D. Poteat, John Smith, Tonia Mehlhorn, Brian Lester, Jesse Morris, Kenneth Lowe, Johnbull O. Dickson, Virginia Eller, and C. R. DeRolph. 2016. Mercury Remediation Technology Development for Lower East Fork Poplar Creek - FY 2015 Progress Report. Oak Ridge National Laboratory, ORNL/TM-2016/48.

Peterson, M. J., M. S. Greeley Jr., R. T. Jett, T. J. Mathews, S. C. Brooks, J. G. Smith, R. A. McManamay, N. J. Jones, and N. Griffiths. 2017. Y-12 National Security Complex Biological Monitoring and Abatement Program-2016 Calendar Year Report. Oak Ridge National Laboratory, ORNL/SR-2017/331.

Peterson, M. J., M. A. Mayes, S. C. Brooks, T. J. Mathews, Alexander Johs, Johnbull O. Dickson, Tonia Mehlhorn, Leroy Goñez-Rodriguez, C. R. DeRolph, D. B. Watson, Virginia Eller, T. A. Olsen, Kenneth Lowe, Ryan McManamay, John Smith, Jesse Morris, and Monica D. Poteat. 2016. Mercury Remediation Technology Development for Lower East Fork Poplar Creek - FY 2016 Progress Report. Oak Ridge National Laboratory, ORNL/TM-2016/494.

Peterson, Mark, Scott Brooks, Teresa Mathews, Mark Bevelhimer, Sridhar Bhaskar, Carrie Miller, Ami Riscassi, and George Southworth. 2014. Evaluation of Lower East Fork Poplar Creek Mercury Sources. Oak Ridge National Laboratory, ORNL/TM-2014/474.

Peterson, Mark J., Scott C. Brooks, Teresa J. Mathews, Melanie Mayes, Alexander Johs, David B. Watson, Monica D. Poteat, and Eric Pierce. 2015. Mercury Remediation Technology Development for Lower East Fork Poplar Creek. Oak Ridge National Laboratory, ORNL/SPR2014/645.

Peterson, Mark J., Melanie A. Mayes, Scott C. Brooks, Teresa Mathews, Alex Johs, Leroy Gonez Rodriguez, Christopher DeRolph, Eric Pierce, David Watson, Katherine A. Muller, Todd Olsen, Kenneth Lowe, Ryan McManamay, John Smith, Jesse Morris, and Michael Jones. 2017. Mercury Remediation Technology Development for Lower East Fork Poplar Creek - FY 2017 Progress Report. Oak Ridge National Laboratory, ORNL/TM-2017/480.

Porat, I., T. A. Vishnivetskaya, J. J. Mosher, C. C. Brandt, Z. M. K. Yang, S. C. Brooks, L. Y. Liang, M. M. Drake, M. Podar, S. D. Brown, and A. V. Palumbo. 2010. "Characterization of Archaeal Community in Contaminated and Uncontaminated Surface Stream Sediments.” Microbial Ecology 60 (4):784-795. doi: 10.1007/s00248-010-9734-2.

Qian, Yun, Xiangping Yin, Hui Lin, Balaji Rao, Scott C. Brooks, Liyuan Liang, and Baohua Gu. 2014. "Why Dissolved Organic Matter Enhances Photodegradation of Methylmercury." Environmental Science \& Technology Letters 1 (10):426-431. doi: 10.1021/ez500254z.

R: A Language and Environment for Statistical Computing. R Foundation for Statistical Computing, Vienna, Austria. URL https://www.R-project.org/.

Richardson, David C., Louis A. Kaplan, J. Denis Newbold, and Anthony K. Aufdenkampe. 2009. "Temporal dynamics of seston: A recurring nighttime peak and seasonal shifts in composition in a stream ecosystem.” Limnology and Oceanography 54 (1):344-354. doi: 10.4319/lo.2009.54.1.0344.

Riscassi, A. L., Carrie L. Miller, and Scott C. Brooks. 2014a. Diel mercury-concentration variations in a mercury impacted stream. Paper read at Goldschmidt, 8-13 June 2014, at Sacramento, CA.

Riscassi, A., C. L. Miller, and S. C. Brooks. 2014b. "Impact of collection container material and holding times on sample integrity for mercury and methylmercury in water.” Limnology and Oceanography-Methods 12:407-420. doi: 10.4319/lom.2014.12.407.

Riscassi, Ami, Carrie Miller, and Scott Brooks. 2016. "Seasonal and flow-driven dynamics of particulate and dissolved mercury and methylmercury in a stream impacted by an industrial mercury source." Environ. Toxicol. Chem. 35 (6):1386-1400. doi: 10.1002/etc.3310.

Sellers, P., C. A. Kelly, J. W. M. Rudd, and A. R. MacHutchon. 1996. "Photodegradation of methylmercury in lakes.” Nature 380 (6576):694-697. doi: 10.1038/380694a0.

Shiffler, R. E. 1988. "Maximum z-scores and outliers.” American Statistician 42 (1):79-80. doi: $10.2307 / 2685269$. 
Siciliano, S. D., N. J. O'Driscoll, R. Tordon, J. Hill, S. Beauchamp, and D. R. S. Lean. 2005. “Abiotic production of methylmercury by solar radiation.” Environ. Sci. Technol. 39 (4):1071-1077. doi: 10.1021/es048707z.

Southworth, G., T. Mathews, M. Greeley, M. Peterson, S. Brooks, and D. Ketelle. 2013. "Sources of mercury in a contaminated stream-implications for the timescale of recovery." Environ. Toxicol. Chem. 32 (4):764-772. doi: 10.1002/etc. 2115.

Southworth, G. R., M. S. Greeley, M. J. Peterson, K. Lowe, and R. H. Ketelle. 2010. Sources of Mercury to East Fork Poplar Creek Downstream from the Y-12 National Security Complex: Inventories and Export Rates. ORNL/TM-2009/231. Oak Ridge National Laboratory, Oak Ridge.

Spencer, Robert G. M., Brian A. Pellerin, Brian A. Bergamaschi, Bryan D. Downing, Tamara E. C. Kraus, David R. Smart, Randy A. Dahlgren, and Peter J. Hernes. 2007. “Diurnal variability in riverine dissolved organic matter composition determined by in situ optical measurement in the San Joaquin River (California, USA).” Hydrol. Proc. 21 (23):3181-3189. doi: 10.1002/hyp.6887.

Stewart, A. J., J. G. Smith, and J. M. Loar. 2011. "Long-Term Water-Quality Changes in East Fork Poplar Creek, Tennessee: Background, Trends, and Potential Biological Consequences.” Environ. Management 47 (6):1021-1032. doi: 10.1007/s00267-011-9630-7.

Taylor, John R. 1997. An Introduction to Error Analysis: The Study of Uncertainties in Physical Measurements. 2nd ed. 2nd ed: University Science Books.

Tennessee Valley Authority. 1985. Instream Contaminant Study, Task 1: Water Sampling and Analysis. Report to U. S. Department of Energy, Oak Ridge Operations Office. Tennessee Valley Authority, Office of Natural Resources and Economic Development, Knoxville, TN.

U. S. EPA. 2001. Method 1630: Methyl Mercury in Water by Distillation, Aqueous Ethylation, Purge and Trap, and CVAFS. U. S. Environmental Protection Agency, EPA-821-R-01-020, January 2001.

U. S. EPA. 2002. Method 1631, Revision E: Mercury in Water by Oxidation, Purge and Trap, and Cold Vapor Atomic Fluorescence Spectrometry. U. S. Environmental Protection Agency, EPA-821-R02-019.

URS | CH2M Oak Ridge LLC. 2013. 2013 Remediation Effectiveness Report for the U.S. Department of Energy Oak Ridge Reservation, Oak Ridge, Tennessee: Data and Evaluations. Water Resources Restoration Program, URS | CH2M Oak Ridge LLC, DOE/OR/01-2594\&D2.

URS | CH2M Oak Ridge LLC. 2014. 2014 Remediation Effectiveness Report for the U.S. Department of Energy Oak Ridge Reservation, Oak Ridge, Tennessee: Data and Evaluations. Water Resources Restoration Program, URS | CH2M Oak Ridge LLC, DOE/OR/01-2640\&D2.

Vishnivetskaya, T. A., J. J. Mosher, A. V. Palumbo, Z. K. Yang, M. Podar, S. D. Brown, S. C. Brooks, B. H. Gu, G. R. Southworth, M. M. Drake, C. C. Brandt, and D. A. Elias. 2011. "Mercury and Other Heavy Metals Influence Bacterial Community Structure in Contaminated Tennessee Streams.” Applied and Environmental Microbiology 77 (1):302-311. doi: 10.1128/aem.01715-10.

Volkmar, E. C., S. S. Henson, R. A. Dahlgren, A. T. O'Geen, and E. E. Van Nieuwenhuyse. 2011. "Diel patterns of algae and water quality constituents in the San Joaquin River, California, USA." Chem. Geol. 283 (1-2):56-67. doi: 10.1016/j.chemgeo.2010.10.012.

Wallace, J. Bruce, JacksonR Webster, and ThomasF Cuffney. 1982. "Stream detritus dynamics: Regulation by invertebrate consumers.” Oecologia 53 (2):197-200. doi: 10.1007/bf00545663.

Waters, T. F. 1972. “The Drift of Stream Insects.” Ann. Rev. Entomol. 17:253-272. doi: 10.1146/annurev.en.17.010172.001345.

Watson, D., S. Brooks, T. Mathews, M. Bevelhimer, C. DeRolph, C. Brandt, M. Peterson, and D. Ketelle. 2016. Evaluation of Lower East Fork Poplar Creek Mercury Sources. Oak Ridge National Laboratory, ORNL/TM-2016/134.

Wei, Q. S., C. H. Feng, D. S. Wang, A. Y. Shi, L. T. Zhang, Q. Wei, and H. X. Tang. 2008. "Seasonal variations of chemical and physical characteristics of dissolved organic matter and trihalomethane precursors in a reservoir: a case study.” Journal of Hazardous Materials 150 (2):257-264. doi: 10.1016/j.jhazmat.2007.04.096. 
Weishaar, James L., George R. Aiken, Brian A. Bergamaschi, Miranda S. Fram, Roger Fujii, and Kenneth Mopper. 2003. "Evaluation of specific ultraviolet absorbance as an indicator of the chemical composition and reactivity of dissolved organic carbon.” Environ. Sci. Technol. 37 (20):47024708. 

APPENDIX A. SUPPLEMENTARY FIGURES 



\section{APPENDIX A. SUPPLEMENTARY FIGURES}
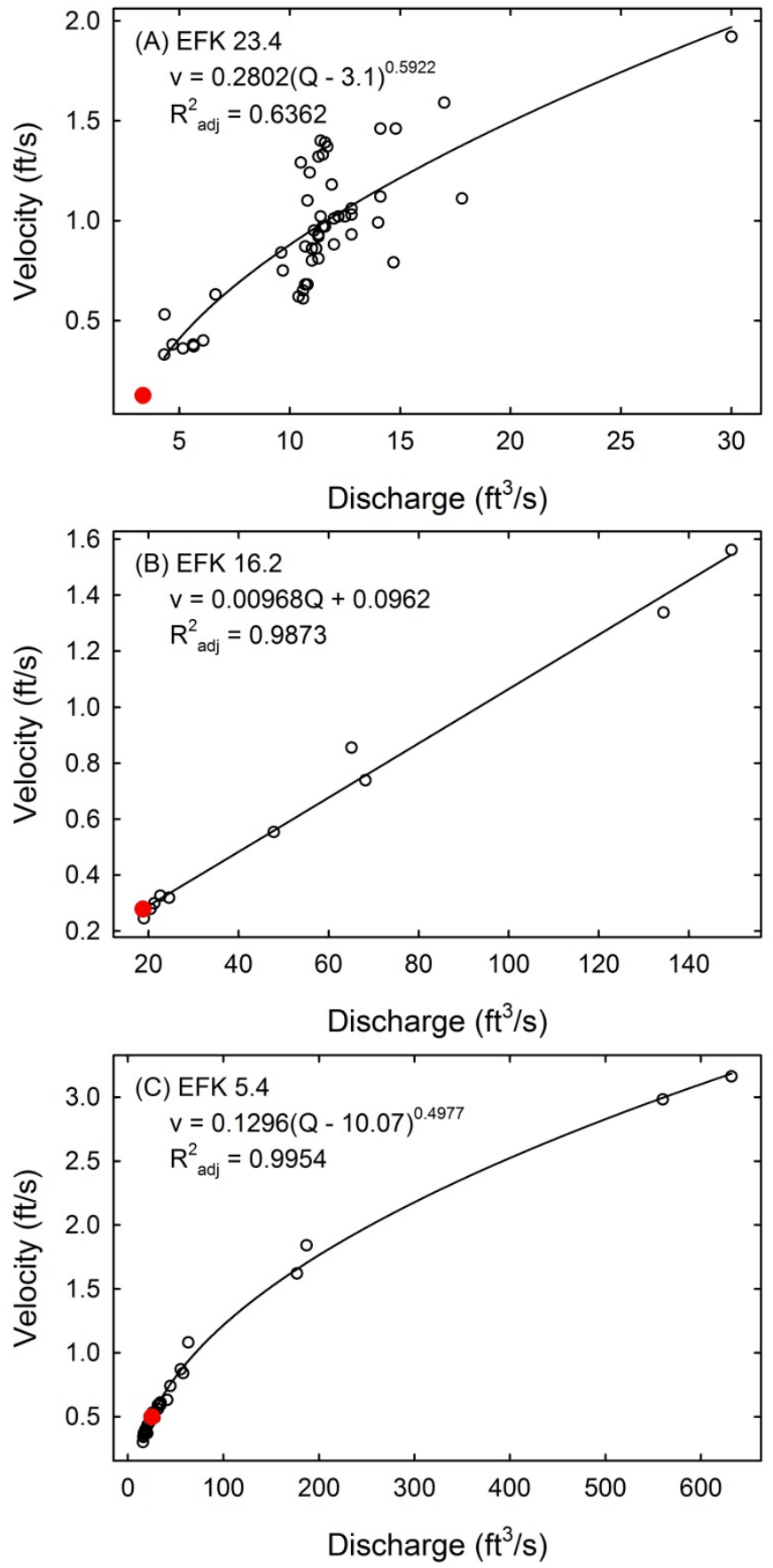

Fig. A1. Velocity versus discharge rating curves used to estimate mean stream velocity and travel time for (a) EFK 23.4, (b) EFK 16.2, and (c) EFK 5.4. Data for EFK 23.4 and EFK 5.4 are from USGS records and data for EFK 16.2 were collected by ORNL staff. Only data rated as "good" by USGS were used. The red symbol on each plot indicates the mean discharge and mean estimated velocity during the sampling period. 


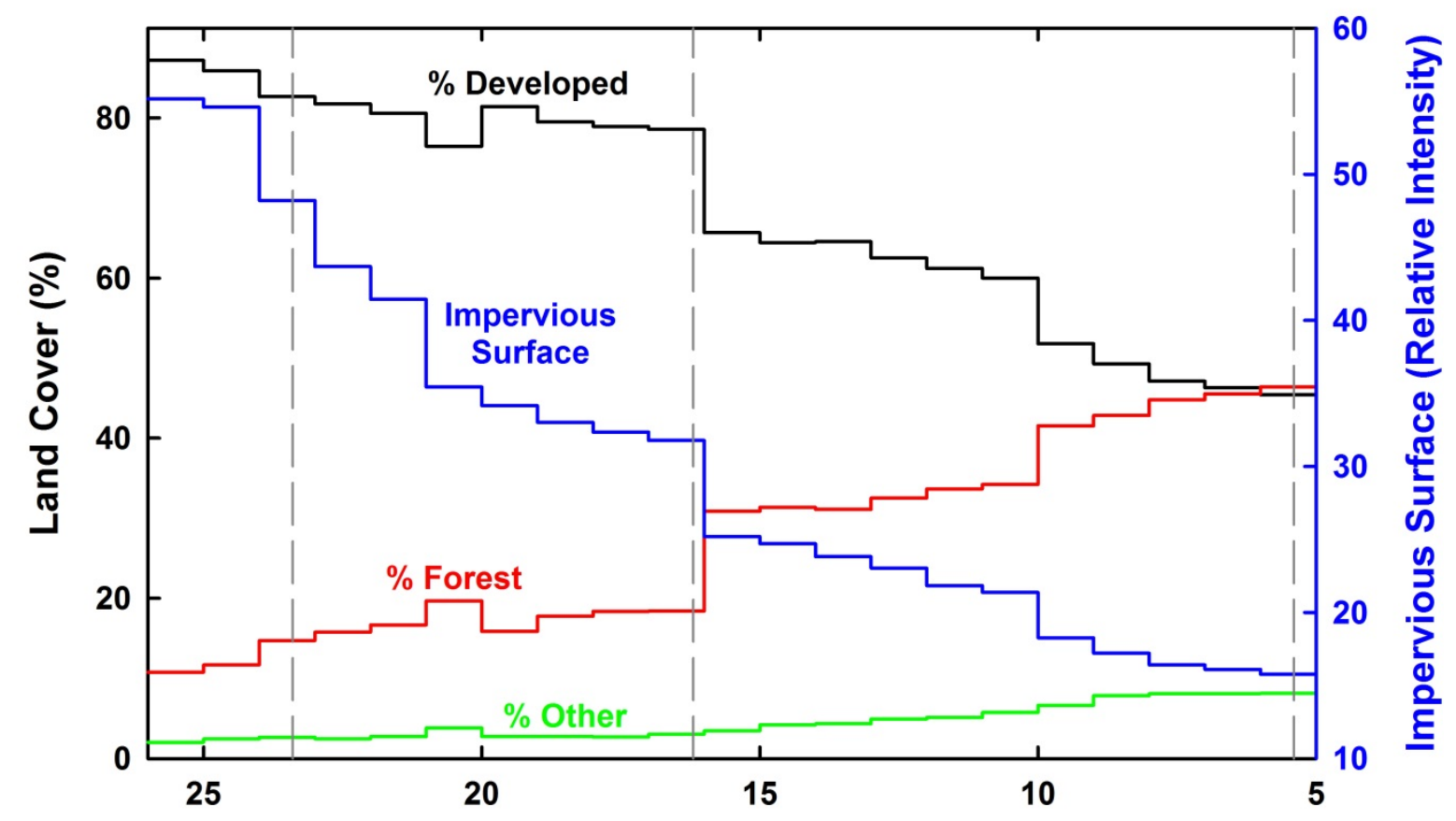

EFK kilometer

Fig. A2. Percent land cover (left y-axis) and impervious surface intensity (right y-axis) for the EFPC watershed. The category "Other" for land cover includes Agriculture, Wetlands, Herbaceous, Barren, Shrub, and Open Water. Land cover data is from the 2006 NLCD. Vertical dashed lines indicate the sampling locations for this study. 

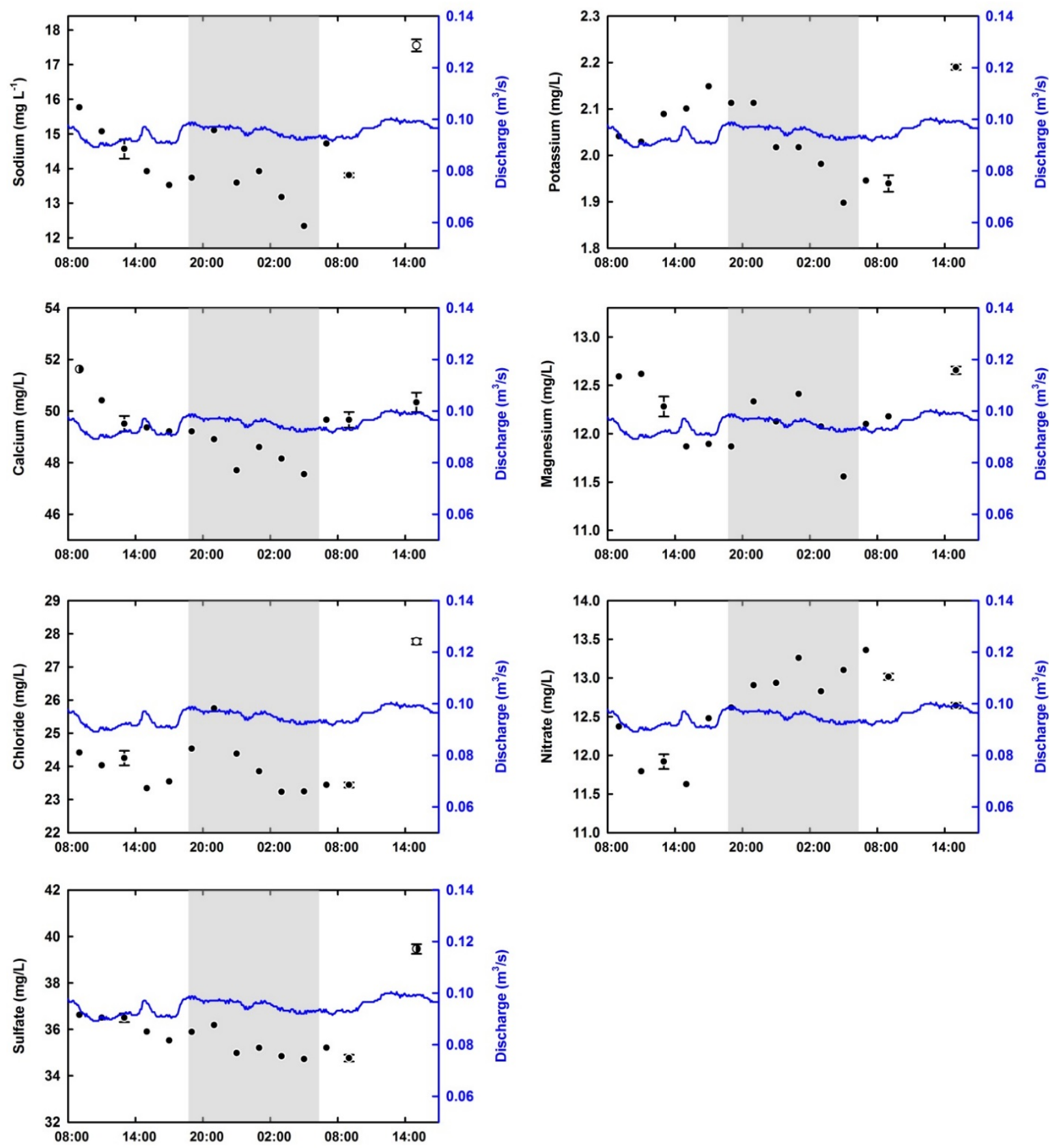

Fig. A3. Major cation and anion concentrations and stream discharge at EFK 23.4. Error bars indicate the range of values for field duplicates. Shaded portion indicates the period from sunset to sunrise. Half-filled symbols indicate potential outliers; open symbols indicate strong potential outliers. 

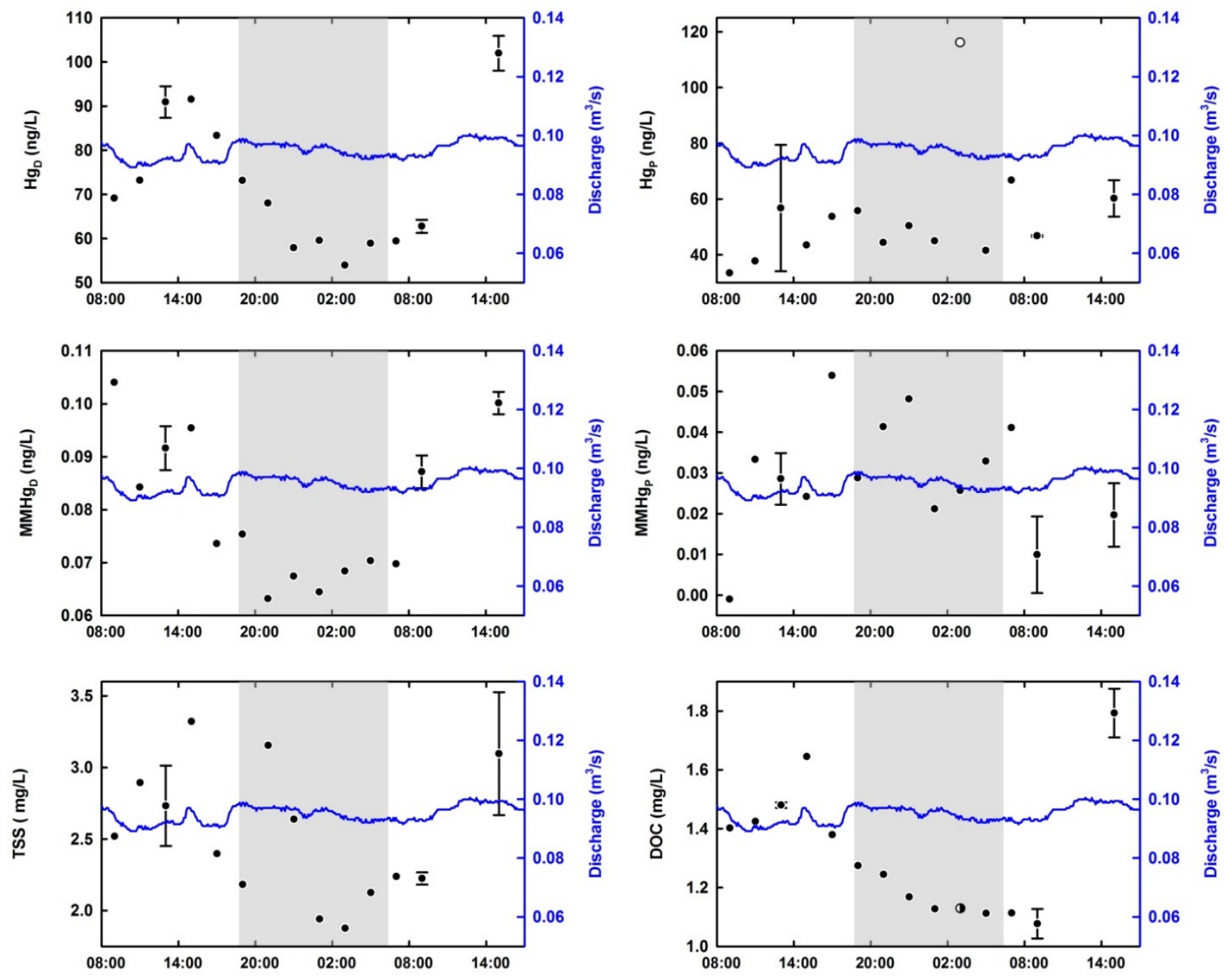

Fig. A4. Hg, MMHg, TSS, and DOC concentrations and stream discharge at EFK 23.4. Error bars indicate the range of values for field duplicates. Shaded portion indicates the period from sunset to sunrise. Half-filled symbols indicate potential outliers; open symbols indicate strong potential outliers. 

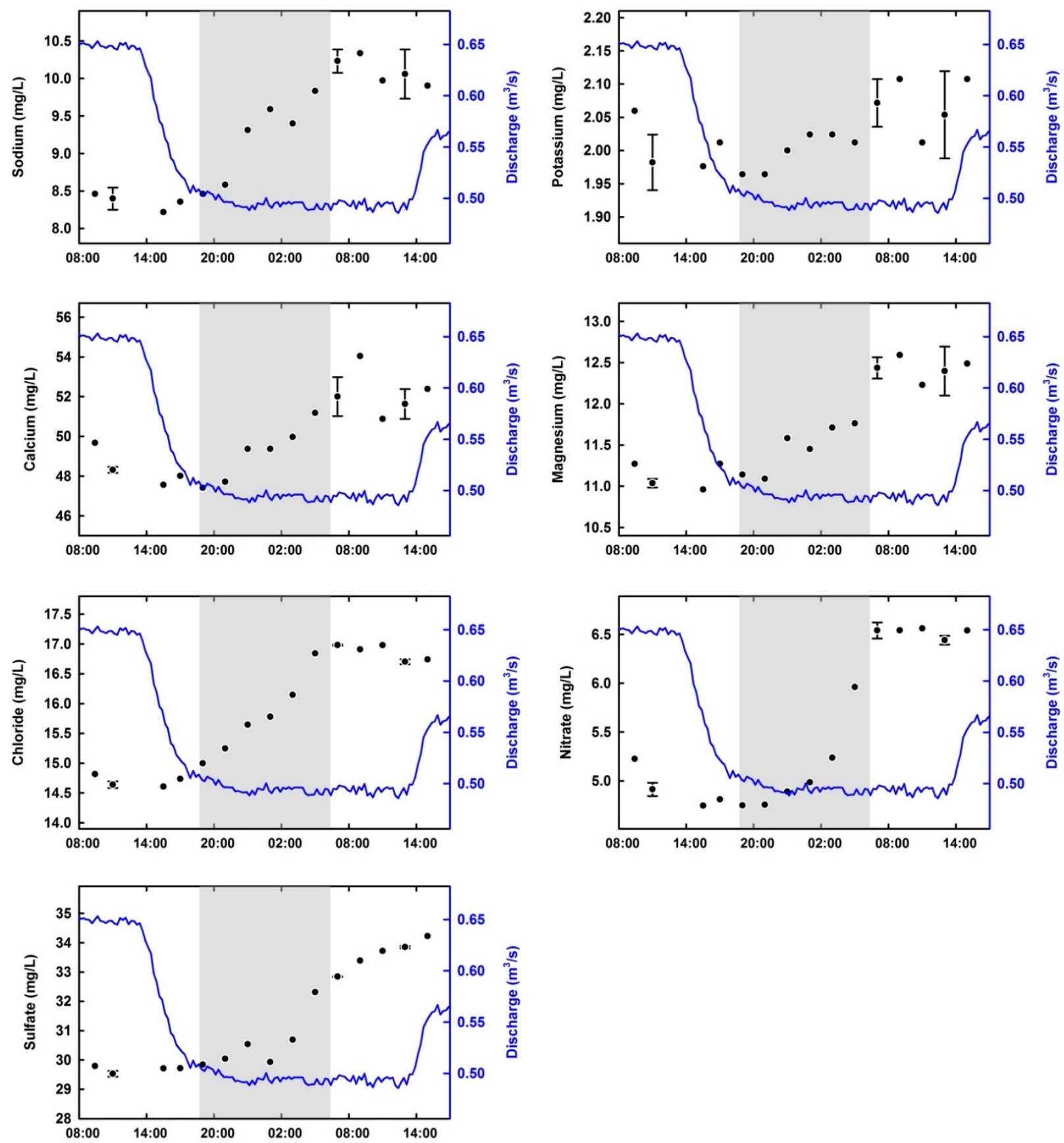

Fig. A5. Major cation and anion concentrations and stream discharge at EFK 16.2. Error bars indicate the range of values for field duplicates. Shaded portion indicates the period from sunset to sunrise. Halffilled symbols indicate potential outliers; open symbols indicate strong potential outliers. 

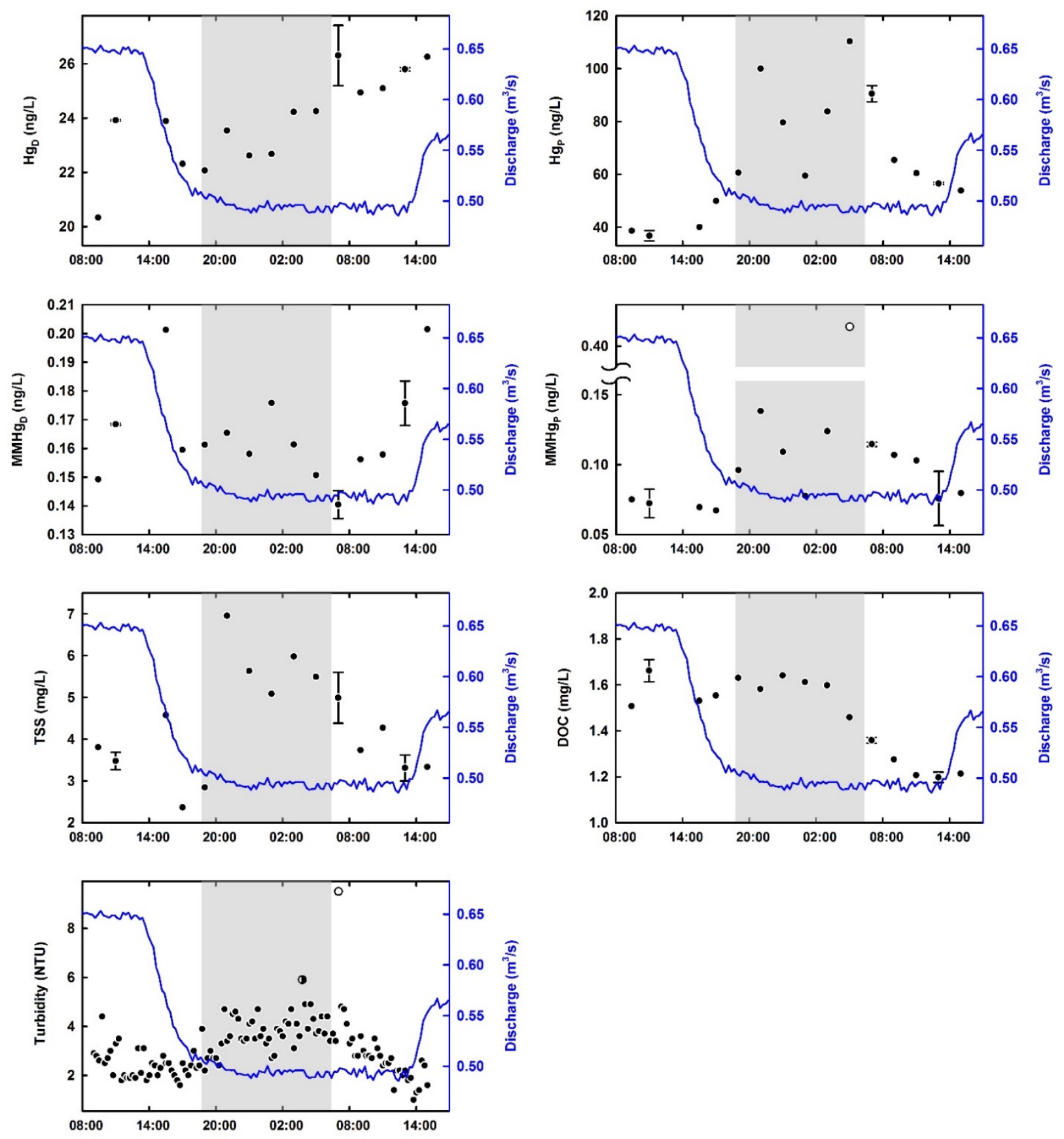

Fig. A6. Hg, MMHg, TSS, DOC concentrations, turbidity, and stream discharge at EFK 16.2. Error bars indicate the range of values for field duplicates. Shaded portion indicates the period from sunset to sunrise. Halffilled symbols indicate potential outliers; open symbols indicate strong potential outliers. 

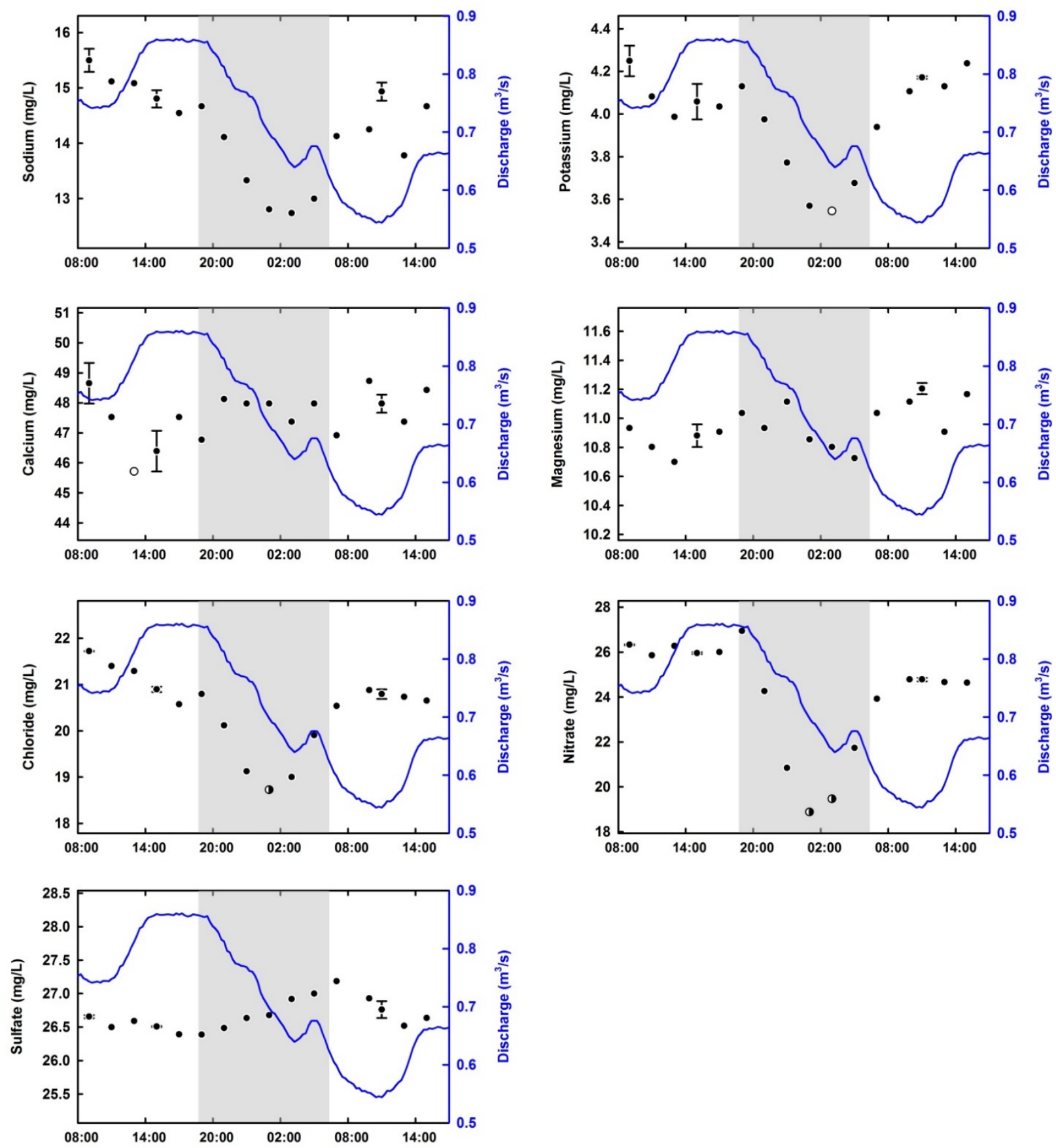

Fig. A7. Major cation and anion concentrations and stream discharge at EFK 5.4. Error bars indicate the range of values for field duplicates. Shaded portion indicates the period from sunset to sunrise. Halffilled symbols indicate potential outliers; open symbols indicate strong potential outliers. 

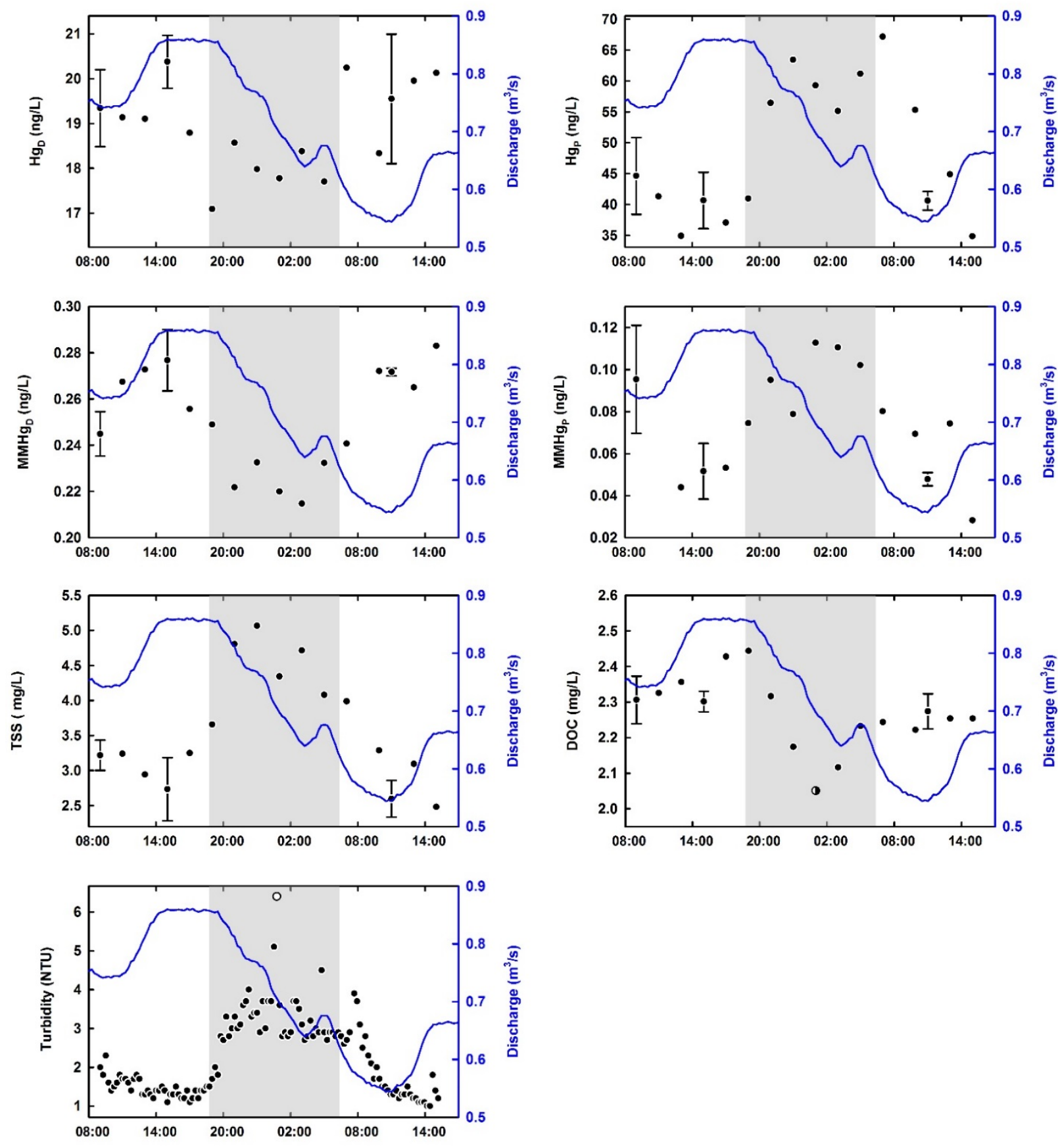

Fig. A8. Hg, MMHg, TSS, DOC concentrations, turbidity, and stream discharge at EFK 5.4. Error bars indicate the range of values for field duplicates. Shaded portion indicates the period from sunset to sunrise. Halffilled symbols indicate potential outliers; open symbols indicate strong potential outliers. 

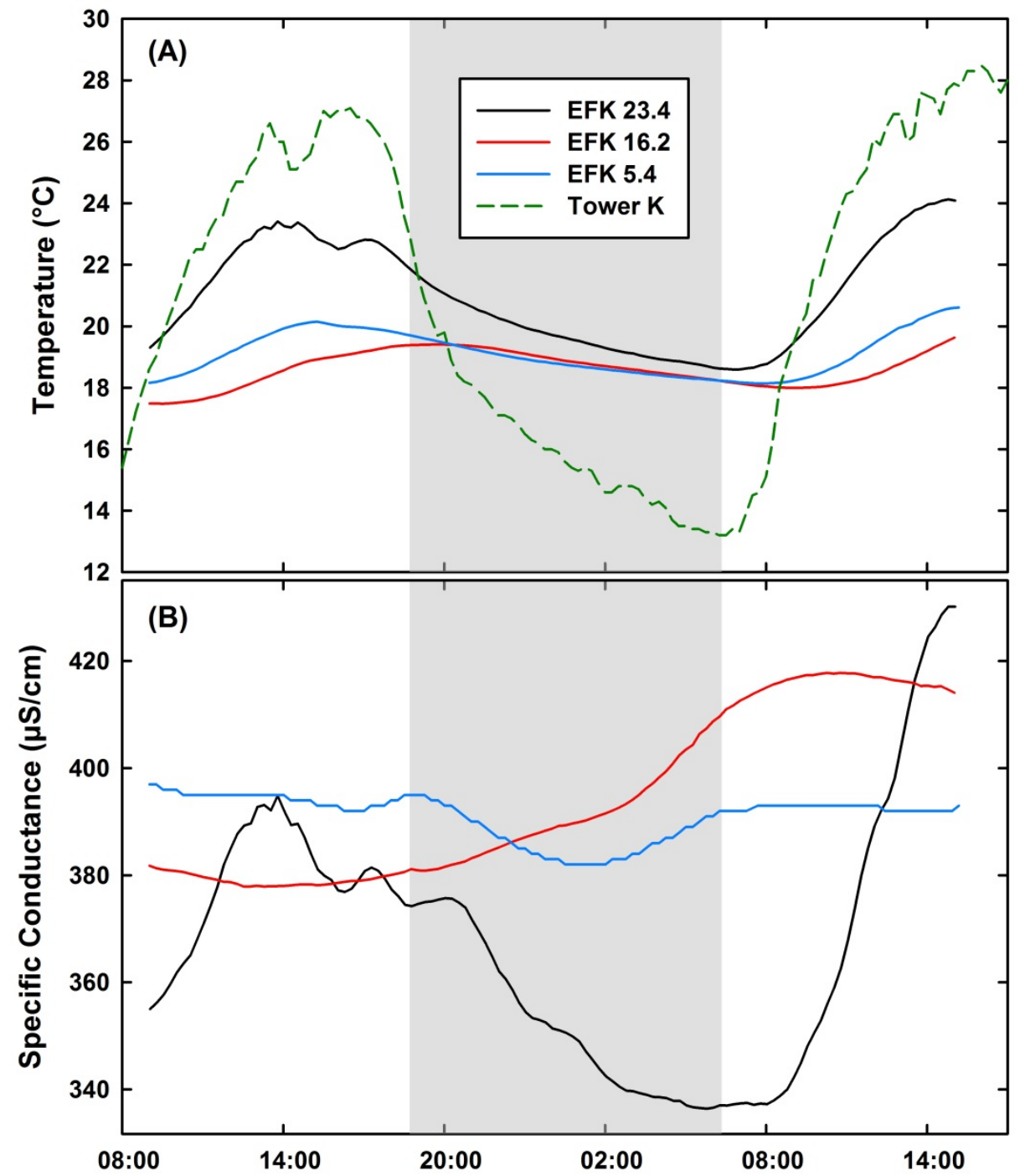

Fig. A9. Temperature (A) and specific conductance (B) at each site over the sampling period. Water temperature for EFK 23.4, EFK 16.2, and EFK 5.4, and 10-meter air temperature for Tower K. Shaded portion indicates the period from sunset to sunrise. 

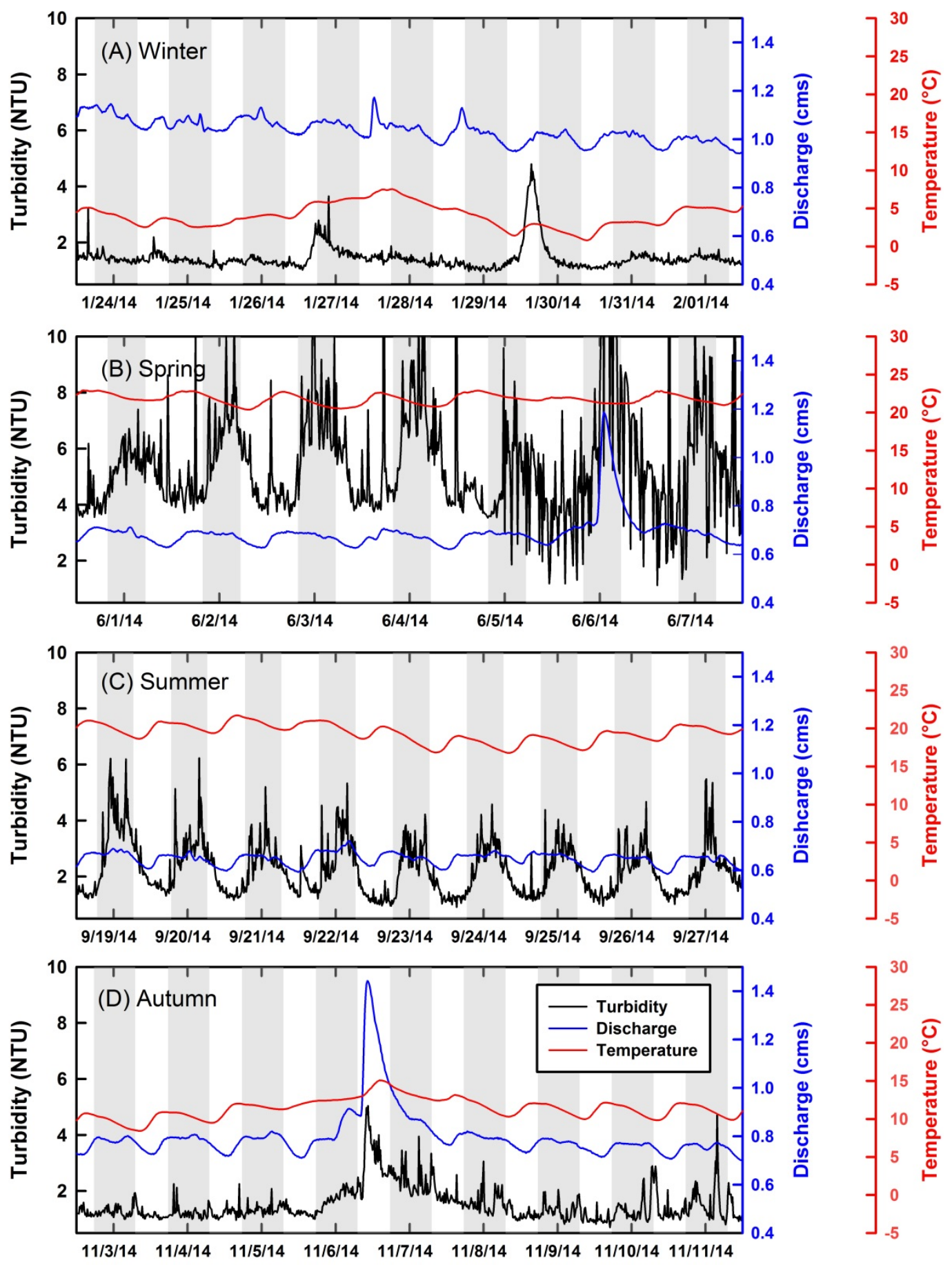

Fig. A10. Representative patterns in turbidity (black line), stream discharge (blue line), and stream temperature (red line) during baseflow in each season at EFK 5.4. Shaded portions represent the period from sunset to sunrise. 

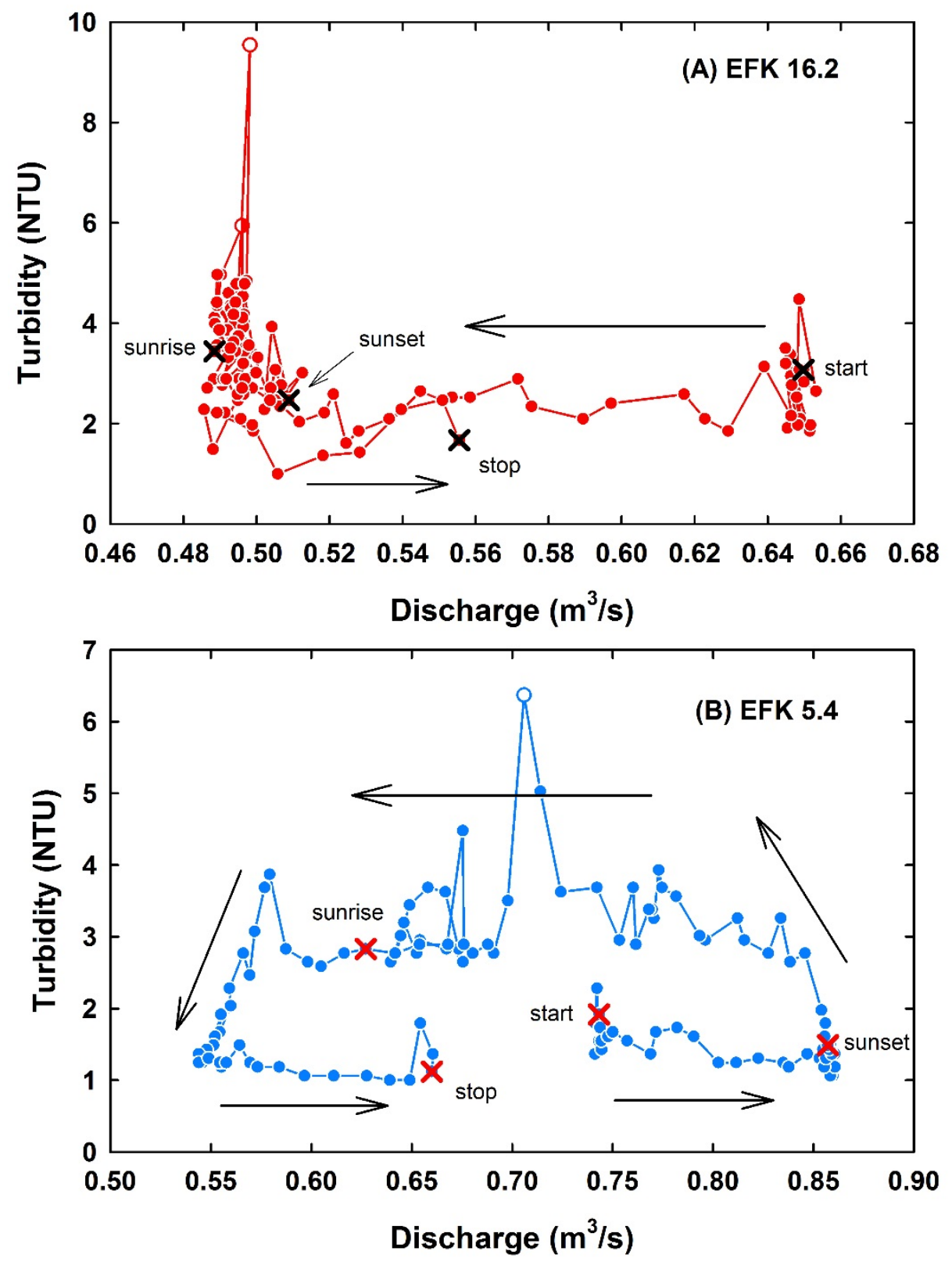

Fig. A11. Turbidity versus discharge hysteresis curves for (A) EFK 16.2 and (B) EFK 5.4. Half-filled symbols indicate potential outliers; open symbols indicate strong potential outliers. 


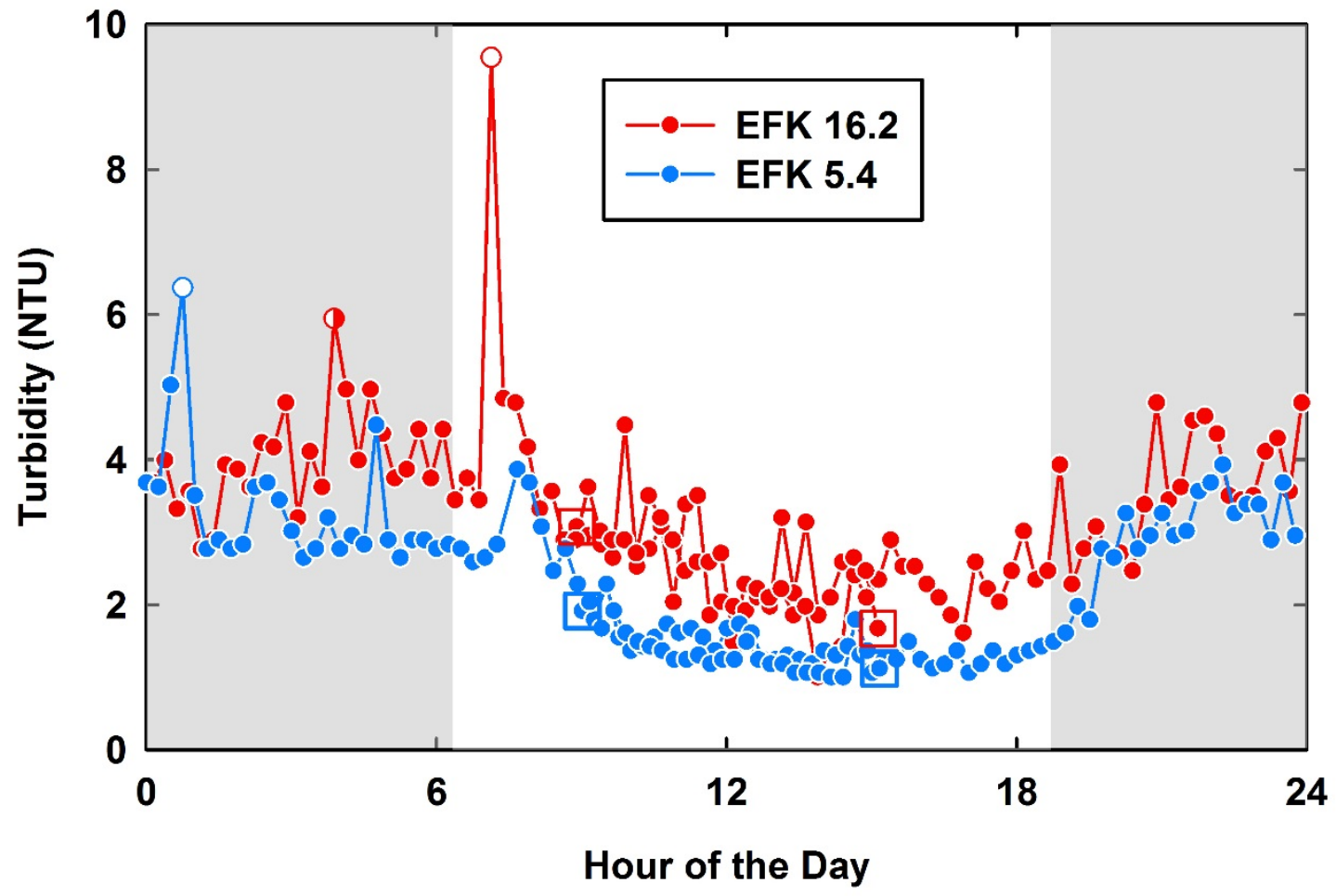

Fig. A12. Turbidity at EFK 16.2 and EFK 5.4 versus hour of the day. Squares indicate the beginning and end of the sampling period. Shaded portion indicates nighttime. Half-filled symbols indicate potential outliers; open symbols indicate strong potential outliers. 


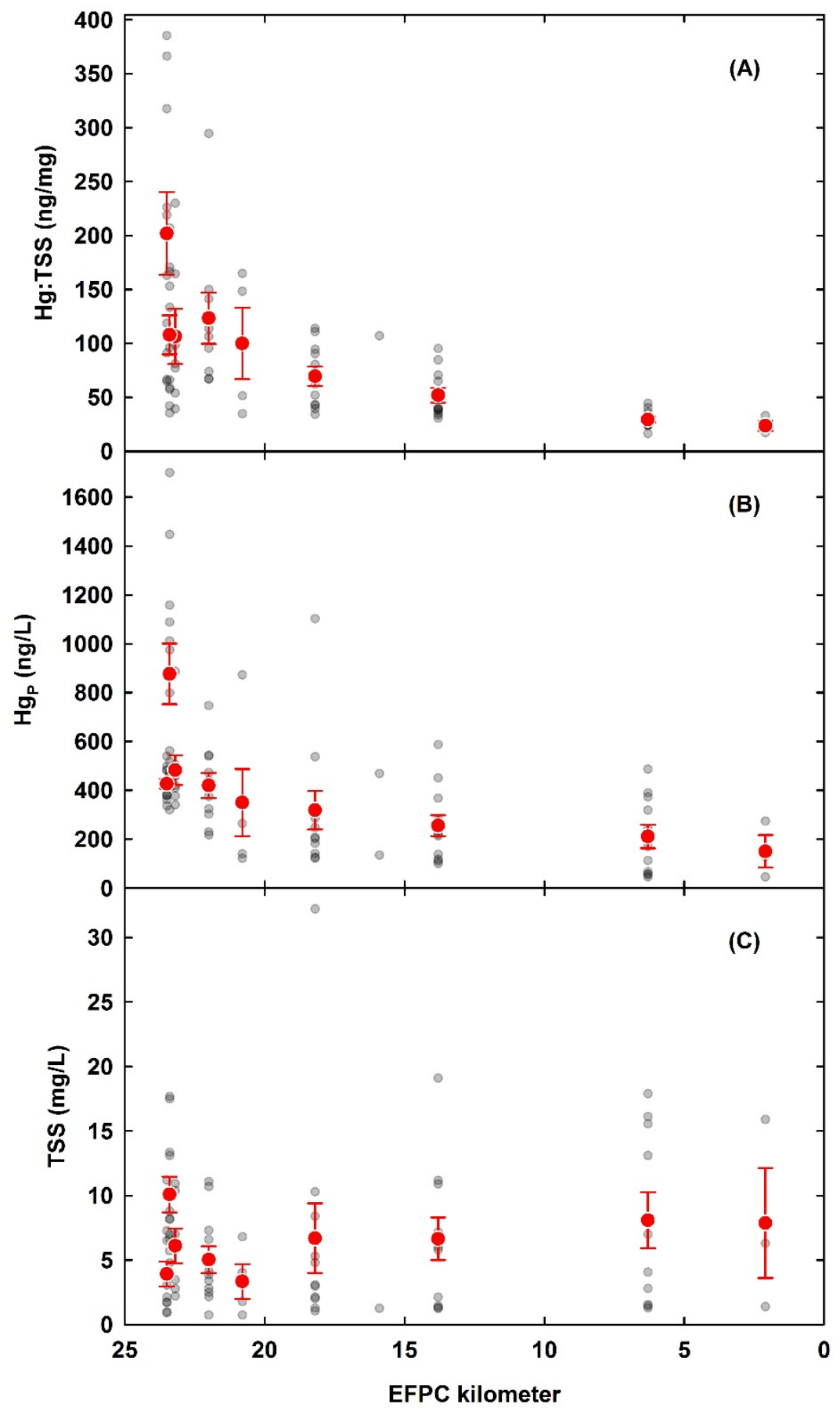

Fig. A13. (A) HgTss, (B) Hg, and (C) TSS concentration along EFPC for samples collected between July 1995 and July 2000. Gray symbols indicate individual samples and the red symbols with error bars represent the mean \pm standard error of the mean for samples at that location. The creek flows from left to right on the $x$-axis

(Bechtel Jacobs Co. LLC 1998, 1999, 2000, Lockheed Martin Energy Systems Inc. 1995, 1996, 1997). 